\title{
Canonical and novel non-canonical activities of the Holliday junction resolvase
}

\section{Yen1}

F. Javier Aguado ${ }^{1, \dagger}$, Raquel Carreira ${ }^{1, \dagger}$, Vanesa Hurtado-Nieves ${ }^{1}$ and Miguel G. Blanco ${ }^{1, *}$

${ }^{1}$ Department of Biochemistry and Molecular Biology, CIMUS, Universidade de Santiago de Compostela-Instituto de Investigación Sanitaria (IDIS), Santiago de Compostela, A Coruña, 15782, Spain.

$\dagger$ These authors contributed equally to this work

* To whom correspondence should be addressed. Tel: +34 881815 386; Fax: +34 881815 405; Email: miguel.gonzalez.blanco@usc.es

\begin{abstract}
Yen1 and GEN1 are members of the Rad2/XPG family of nucleases that were identified as the first canonical nuclear Holliday junction (HJ) resolvases in budding yeast and humans due to their ability to introduce two symmetric, coordinated incisions on opposite strands of the HJ, yielding nicked DNA products that could be readily ligated. While GEN1 has been extensively characterized in vitro, much less is known about the biochemistry of Yen1. Here, we have performed the first in-depth characterization of purified Yen1. We confirmed that Yen1 resembles GEN1 in many aspects, including range of substrates targeted, position of most incisions they produce or monomeric state in solution. However, we have also observed unexpected alternative processing of substrates, such as nicked HJs and a different conformational preference on intact HJs. Moreover, we demonstrate that Yen1 is endowed with additional nuclease activities, like a nick-specific 5'-3' exonuclease or $\mathrm{HJ}$ arm-chopping that could apparently blur its classification as a canonical HJ resolvase. Despite this, we show that Yen1 fulfills the requirements of a canonical HJ resolvase and hypothesize that its wider array of nuclease activities might contribute to its function in the removal of persistent recombination or replication intermediates.
\end{abstract}




\section{INTRODUCTION}

Holliday junctions (HJs) are four-way secondary DNA structures where two duplexes exchange a pair of single strands. HJs and similar cruciform structures may arise during the processes of double-strand break (DSB) repair by homologous recombination (HR), postreplication repair or during the reversal of stalled replication forks. Due to the physical linkage that HJs establish between two DNA molecules, their persistence until late stages of the cell cycle may compromise the correct segregation of sister chromatids or homologous chromosomes in both the mitotic and meiotic scenarios (1). Hence, eukaryotic cells are endowed with two main pathways to ensure their timely removal and the disengagement of the two DNA molecules. First, the combined actions of a RecQ-family helicase Sgs1 in $S$. cerevisiae (BLM in mammals), the type IA topoisomerase Top3 (TopoIIIa) and the OB-fold containing accessory protein Rmi1 (RMI1/RMI2) drive the convergent branch migration of two HJs and fuse them into a hemicatenate structure that can be subsequently decatenated. This process, double $\mathrm{HJ}$ dissolution, leads to the formation of non-crossover (NCO) products, exclusively (2). Second, structure-selective endonucleases (SSEs) like S. cerevisiae Mus81Mms4, Slx1-Slx4 and Yen1 (MUS81-EME1/EME2, SLX1-SLX4 and GEN1) can cleave these HJs in a process generally referred to as HJ resolution, which may yield both NCOs and crossover (CO) depending on the orientation of the cuts across the HJs (3-15). Additionally, a fourth nuclease, Mlh1-Mlh3, plays a major role in the resolution of double HJs into COs to ensure chiasmata formation and accurate segregation of homologous chromosomes during meiosis I (16-19).

All these SSEs with the ability to cleave HJs are generally termed HJ resolvases. The extensive biochemical characterization of phage, prokaryotic and mitochondrial resolvases, like T4 Endo VII, T7 Endo I, E. coli RuvC, S. cerevisiae Cce1 or S. pombe Ydc2 defined the paradigm of "canonical" HJ resolution, whereby the enzyme introduces a pair of symmetric, coordinated nicks in opposite strands across the junction, yielding two nicked DNA duplexes that can be directly ligated without further processing (20-37). The two incisions take place within the lifetime of the protein-DNA complex, with the first one being the limiting step of the reaction and greatly accelerating the second cut (38-40). Resolvases that follow this mode of HJ resolution have been dubbed canonical resolvases. Oppositely, non-canonical resolvases typically sever HJs by non-coordinated, asymmetrical incisions that release DNA molecules containing small gaps or flaps, thus requiring additional processing before religation (41). 
Yen1 and GEN1 were identified as the first eukaryotic, nuclear SSEs displaying canonical HJ resolvase activity in budding yeast and humans, respectively (10). Both belong to the subclass IV of the Rad2/XPG family of SSEs and orthologous proteins are present in most organisms analysed, with the notable exception of $S$. pombe $(10,42,43)$. These enzymes are characterized by the presence of a bi-partite nuclease domain (XPG-N/XPG-I), a conserved helix-hairpinhelix motif and a recently identified DNA interaction site mediated by a chromodomain in the human and $C$. thermophilum orthologs (44-46) (Figure 1A). The biochemical analysis of various members of this subclass IV in humans, nematodes, flies, fungi and plants indicate that all these nucleases retain the characteristic 5'-flap nuclease activity of the Rad2/XPG family, but in most cases have also evolved the ability to resolve HJs in a RuvC-like manner and to process other branched DNA structures like model replication forks and nicked HJs (10, 43, 44, 46-56).

In budding yeast, the role of Yen1 in resolution of HR intermediates has been considerably studied. While deletion of YEN1 confers no overt DNA repair defects either on its own or in the absence of other members of the Rad2/XPG family of nucleases, it dramatically increases the DNA damage sensitivity of $m u s 81 \Delta$ and $m m s 4 \Delta$ mutants (57-61). Yen1 seems dispensable in meiotic recombination, but double mus $81 \Delta$ yen $1 \Delta$ display meiotic chromosome segregation abnormalities and cannot sporulate $(19,57,62-64)$. These observations have consequently led to the interpretation that Yen1 acts as a back-up mechanism for Mus81-Mms4 in the removal of mitotic and meiotic recombination intermediates. However, it has been recently shown that Yen1 also has a specific role, non-redundant with Mus81-Mms4 or Slx1-S1x4, in the processing of replication intermediates that persist in the absence of the nuclease/helicase Dna2 $(65,66)$. Additionally, it has been shown that Yen1 subcellular localization, catalytic activity and chromatin accumulation are strictly controlled by post-translational modifications. Phosphorylation of Yen1 by the Cdc28 (CDK) kinase both reduces its DNA binding activity and promotes its export to the cytoplasm in S-phase. At the onset of anaphase, the activation of the Cdc14 phosphatase reverts this modification and allows Yen1 activation and reingression into the nucleus, where it acts to remove persistent recombination intermediates prior to cell division $(62,67-69)$. More recently, it has been observed that Yen1 can be a substrate for the SUMO ligases Siz1 and Siz2 and the SUMO-targeted ubiquitin ligase Slx5Slx 8 after DNA damage, which drive its polyubiquitination and subsequent proteasomal degradation before entry in S-phase (70). Arguably, these different layers of Yen1 regulation prevent it from targeting branched replication and recombination intermediates from S-phase 
until anaphase, limiting its action to persistent branched DNA intermediates in late stages of mitosis. In this sense, Yen1 mutants that bypass these regulatory mechanisms, such as Yen $1^{\mathrm{ON}}$ (67) (identical to Yen $1^{9 \mathrm{~A}}(68)$ ) or Yen $1^{\mathrm{K} 714 \mathrm{R}}$ (70) have proved extremely useful to ascertain the cellular consequences of premature activation or nuclear persistence of this resolvase. In particular, Yen $1^{\mathrm{ON}}$ has been widely employed in different experimental set-ups to uncouple the nucleolytic processing of HR intermediates from cell cycle progression in both mitotic and meiotic contexts. These studies have collectively revealed that in wild-type cells the precise timing of Yen 1 activation is essential to minimize genome instability, CO formation and lossof heterozygosity during mitosis or to properly establish CO interference during meiosis I. Contrarily, in mutants deficient in the processing of HR or replication intermediates, the sustained activation of Yen $1^{\mathrm{ON}}$ alleviates or suppresses the phenotypes associated to the toxic accumulation of replication or recombination intermediates $(66,67,71-78)$.

Despite these advances in our understanding of Yen1 functions and regulation, our knowledge about its biochemical properties is relatively lacking compared to some of its orthologs in other organisms, as it mainly derives from its initial identification as a canonical resolvase employing whole-cell extracts (10) and a basic description of its two activation states once the protein was successfully purified (67). Here, we present the first comprehensive analysis of Yen1 biochemical properties, with a special focus in the characterization of its activities as a canonical HJ resolvase. Our results reveal that, despite its general behavior as a bona-fide canonical HJ resolvase, Yen1 is endowed with additional nucleolytic activities that may blur this adscription, at least according to its in vitro properties. In this sense, we have identified a novel nick-specific 5'-3'exonuclease activity that renders Yen1 resolution products unable to be ligated as well as an alternative, non-canonical two-step mode of HJ processing, which we term "arm-chopping". Additionally, we have discovered that despite their many similarities, Yen1 and human GEN1 display different preferences for HJ strand cleavage. We speculate that such activities might contribute to the processing of particularly recalcitrant branched DNA intermediates, but also account for the detrimental effects of its premature activation.

\section{MATERIAL \& METHODS}

\section{Plasmids and strains}


All S. cerevisiae strains and plasmids employed are described in Supplementary Tables S1 and $\mathrm{S} 2$, respectively.

The coding sequence of $Y E N 1^{W T}$ in p416ADH1-YEN1 ${ }^{\text {WT }}$-V5-6xHis (51) was mutagenized

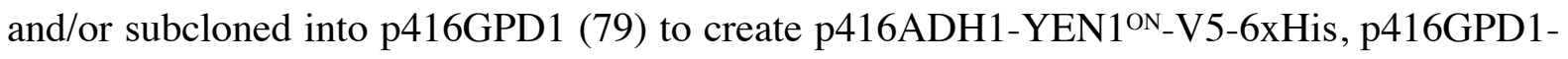

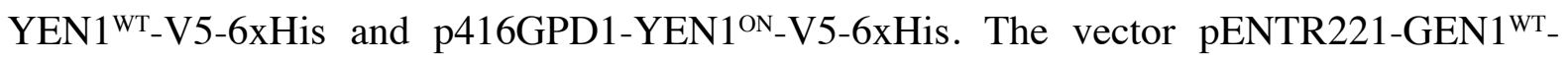
FTH-STOP, a kind gift from Gary Chan and Stephen C. West that contains the coding sequence of C-terminally tagged GEN1 ${ }^{\text {wT }}-3 \times$ FLAG-2xTEV-10xHis (FTH tag), was modified by sitedirected mutagenesis and inverse PCR to generate pENTR221-GEN1 1 ${ }^{\text {nuc }}-F T H-S T O P$, which encodes a constitutive nuclear form of GEN1 by mutation of its nuclear export signal and addition of 3xSV40 nuclear localization signals (50). From these two vectors, derivative plasmids carrying either GEN1 ${ }^{\text {wT }}$ or GEN1 ${ }^{\text {nuc }}$ (pENTR221-GEN1-GO, pYES-EXP52-GEN1V5-6xHis and pYES-EXP52-GEN1 1-527-V5-6xHis, pAG306GAL-GEN1-FTH) were created by standard subcloning, inverse PCR and/or Gateway recombination. Details of each cloning can be provided upon request.

\section{Genotoxicity assays}

Yeast strains were grown to mid-logarithmic phase in SC-URA containing $2 \%$ glucose. The cultures were then normalized to an $\mathrm{OD}_{600}=0.5$ and 10 -fold serial dilutions were spotted onto fresh SC-URA plates containing 1\% raffinose, $2 \%$ galactose and increasing concentrations of MMS. Plates were incubated in the dark for 3 days at $30^{\circ} \mathrm{C}$ and then photographed in a Gel Doc XR+ (Bio-Rad).

\section{Immunofluorescence microscopy}

Strains carrying V5-tagged versions of Yen1 or GEN1, either in a WT or mus81 4 yen1 $\Delta$ background (Supp. Table 1), were cultured in SC-URA for $16 \mathrm{~h}$, then diluted to an $\mathrm{OD}_{600}=0.2$ in fresh medium and incubated for 5 hours. Cells were then fixed by addition of 0.1 vol formaldehyde and incubation at $4^{\circ} \mathrm{C}$ overnight. Cells were washed once in $0.1 \mathrm{M}$ phosphate buffer $\mathrm{pH} 7.4$, once in spheroplasting buffer $\left(0.1 \mathrm{M}\right.$ phosphate buffer $\mathrm{pH} 7.4,0.5 \mathrm{mM} \mathrm{MgCl}{ }_{2}$ and 1.2 M sorbitol) and then incubated in $200 \mu \mathrm{L}$ of spheroplasting buffer containing $28 \mathrm{mM}$ $\beta$-mercaptoethanol at $30^{\circ} \mathrm{C}$ for $15 \mathrm{~min}$. 100-T Zymolyase (AMSBIO) was added to a final concentration of $1 \mathrm{mg} / \mathrm{mL}$ and incubated at $30^{\circ} \mathrm{C}$ for an additional $10 \mathrm{~min}$. Spheroplasts were then attached to a polylysine-coated multi-well microscope slide and dehydrated in consecutive methanol and acetone baths at $-20^{\circ} \mathrm{C}$. Slides were blocked for $30 \mathrm{~min}$ at room temperature in 
PBS containing 1\% BSA and then incubated with mouse monoclonal anti-V5 antibodies (1:200 dilution, Invitrogen \#R960-25) at $25^{\circ} \mathrm{C}$ for $1 \mathrm{~h}$. After washing with PBS-BSA, the slides were incubated with an Alexa Fluor 488-coupled anti-mouse antibody from goat (1:200 dilution, Life technologies \#A-11001). DNA was stained with DAPI. Images were acquired using a confocal microscope Leica TCS SP8 with HC PL APO CS2 63x/1.40 OIL lens, under the control of LAX software.

\section{Protein analysis}

For the preparation of soluble protein lysates containing Yen1 or GEN1, strains expressing different versions of V5-tagged Yen1 or GEN1 were cultured in 15 mL SC-URA supplemented with $2 \%$ glucose. When a density of $\sim 0.6 \times 10^{7}$ cells $/ \mathrm{mL}$ was reached, cells were harvested, rinsed in water and resuspended in $15 \mathrm{ml}$ SC-URA containing $1 \%$ raffinose and $2 \%$ galactose and incubated for $6 \mathrm{~h}$ at $30^{\circ} \mathrm{C}$ to induce the protein expression. Cells were then harvested and resuspended in lysis buffer (40 mM Tris- $\mathrm{HCl}$ pH 7.5, $150 \mathrm{mM} \mathrm{NaCl}, 10 \%$ glycerol, $0.10 \%$ NP40, $1 \mathrm{mM}$ DTT, $1 \mathrm{mM}$ PMSF, $5 \mathrm{mM} \mathrm{NaF}, 5 \mathrm{mM} \mathrm{H}_{2} \mathrm{NaPO}_{4}, 5 \mathrm{mM} \beta$-glycerophosphate) and disrupted using a Mini-Beadbeater-16 (BioSpec). Lysates were quantified by Bradford method, normalized to $2 \mathrm{mg} / \mathrm{ml}$ and protein expression was analysed by western blotting employing anti-V5 antibody (1:3000 dilution, Invitrogen, \#R960-25).

Mobility-shift detection of phosphorylated Yen1 variants by western-blotting was performed by separating $400 \mathrm{ng}$ of purified Yen $1^{\mathrm{P}}$, Yen $1^{\lambda}$, Yen $1^{\mathrm{ON}-\mathrm{P}}$ and Yen $1^{\mathrm{ON}-\lambda}$ in $7.5 \%$ SDS-PAGE gels, either unmodified or containing $40 \mu \mathrm{M}$ Phos-tag (Wako Chemicals) and $160 \mu \mathrm{M} \mathrm{MnCl}_{2}$. Prior to transference, Phos-tag gels were washed with transfer buffer containing $100 \mathrm{mM}$ EDTA for $30 \mathrm{~min}$ at RT, and then washed $3 \times 15 \mathrm{~min}$ with transfer buffer. Proteins were detected with anti-FLAG M2-HRP (1:3000 dilution, Sigma \#A8592).

\section{Protein purification}

Wild-type Yen1, deregulated Yen $1^{\mathrm{ON}}$ and catalytically inactive Yen ${ }^{\mathrm{ND}}$ (E193A, E195A) were all purified as fusions with a C-terminal FTH tag, as previously described (67). Yen $1^{\mathrm{P}}$ represents a highly phosphorylated version of the wild-type protein, purified from cells arrested before anaphase entry in a $c d c 14-1$ mutant. Yen $1^{\lambda}$ is a lambda-phosphatase treated version of Yen1 $^{\mathrm{P}}$ (67). For control reactions with FTH-tagged GEN1 or GEN1 ${ }^{1-527}$, samples for initial experiments were kindly provided by Gary Chan and Stephen C. West. Additional batches were purified as described (38). All proteins were tested for non-specific exonuclease, 
endonuclease, and protease contaminant activities (not shown) and analysed by SDS-PAGE through Novex Value 4-20\% Tris-Glycine Mini Gel (Thermo Fisher Scientific) followed by Coomassie staining.

\section{Hydrodynamic analysis of Yen1}

Glycerol gradient sedimentation and size exclusion chromatography were carried out essentially as described (54), with the following modifications. $25 \mu \mathrm{g}$ Yen $1^{\lambda}$ were loaded on $15 \%-35 \%$ glycerol gradients prepared in $40 \mathrm{mM}$ Tris- $\mathrm{HCl}, \mathrm{pH} 7.5,500 \mathrm{mM} \mathrm{NaCl}, 0.1 \% \mathrm{NP}-$

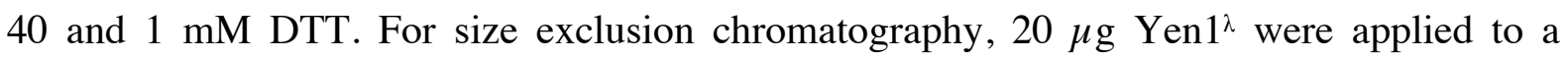
Superdex 200 PC 3.2/30 column (GE Healthcare) in the same buffer. In both cases, the fractions collected were analysed by SDS-PAGE through 4-12\% MOPS NuPage gradient gels (Thermo Fisher Scientific) followed by Coomassie staining.

\section{DNA substrates}

Synthetic substrates were prepared essentially as described (80), employing PAGE-purified ssDNA oligonucleotides. All the oligonucleotides are listed in Supplementary Table S3 and the strand composition of each substrate is described in Supplementary Table S4. Briefly, labelled and unlabelled oligonucleotides were mixed in a 1:3 ratio, boiled in a water bath, cooled down to room temperature overnight and fully-ligated substrates purified from $10 \%$ polyacrylamide gels. For radioactive substrates, oligos were either 5 '-end labelled with $\left[\gamma^{-32} \mathrm{P}\right]$ ATP (3000 Ci/mmol, Perkin Elmer) and T4 PNK (Thermo Fisher) or 3'-end labelled with [ $\alpha$ $\left.{ }^{32} \mathrm{P}\right]$-cordycepin $(3000 \mathrm{Ci} / \mathrm{mmol}$, Perkin Elmer) and terminal transferase (New England Biolabs). For fluorescent substrates, 5'-IRDye 700, 5'-IRDye 800-labelled (Integrated DNA Technologies) or 3'-6FAM-labelled oligonucleotides (Sigma-Aldrich) were employed. Unlabelled substrates were prepared with equimolecular mixtures of oligonucleotides and purified from native $10 \%$ polyacrylamide gels by UV-shadowing. When appropriate, oligonucleotides containing 1 or 3 consecutive phosphorothioate (SP) linkages (SigmaAldrich) were employed.

\section{Nuclease assays}

For the mapping of the incisions on each oligonucleotide, $5 \mathrm{nM}$ protein was incubated with 20 $\mathrm{nM}$ unlabelled substrate (unless otherwise stated) supplemented with $\sim 0.1 \mathrm{nM} 5$ '-32 P-endlabeled substrate in $25 \mu 1$ of reaction buffer $(50 \mathrm{nM}$ Tris- $\mathrm{HCl} \mathrm{pH} 7.5,0.5 \mathrm{mM} \mathrm{MgCl}, 50 \mathrm{mM}$ 
$\mathrm{NaCl}, 2 \%$ glycerol for Yen1; $50 \mathrm{mM}$ Tris-HCl pH 7.5, $1 \mathrm{mM} \mathrm{MgCl}_{2}, 25 \mathrm{mM} \mathrm{NaCl}, 1 \mathrm{mM}$ DTT, $1 \%$ glycerol for GEN1). After $10 \mathrm{~min}$ of incubation at $30^{\circ} \mathrm{C}$ (Yen1) or $37^{\circ} \mathrm{C}$ (GEN1), 10 $\mu 1$ of each reaction were deproteinized by addition of $2.5 \mu 1$ stop solution ( $2 \%$ SDS, $10 \mathrm{mg} / \mathrm{ml}$ proteinase $\mathrm{K}$ ) and further incubation for $20 \mathrm{~min}$ at $37^{\circ} \mathrm{C}$. Another aliquot of $10 \mu \mathrm{l}$ was mixed with 1 volume of $2 \mathrm{X}$ denaturing loading buffer (TBE 1X, 80\% formamide) and incubated at $99^{\circ} \mathrm{C}$ for $3 \mathrm{~min}$. The radiolabelled products were then separated by PAGE through $10 \%$ native or denaturing (7M urea) gels. Radiolabelled molecules were analysed by phosphorimaging using a Typhoon FLA 9500 and quantified by densitometry using ImageQuant software (GE Healthcare). In experiments employing an X0 HJ with one SP in strand X0-3 (X0-SP), $5 \mathrm{nM}$ unlabelled substrate was used, and the incubation time was $5 \mathrm{~min}$ for Yen $1^{\lambda}$ and $2.5 \mathrm{~min}$ for GEN1. In experiments employing an X0 HJ with 3 SP in strands X0-2 and X0-4 (HJ-2SP) 5 $\mathrm{nM}$ unlabelled substrate was used and $30 \mathrm{~min}$ incubation for Yen1 and $2.5 \mathrm{~min}$ for GEN1.

To assess the preference for the axis of HJ resolution, reactions were carried out as described for the mapping analyses. $5 \mathrm{nM}$ unlabelled J3 HJ spiked with $\sim 0.5 \mathrm{nM} 5$ '-32P-end-labeled junction was incubated with $5 \mathrm{nM} \mathrm{Yen} 1^{\lambda}\left(30^{\circ} \mathrm{C}, 10 \mathrm{~min}\right)$ or $\mathrm{GEN} 1\left(37^{\circ} \mathrm{C}, 5 \mathrm{~min}\right)$. The radiolabelled products were separated by $12 \%$ denaturing PAGE and quantified by phosphorimaging as described.

For religation experiments, $0.5 \mathrm{nM} 5$ ' -32 P-end-labeled asymmetric HJ X1-T (38) or X1-T-SP were incubated with $10 \mathrm{nM}$ Yen1 or GEN1 for 30 min under the same conditions as described above. $10 \mu 1$ aliquots of each reaction were either left untreated or adjusted to $1 \mathrm{X}$ T4 ligase buffer, supplemented with 5U of T4 DNA ligase (Fisher, \#EL0014) and further incubated for $1 \mathrm{~h}$ at $25^{\circ} \mathrm{C}$. All reactions were stopped by adding 1 vol of $2 \mathrm{X}$ denaturing loading buffer and incubated at $99^{\circ} \mathrm{C}$ for $3 \mathrm{~min}$. Products were then analysed by $10 \%$ denaturing PAGE and phosphorimaging as described above.

For exonuclease assays, $\sim 0.5 \mathrm{nM}$ of either 5'- or 3'- ${ }^{32} \mathrm{P}$-end-labeled nicked or gapped dsDNA substrates were incubated with increasing concentrations of Yen1 $(0,0.25,0.5,1,2,4,8 \mathrm{nM}$ in Figure 5C; 0, 0.5, 2, $8 \mathrm{nM}$ in Figure 5D) for $10 \mathrm{~min}$ at $30^{\circ} \mathrm{C}$ in a total volume of $20 \mu 1$. After incubation, all reactions were stopped with $5 \mu 1$ stop buffer, $37^{\circ} \mathrm{C}, 1 \mathrm{~h}$. For analysis under native conditions, reactions were mixed with 0.2 vol 6X native loading buffer (15\% Ficoll-400, 60 mM EDTA, 19.8 mM Tris-HCl pH 8.0,0.48\% SDS), and separated in 10\% PAGE native gels. For analysis under denaturing conditions, reactions were mixed with 1 vol of $2 \mathrm{X}$ denaturing loading buffer, boiled and loaded on12\% PAGE gels containing 7M urea. 
Exonuclease experiments with 6FAM-fluorescent substrates (Figure 5E) were carried out with $50 \mathrm{nM}$ enzyme, $10 \mathrm{nM}$ substrate and incubated at $30^{\circ} \mathrm{C}$ for Yen 1 or $37^{\circ} \mathrm{C}$ for GEN1 for $10 \mathrm{~min}$. Reaction products were separated through $13 \%$ PAGE gels containing 7M urea and visualized in a Typhoon FLA 9500.

Time-course experiments for Yen1 were carried out using $50 \mathrm{nM}$ IRDye-800 fluorescent DNA substrates and $40 \mathrm{nM}$ Yen1 for reactions with X0 HJ or RF substrates and $10 \mathrm{nM}$ Yen1 in those with the 5'-flap substrate. Reactions were incubated at $30^{\circ} \mathrm{C}$, aliquots taken at each time point and stopped by addition of $2.5 \mu 1$ stop solution and further incubation at $37^{\circ} \mathrm{C}$ for $30 \mathrm{~min}$. Products were separated through 10\% native PAGE and analysed using an Odyssey infrared imaging system and Application software (LI-COR Biosciences).

Nuclease assays with whole-cell lysates from strains expressing Yen1 or GEN1 were performed with IRDye-700 labelled X0 as stated above. $1 \mu 1$ of normalized lysate $(\sim 2 \mathrm{mg} / \mathrm{ml}$ total protein) was added to each reaction and incubated for $1 \mathrm{~h}$ at $30^{\circ} \mathrm{C}$. Products were analysed by $10 \%$ native PAGE and the gels were scanned using an Odyssey infrared imaging system (LI-COR Biosciences).

\section{Cruciform assays}

In experiments with the cruciform-forming pIR9 plasmid (48), extrusion of the cruciform was favored by preincubation at $37^{\circ} \mathrm{C}$ in extrusion buffer $(50 \mathrm{mM}$ Tris- $\mathrm{HCl} \mathrm{pH} 7.5,50 \mathrm{mM} \mathrm{NaCl}$, $0.1 \mathrm{mM}$ EDTA). Cruciform cleavage assays were carried out in $10 \mu 1$ Yen1 reaction buffer containing $4.5 \mathrm{nM}$ plasmid and $90 \mathrm{nM}$ of Yen1 or $50 \mathrm{nM}$ GEN1. Resistance to digestion by EcoRI was employed to measure cruciform extrusion levels. Products were separated in $0.8 \%$ agarose gels, stained with ethidium bromide, and imaged and quantified on a Gel Doc XR + System (Bio-Rad). For the labeling experiments, reactions were carried in a final volume of 20 $\mu 1$, from which half of the reaction was loaded on agarose gels as described, and the other half was denatured at $99^{\circ} \mathrm{C}$ for $3 \mathrm{~min}$. After this, $50 \mathrm{mM}$ Tris- $\mathrm{HCl}$ was added to the reaction for a final volume of $60 \mu 1$ to pass through a G-25 MicroSpin column. Following this step, reaction products were labeled by adding $1 \mu 1\left[\gamma^{32} \mathrm{P}\right]$-ATP and T4 PNK for $1 \mathrm{~h}$ at $37^{\circ} \mathrm{C}$. The nonincorporated isotope was eliminated using G-25 columns and the eluted DNA was precipitated with $2 \mathrm{vol}$ of ethanol, $0.1 \mathrm{vol}$ of $3 \mathrm{M}$ sodium acetate $\mathrm{pH} 5.2$ and $0.02 \mathrm{vol}$ of $5 \mathrm{mg} / \mathrm{ml}$ glycogen. The pellet was resuspended in $10 \mu \mathrm{L} 2 \mathrm{X}$ denaturing loading buffer and samples analysed in $15 \%$ denaturing gels as described above. 
For the ligation experiment, pIR9 was incubated with Yen1 as previously described. In addition, incubation of the cruciform plasmid with Nt.BspQI (NEB) was used as a control for a nicked circle. After the nuclease reaction, the DNA was purified by using commercial DNA purification kits (E.Z.N.A.Cycle-Pure Kit, Omega Bio-tek \#D6492-02). Following the purification, $5 \mathrm{U}$ T4 DNA ligase were added to $100 \mathrm{ng}$ of purified DNA in the supplemented buffer, for $1 \mathrm{~h}$ at $37^{\circ} \mathrm{C}$. Products were analysed as stated above.

\section{RESULTS}

\section{Yen1 and GEN1 cleave four- and three-way junctions at similar, but not identical, positions}

Yen1 nuclease activity is regulated by CDK-dependent phosphorylation events that inhibit both its overall DNA-binding and catalytic activity $(67,68)$. However, it is not known whether these changes may also alter the position of the incisions that Yen1 creates on the substrates. To investigate this, we purified highly phosphorylated $\left(\right.$ Yen1 $\left.{ }^{\mathrm{P}}\right)$ and in vitro, lambda phosphatasedephosphorylated (Yen1 ${ }^{\lambda}$ ) versions of Yen1 (Figure 1B) and mapped the cleavage sites they introduced on several branched DNA structures, including HJs, 3-way junctions (3WJ), replication forks and 5'-flap substrates employing 7M urea denaturing PAGE (Figure 1C-F). The same reactions were also analysed by native PAGE (Supp. Fig. 1). We observed that, despite their different efficiency, the incision sites produced by $\mathrm{Yen}^{\mathrm{P}}$ and Yen $1^{\lambda}$ on all the tested substrates are entirely coincident, indicating that the upregulation of Yen1 activity by dephosphorylation does not alter its cleavage specificity.

In parallel, we also compared Yen1 incisions with those created by its human homolog GEN1 on the same set of substrates (Figure 1C-G and Supp. Fig. 1). On the static, fully-ligated X0 HJ substrate (10), GEN1 typically introduces symmetrical nicks $1 \mathrm{nt}$ at the 3 'of the branching point specifically on strands 1 and 3 (Figures $1 \mathrm{C}$ and $1 \mathrm{G}$ ), in agreement with previous reports (10, $38,54)$. On top of these cuts, Yen 1 can nick strands 2 and 4 of X0, typically 1 or $2 \mathrm{nt}$ at the 3 ' of the branching point. Therefore, it seems that while GEN1 preferentially resolves the X0 HJ over the 1-3 axis, Yen1 can process it across both the 1-3 and 2-4 axis. Interestingly, the analysis of the cleavage products by native PAGE revealed that Yen1, but not GEN1, gives rise to two additional species apart from the nicked duplex expected by canonical resolution (Supp. Fig. 1). These species migrate in positions comparable to those of a replication forklike (RF-like) structure and a $30 \mathrm{nt}$ duplex, which would be consistent with the cleavage of two 
annealing strands, and thus releasing one helical arm of the junction. Differences between the two enzymes in their preference to cleave specific strands can also be observed on a fully continuous 3WJ (Figures 1E and 1G). For this substrate, Yen1 has a marked preference to incise strand 1, again $1 \mathrm{nt}$ at the 3' of the branching point, while GEN1 produces detectable nicking on all strands of this substrate. Together with the results obtained with the XO HJ, this suggests that the two enzymes may recognize or remodel these continuous branched substrates in a different manner. However, substrates with discontinuous strands like model replication forks (RFs) or 5'-flaps were almost exclusively processed by both Yen1 and GEN1 on strand 4, 1 or $2 \mathrm{nt}$ at the $3^{\prime}$ from the branching point of the $5^{\prime}$ arm/flap (Figures 1D, 1F and 1G). An additional incision $4 \mathrm{nt}$ into the 5'-flap strand for GEN1 that has been previously observed was also recapitulated in our analysis (Chan and West, 2015). Additionally, we also tested if Yen1 could nick any of the strands of 3'-flap, splayed arm, double- and single- stranded DNA substrates. In agreement with our previous results showing no cleavage of these species (67), we did not detect incisions produced by Yen1 on any of their constituent strands (Supp. Fig. 2).

\section{Yen1 can incise both the opposing and 5' strands of nicked HJs}

Nicked HJs are important intermediates during HR, being the precursors of fully ligated HJs and regarded in many instances as the key intermediate to generate crossovers $(81,82)$. To specifically assess how Yen1 resolves these structures, we generated the 4 possible nicked HJs based on the $\mathrm{X} 0$ structure (X0n1 to X0n4, with 1-4 indicating the nicked strand) and independently labelled each of the intact strands. The resulting set of 12 substrates was incubated with Yen1 or GEN1 and their incisions mapped as described in the previous section. When we labelled the strand opposing the nick (Figure 2A), we observed that both Yen1 and GEN1 hydrolysed it $1 \mathrm{nt}$ to the 3'-side of the junction point (position 31) for X0n3. In junctions $\mathrm{X} 0 \mathrm{n} 1, \mathrm{X} 0 \mathrm{n} 2$ and X0n4, Yen1 still cleaves mainly at position 31, but GEN1 does it 1-3 nt to the 3'-side of the junction point, mainly in position 32 of the oligo (Figures 2A and G). Interestingly, these incisions on the nicked $\mathrm{X} 0$ are not perfectly symmetrical to the pre-existing nick in position 30 and thus would lead to duplex products that would contain typically $1 \mathrm{nt}$ (up to 3 nt) gaps or 3'-flaps, as it has been observed for the Arabidopsis orthologs (48). 
It is generally considered that the presence of a nick in a HJ increases its flexibility and the accessibility of the SSEs for the cleavage of the opposite strand, thus favouring counter-nicking and resolution of the junction (83). Accordingly, analysis of the same reaction products on native gels also revealed that the expected $60 \mathrm{nt}$ duplex resulting from resolution of the X0n1 and X0n3 was almost the exclusive product for GEN1 (Figure 2B). However, in the case of Yen1, the same pattern of 3 bands (RF-like, nicked duplex, small duplex) observed with intact $\mathrm{X} 0$ was still present, to different extents, with all the nicked X0 versions. Surprisingly, the major product of GEN1 on X0n2 and X0n4 was the small duplex molecule, which necessarily involves the cleavage of the 5'strand with respect to the nick. Indeed, when we labelled the 5 'strand in all the nicked HJs, we detected mild cleavage by both nucleases in all cases, except for GEN1 on X0n3-4* (Figure 2C and 2G) and consistently, we observed again the presence of the small duplexes in the native gels, except for X0n3-4* (Figure 2D). Conversely, we detected no incisions or the presence of the small duplex product when the nicked junctions were labelled on the 3'strand with respect to the nick (Figures $2 \mathrm{E}$ and $2 \mathrm{~F}$ ).

The removal of one arm from a nicked HJ to produce a three-arm structure has already been observed for the A. thaliana orthologs of Yen1, AtGEN1 and AtSEND1 (48), being referred to as Ref-I (Replication Fork Intermediate) activity. Interestingly, the small duplex that we observe when we label the strand opposite the nick (Figure 2B) cannot arise directly as a consequence of this Ref-I activity. Instead, it must involve a sequential reaction, in which the first incision by Ref-I activity on the 5'strand with respect to the nick is followed by a second incision on the resulting RF-like intermediate, with the typical 5' polarity of the Rad2/XPG family (Supp. Fig. 3A).

\section{Both symmetrical resolution and arm-chopping contribute to the formation of nicked duplex DNA from a synthetic $\mathbf{H J}$}

The paradigm of canonical $\mathrm{HJ}$ resolution proposes that two symmetrical, coordinated incisions across the axis of the HJ produce a pair of nicked duplexes $(21,84)$. Surprisingly, when we analysed the cleavage products generated by Yen1 on an intact X0 HJ in native gels (Supp. Fig. 1), we detected the formation of, apparently, the same two additional species that we observed with the nicked X0 HJs: one with a migration compatible with a RF-like structure and another migrating like a small ( $30 \mathrm{nt})$ DNA duplex. 
This suggests that Yen1 may exhibit an alternative way of processing an intact HJ: the cleavage of both strands in one arm of the HJ, releasing a small dsDNA fragment and a RF-like, threearm structure (Supp. Fig. 3B). This arm-chopping activity has also been observed for some of Yen1 orthologs such as OsGEN1 (56), AtGEN1 and AtSEND1 (48) and DmGEN1 (49). Importantly, the RF-like structure produced by this arm-chopping would be susceptible of further processing to yield a nicked dsDNA product, similar to the one expected by symmetrical resolution, in a situation analogous to that described for the Ref-I activity on nicked HJs (Supp. Fig. 3A). This poses an interesting caveat: is Yen1 able to symmetrically resolve an intact HJ into two nicked dsDNA molecules or do these nicked duplexes arise from a two-step mechanism involving arm-chopping? To address this question, we generated an X0 HJ variant in which the opposing oligos X0-2 and X0-4 were modified to contain three hydrolysisresistant phosphorothioate linkages (SP) between nucleotides 30, 31, 32 and 33 (Figure 3A). Therefore, this structure could only be processed by symmetrical resolution, i.e. by the introduction of two nicks on oligos X0-1 and X0-3, respectively. After confirming that oligos X0-2 and X0-4 where resistant to cleavage by both Yen1 and GEN1 (Figure 3B), we compared the ability of both resolvases to process this structure with respect to an unmodified $\mathrm{X} 0 \mathrm{HJ}$ and verified that the ability of each enzyme to introduce a nick at nucleotide 31 in the oligo 1 was similar for both substrates (Figure 3C). Remarkably, when analysing the same reactions on native gels, we observed that both the RF-like and small duplex products that Yen1 generates on the X0 disappear when the X0-2SP is employed, while most of the nicked duplex product remained (Figure 3D). We quantified the formation of nicked duplex and total cleavage (RFlike + nicked duplex + small duplex) in each reaction and observed that, for GEN1, total cleavage is equivalent to nicked duplex formation, as expected for a canonical resolvase. For Yen1, the nicked duplex represents approximately $2 / 3$ of the total cleavage (19\% vs $28 \%$ ) on a normal X0, with an undetermined contribution from each mechanism. However, on the X02SP virtually all cleavage products correspond to the nicked duplex (14\%), which in this case can only arise from symmetrical resolution (Figure 3D). Therefore, these results demonstrate that Yen 1 is capable of symmetrical resolution of an intact HJ, despite being endowed with an alternative arm-chopping mode of $\mathrm{HJ}$ processing.

\section{Yen1 and GEN1 display a different preference in strand cleavage on a $\mathrm{HJ}$ with a fixed conformation.}


In the presence of $\mathrm{Mg}^{2+}$, $\mathrm{HJ}$ s undergo a conformational change from an open, square structure into a form where pairs of arms are coaxially stacked (85). This implies the existence of two DNA strands that will appear as continuous as opposed to two exchanging strands. Some HJ resolvases like RuvC, T7 Endo I and GEN1 show a preference for the cleavage of the continuous strands $(32,54,86,87)$, while Hjc or T4 Endo VII incise the exchanging strands (88-90). To assess if Yen1 displays any bias in cleavage orientation, we determined the incision sites it produced on a $\mathrm{J} 3$ synthetic HJ. In solution, this junction exists almost exclusively as a conformer with arm-stacking of 2 over 4 and 1 over 3 (Figure 4A) (31). As previously reported, GEN1 preferentially nicks the $x$ and $h$ strands (Figure 4B-D) (54). Unexpectedly, and despite a comparatively low activity on this substrate, Yen1 processed the $\mathrm{J} 3 \mathrm{HJ}$ through incisions in the $b$ and $r$ strands (Figure 4B-D). Therefore, these results indicate that, like GEN1 and other resolvases, Yen1 displays a marked preference bias for the cleavage of one particular axis of this $\mathrm{J} 3$, which could be due to a different docking mode on the junction or sequence preference compared to its human counterpart.

\section{A novel 5'-3' exonuclease activity in Yen1 prevents the ligation of its $\mathrm{HJ}$ resolution products}

GEN1 was first characterized as a "canonical" HJ resolvase due to its ability to introduce symmetrical nicks that lead to the formation of nicked dsDNA molecules that can be ligated without any further processing (10). As we have shown, Yen1 can also introduce symmetrical incisions, but its ability to produce resolution products that can be directly ligated remains unaddressed. Therefore, we decided to test if $\mathrm{HJ}$ resolution by Yen1 also fulfils this condition. For this purpose, we employed the X1-T asymmetrical HJ that allows the ligation of cleavage products created by GEN1 (38). Resolution of X1-T across strands 1 (53 nt, 5'-labelled) and 3 (60 nt) and further religation of the nicked product with T4 DNA ligase creates a new hybrid 5'-labelled strand of $60 \mathrm{nt}$ that can be detected by denaturing PAGE (Figure 5A). Using this set-up, we confirmed that GEN1 resolution products can be readily ligated ( $>40 \%$ ) (Figure 5B), as previously reported $(10,38,54)$. However, ligation products were almost undetectable for Yen1. Given that the nicks produced on this junction are symmetrical and thus a priori able to be sealed, we speculated that Yen1 might be further processing its cleavage products. To test this hypothesis, we created nicked dsDNA substrates and determined whether Yen1 could act on them. When we labelled the 5'-phosphate group at the nick, we observed that incubation 
with Yen1 resulted in the loss of the labelling, as determined by the appearance of a fast migrating band in both native and denaturing gels (Figure 5C, left panel). Conversely, when labelling the 3'-end of the same strand downstream the nick, Yen1 produced a slight shift of the substrate in native PAGE and the degradation of the substrate up to 27 nucleotides in denaturing PAGE (Figure 5C, right panel). Both results indicate that Yen1 is endowed with a 5'-3' exonuclease activity specific for nicked DNA molecules. To further characterize this previously undescribed exonuclease activity, we created a series of 3'-labelled dsDNA substrates with gaps of increasing length and checked if Yen1 could extend such gaps (Figure 5D). We observed that nicks and gaps up to $2 \mathrm{nt}$ could be efficiently extended into $3 \mathrm{nt}$ gaps. However, $3 \mathrm{nt}$ gaps became poor substrates for Yen 1 exonuclease activity and 4 or $5 \mathrm{nt}$ gaps were not further extended, indicating that, in this context, it acts as a low processivity exonuclease. Consistently with the exonuclease nature of this activity, addition of an SP linkage between the first two nucleotides of the downstream oligo in a nicked dsDNA, prevented Yen1 from processing this substrate (Figure 5E). Interestingly, the same experiment also revealed that GEN1 is endowed with the same activity, albeit it is comparatively weak, excising only 1 nt. Finally, we hypothesized that if this exonuclease activity was processing the resolution products of Yen1 on the X1-T HJ and preventing their ligation, the inclusion of an SP linkage between nt 31-32 in the oligo 3 of this X1-T HJ (1 nt at the 3'of the incision for resolution) should prevent this activity and allow their ligation. Indeed, when the resolution products created by Yen 1 on such X1-T-SP were incubated with T4 ligase, the $60 \mathrm{nt}$ ligated strand could be detected, unlike with the unmodified X1-T HJ (Figure 5F). Altogether, these results reveal the existence of a 5'-3' exonuclease activity in Yen1 that specifically extends nicks in dsDNA molecules into single-stranded gaps up to $3 \mathrm{nt}$ long. Such activity efficiently processes the products of symmetrical resolution by Yen1, rendering them unable to be ligated in vitro.

\section{Yen1 is a monomer in solution}

Coordinated $\mathrm{HJ}$ resolution requires the introduction of near-simultaneous nicks across one of the axes of the structure. In bacteria and archaea, this is facilitated by the dimeric nature of $\mathrm{HJ}$ resolvases in solution (41). However, Yen1 orthologs are monomers in solution, like all the members of the Rad2/XPG family and, hence, it has been proposed that coordinated incisions require their dimerization on the HJs $(38,49,51,54)$. To assess the state of Yen1 in solution, we analysed its hydrodynamic properties by size exclusion chromatography and sedimentation 
through glycerol gradients (Supp. Fig. 4). The observed values of Stokes radius (4.9 nm) and $\mathrm{S}$ value (3.9) for Yen1, allowed us to estimate an apparent molecular weight of $80 \mathrm{kDa}$ in solution, which would be consistent with a monomeric state, as reported for other orthologs.

\section{Yen1 can process a plasmid with a cruciform structure by both resolution and arm- chopping}

Canonical HJ resolution involves the introduction of a pair of nicks in a coordinated manner, this is, within the lifetime of the enzyme dimer-HJ complex. The ability of numerous resolvases to introduce coordinated cuts has been extensively tested employing plasmid-based substrates that extrude palindromic sequences as cruciform, like pIRbke8 derivatives $(54,91)$ or pIR9 (48). Coordinated cleavage of the cruciform structure leads to the linearization of the plasmid, while individual nicks on the cruciform allow the release of negative supercoils and result in the reabsorption of the cruciform into a relaxed nicked circular DNA (Figure 6A). It has been shown that dimers of human GEN1 and CtGEN1 introduce coordinated nicks on the cruciform within the lifetime of the enzyme-DNA complex, leading almost exclusively to the formation of linear products $(38,51,54)$. We wanted to address if Yen1 also displays a similar level of coordination when processing this substrate. Interestingly, we observed that the incubation of the cruciform-containing plasmid pIR9 with Yen1 gave rise to a mix of products depending on the phosphorylation status of the enzyme: the phosphorylated version of Yen1 resulted mostly in its conversion to the slowest migrating band, the relaxed circular form of the plasmid (Figure 6B), while the major product after incubation with the more active, dephosphorylated version of Yen1 was the linearized vector. These results suggest that the activation of Yen1, in addition to the enhancement of its nuclease activity, may also improve its ability to carry out coordinated cleavage within the lifetime of the enzyme dimer-DNA complex.

However, we were still surprised by the level of non-coordinated cleavage that Yen1 was able to promote, as evidenced by the presence of the relaxed form of the plasmid in these experiments. Given our previous observations of Yen1 arm-chopping activity, we wondered whether this activity could also act on a cruciform-bearing plasmid. If so, it would imply a coordinated pair on incisions, but in an asymmetrical manner, that could lead to the formation of a relaxed, gapped circle (Figure 6A, central row), a product that would be electrophoretically indistinguishable from a relaxed, nicked circle in an agarose gel. To elucidate if Yen1 gives 
rise to nicked circles (uncoordinated cleavage) or gapped circles (coordinated cleavage), we designed two different experiments. First, we argued that if the relaxed circles were nicked molecules, they could be religated; if they contained ssDNA gaps, they should not religate. As shown in Figure 6C, nicked circles produced with Nt.BspQI are readily ligated, and migrate as a supercoiled DNA band, while only a minor fraction of the relaxed circle can religate in the reactions with Yen1 (Figure 6C). This suggests that the main circular product generated by Yen1 could be a gapped molecule. However, since such gapped circles might arise from nicks extended into gaps by Yen1 itself through its exonuclease activity, a second experiment was designed to specifically detect the DNA fragment that would be released only if Yen 1 catalyzed an arm-chopping reaction on one of the hairpins of the cruciform structure (Figure 6D), by labelling all the reaction products and analysing them in a denaturing gel. For the experiment, the cruciform-based plasmid was incubated with a variety of enzymes: 3 different versions of Yen1 (Yen $1^{\mathrm{wT}-\lambda}$, Yen $1^{\mathrm{ON}-\lambda}$ and Yen1 ${ }^{\mathrm{ND}}$ ), GEN1 as a control for a linear product, Nt.BspQI as a control for a nicked product, and EcoRI, which is commonly used to test the extrusion level of the plasmid. When these reactions were analysed in a denaturing gel, we could only detect bands consistent with the expected size of the released hairpin (66 nt) in those reactions containing active Yen1, but not in any of the other controls (Figure 6E). All these results strongly suggest that a significant fraction of the relaxed, circular molecules arise from an armchopping mechanism. Therefore, Yen 1 seems to mainly promote the coordinated incision of plasmid-borne cruciform structures, albeit occasionally in an asymmetrical manner.

\section{The assembly of a Yen 1 dimer on the $\mathrm{HJ}$ accelerates the rate of the first incision during HJ resolution.}

Our results with the plasmid-borne cruciform indicate that HJ processing by Yen1 proceeds by the introduction of coordinated incisions within the lifetime of a nuclease dimer-HJ complex. For the dimeric prokaryotic and mitochondrial resolvases such coordination is ensured by the acceleration of the cleavage of the second strand after the first incision (92). However, eukaryotic Rad2/XPG family HJ resolvases are monomeric in solution and dimerization happens on the HJ $(38,48,49,51)$ (Supp. Fig. 4). It has been shown for human GEN1 that dimerization on the $\mathrm{HJ}$ substrate stimulates the first incision of the junction by one of the monomers, which is the rate-limiting step for HJ resolution (38), while experiments with CtGEN1 have confirmed that cleavage of the second strand is accelerated after the first incision 
(51). To test if the formation of the dimer on a HJ could also favour the initial incision by Yen1, we created a modified $\mathrm{X} 0 \mathrm{HJ}$ with an SP bond at the expected cleavage position of Yen1 in oligo X0-3, between nucleotides 31 and 32 (Figure 7A). When incubated with Yen1 or GEN1, this X0-SP cannot be resolved as efficiently as a normal X0 junction (Figure 7B), mostly due to a drastic decrease in the cleavage of strand X0-3 (Figure 7C), as previously shown for GEN1 (38). Then, we titrated a binding proficient, but catalytically inactive version of Yen1 (Yen $1^{\mathrm{ND}}$ ) in reactions with limiting amounts of active Yen1 to see how an increase of total dimers in the reaction would affect the initial incision. In agreement with published results for GEN1, the nicking of strand X0-1 was stimulated by addition of Yen1 $1^{\mathrm{ND}}$, up to a 1:4 WT:ND molar ratio (Figure 7D and E). As expected, further titration resulted in an inhibitory effect, likely due to the sequestration of HJs by inactive dimers. These results indicate that formation of a Yen1 dimer on the HJ favours the rate-limiting, initial incision.

\section{Yen1 $^{\text {ON }}$ displays the same cleavage specificity as Yen1}

Yen $1^{\text {ON }}$ is a mutant version of Yen 1 where all nine serines in CDK consensus sites (Figure 1A) have been substituted for alanines, rendering the protein constitutively active and nuclear throughout the cell cycle (60). This mutant serves as a powerful tool to explore the consequences of its premature activation without the need of interfering with the cell cycle progression machinery $(66,67,71-78)$. While we have previously shown that the range of substrates that Yen $1^{\text {ON }}$ can process overlaps entirely with that of Yen1 $(67,68)$, we did not know whether the specificity of the incisions within each substrate remained unaltered, so we mapped the cleavage sites produced by Yen $1^{\mathrm{ON}}$ on the same set of substrates (Supp. Fig. 5A). We did not observe any difference on the position of the sites cleaved by Yen $1^{\text {ON }}$ with respect to those cleaved by the wild-type enzyme, confirming that despite its lack of CDK-dependent regulation, Yen $1^{\mathrm{ON}}$ retains the same cleavage specificity, thus representing a good proxy for the status of maximum Yen1 activation. However, when comparing the kinetics of in vitrodephosphorylated wild-type Yen1 with those of Yen $1^{\mathrm{ON}}$, we noticed that the cleavage rate of the former was always lower (Supp. Fig. 5B and C). In this sense, previous phosphomapping analyses of Yen 1 revealed that there are at least $20 \mathrm{~S} / \mathrm{T}$ residues at non-CDK consensus sites phosphorylated in vivo $(67,68,93)$. Since the Yen $1^{\text {ON }}$ preps we employed were not in vitrodephosphorylated, we wanted to assess if phosphorylation at those non-CDK consensus sites could also be contributing to the regulation of Yen1 activity. For this, we dephosphorylated 
Yen $1^{\text {ON }}$ by treatment with lambda-phosphatase and compared its ability to process different substrates with respect to the mock-treated protein (Supp. Fig. 5D and E). Both versions displayed similar cleavage kinetics, indicating that phosphorylation at CDK sites represent the major regulatory switch for Yen1 nuclease activity, with none or minor contribution from other phosphoresidues. Since this result did not explain the differences in activity between dephosphorylated Yen1 and Yen $1^{\mathrm{ON}}$, we tested if some level of residual phosphorylation could still be detected for these proteins after lambda-phosphatase treatment using Phos-Tag containing SDS-PAGE gels that specifically reduce the mobility of phosphoproteins. Indeed, we observed that while the phosphatase treatment apparently abolished all phosphorylation on Yen $1^{\text {ON }}$, a detectable shift was still present for wild-type Yen1 (Supp. Fig. 5F). Therefore, the more likely explanation for the difference in activity between dephosphorylated wild-type Yen1 and Yen $1^{\text {ON }}$ is due to the inability of lambda phosphatase treatment to fully remove all phosphorylation from relevant serines at Yen1 CDK consensus sites and thus preventing full activation of the enzyme.

\section{Expression in yeast of constitutively nuclear human GEN1 ${ }^{\text {nuc }}$ does not fully recapitulate the genotoxicity of misregulated Yen1.}

The ability of both Yen1 and GEN1 to target branched DNA molecules is tightly controlled throughout the cell cycle. To understand the importance of such regulation, two mutants that can access and cleave their potential targets at any cell cycle stage - Yen $1^{\text {ON }}$ and GEN1 ${ }^{\text {nuc }}$ were expressed in budding yeast and human cells, respectively $(50,67)$. Interestingly, while expression of both these mutants lead to an increase of COs, only Yen $1^{\text {ON }}$ causes hypersensitivity to genotoxic stress. To figure out whether this higher toxicity of Yen $1^{\mathrm{ON}}$ expression in yeast cells depends on some specific feature of the yeast chromatin biology or on the biochemical differences between Yen1 and GEN1, we decided to set up an in vivo experiment to compare the effects of the expression of these mutants in the same organism. For this, we created a series of $S$. cerevisiae strains harboring different cassettes to express Yen1, Yen $1^{\mathrm{ON}}$, GEN1, GEN1 ${ }^{\text {nuc }}$ and the GEN1 truncated versions GEN1 ${ }^{1-527}$ and GEN1 $1^{1-527 n u c}$, all under the control of either the inducible GAL1 or the constitutive GPD1 promoters in both wild-type and resolution-deficient (mus81 1 yen1 1 ) backgrounds. To ensure that any observed toxicity for Yen $1^{\mathrm{ON}}$ was not merely due to a dose or localization effect, we aimed for a set of strains where GEN1 variants displayed constitutive nuclear localization as well as similar or 
higher protein expression levels and similar or higher biochemical activity in whole-cell extracts when compared to strains carrying Yen $1^{\mathrm{ON}}$. Among all combinations tested, these premises could only be fulfilled in media containing galactose when Yen1 and Yen $1^{\text {ON }}$ were expressed under the control of the GPD1 promoter, and GEN1 ${ }^{1-527}$ and GEN1 1-527nuc were expressed under the control of the GAL1 promoter (Figure 8A-C). Under these conditions, we compared the effect of Yen $1^{\mathrm{ON}}$ and GEN1 $1^{1-527 \mathrm{nuc}}$ in increasing hypersensitivity to the genotoxic agent methyl methanesulfonate (MMS) in a wild-type background (Figure 8D). To verify the functionality of the enzymes, we also performed this experiment in the resolution-deficient mus $81 \Delta$ yen $1 \Delta$ double mutants (Figure 8E), where premature activation of Yen1 provides increased resistance to MMS (67). In the WT strain, expression of Yen $1^{\mathrm{ON}}$ conferred strong sensitivity at the lower dose of MMS tested (Fig. 8D), whereas expression of GEN1 ${ }^{1-527 n u c}$ induced a milder sensitivity, despite showing comparable expression levels and a more potent nuclease activity on extracts (Fig. 8A and B). However, when we analysed the survival of the mus $81 \Delta$ yen $1 \Delta$ double mutants to the MMS treatment, we observed that Yen $1^{\mathrm{ON}}$ was also more efficient in providing resistance to MMS than GEN1 ${ }^{1-527 n u c}$ (Figure 8E). Therefore, while Yen $1^{\text {ON }}$ expression is more toxic than that of GEN1 $1^{1-527 n u c}$, despite its lower biochemical activity in whole cell extracts, we cannot conclusively affirm that this toxicity derives from specific differences in their biochemical properties, as GEN1 $1^{1-527 n u c}$ does not seem comparably functional in the processing of HR intermediates when expressed in yeast.

\section{DISCUSSION}

The original identification of Yen1 as a canonical HJ resolvase in S. cerevisiae relied on experiments carried out employing whole cell-extracts and protein immobilized on agarose beads (10). Since then, much of what we know about Yen1 properties has been extrapolated from other orthologs in the subclass IV of the Rad2/XPG family that were successfully purified before. Despite the subsequent purification of functional Yen1 to homogeneity, only a basic study of its mechanism of activation was described (67). Here, we presented the first exhaustive biochemical characterization of Yen1, focused on the evaluation of its properties compared to the well-studied human canonical HJ resolvase GEN1.

\section{The high- and low-activity versions of Yen1 display identical incision patterns}


We had previously shown that the phosphorylation status of Yen1 does not affect the range of substrates it can target (67), which are similar to those described for GEN1 $(10,38,54)$. Here, we have additionally confirmed that these changes in phosphorylation do not alter the position of the incisions that Yen1 produces on a wide range of substrates (Figure 1, Supp. Fig. 1 and 2). In a similar way, the constitutively active mutant Yen $1^{\mathrm{ON}}$ incises all the tested substrates at identical positions when compared to the wild-type Yen1 (Supp. Fig. 5). Therefore, this work further substantiates that the activation of Yen1 by dephosphorylation does not qualitatively change how the enzyme processes these oligonucleotide-based substrates.

\section{Yen1 may present a particular interaction mode with HJs and other substrates.}

In addition to some of the distinct incisions in various substrates that we have observed, a particularly striking difference between Yen1 and GEN1 is their opposed preference for the crossing and continuous strands, respectively, of the J3 HJ (Figure 4). Despite its closer phylogenetic relation to Yen1, a preference for the continuous strands has also been observed in the fungal CtGEN1 (51). This suggests that Yen1 might bind or remodel the junction in different ways compared to GEN1, CtGEN1 and, potentially, other orthologs. While structural details are not available for Yen1, we have identified a Saccharomyces genus-specific, disordered region in the XPG-N domain in Yen1, whose deletion renders the protein inactive (our unpublished data). This suggests that this region, which is located near essential catalytic residues like D41, could be to some extent involved in the positioning of the catalytic residues and hence modify the way Yen1 specifically interacts with the HJ with respect to other orthologs from other genera.

We would also like to note that we have detected unanticipated cleavage products by human GEN1 on oligo X0-1 in substrates like the 3'-flap, splayed arm or ssDNA (Supp. Fig. 2). These products can be observed in GEN1 preparations from other groups (49). Since this activity can be observed on X0-1 as ssDNA, but not on ssDNA poly-T oligos, we think that this oligo may form a stable secondary structure that can be recognized and targeted by GEN1, but not Yen1, revealing another difference between the two enzymes.

\section{Yen1 non-canonical activities and the paradigm of canonical $\mathrm{HJ}$ resolution}


The paradigm of canonical resolution states that the symmetrical, coordinated incisions across one of the axis of the junction must occur within the lifetime of the enzyme-substrate complex, yielding nicked DNA molecules that can be sealed without the need for further processing (41, 84). This work demonstrates that Yen1 can be considered a canonical resolvase since i) it can create symmetrical cuts on a HJ (Figure 1), ii) the incisions occur mainly in a coordinated manner (Figure 6) and iii) its resolution products, in a first instance, could be ligated (Figure 5). However, the existence of the novel arm-chopping and nick-exonuclease activities plays a confounding role in the interpretation of biochemical assays traditionally employed to assess the coordination of incisions and the ligation of resolution products, respectively.

In this sense, our results regarding cleavage coordination with the cruciform extruding plasmid pIR9 (48) led us to propose an extension to the usual interpretation for this type of experiments, where an undetermined, but likely major fraction of the relaxed circular species produced by Yen1 corresponds to gapped, rather than nicked circles, resulting from arm-chopping activity (Figure 6 and Supp. Fig. 3B). In this way, Yen1 would process this cruciform mainly in a coordinated, albeit not always symmetrical manner. This coordination would be consistent with the idea that Yen1, despite being a monomer in solution (Supp. Fig. 4), needs to dimerize on the substrate in order to accelerate the rate of the first incision (Figure 7C-D), the limiting step of the reaction, as previously proposed for GEN1 in humans, D. melanogaster, $C$. thermophilum and other eukaryotic resolvases $(38,40,46,47,49,54,94)$. With respect to the nick-exonuclease activity, it is interesting to note that it has also been detected for GEN1, albeit it does not seem robust enough to prevent the majority of the resolution products from being religated (Figure 5E and F). Importantly, we have never observed exonuclease activity of Yen1 on dsDNA or ssDNA substrates (Supp. Fig. 2), reinforcing the notion that this activity is specific of nicked dsDNA molecules. At this point we cannot categorically rule out that such activity stems from partial DNA breathing that creates pseudo-5'flaps at the nicks that are processed endonucleolytically. However, if this was the case, we would expect that GEN1, being generally more active on 5'-flaps than Yen1, should also display a stronger activity on the nicked dsDNA, which is not the case.

Altogether, our results support that Yen1 has a canonical resolvase behaviour in vitro, despite the presence of two additional activities that may blur such classification. 


\section{Could the detrimental effects of Yen1 premature activation be due to non-canonical activities operating in vivo?}

Yen1 and GEN1 ability to access and process their targets in chromatin is strictly regulated throughout the cell cycle $(62,63,67-69)$. However, the misregulation of Yen1 seems to elicit a more detrimental effect than misregulation of GEN1, especially in terms of DNA damage sensitivity $(50,67)$. Such effect could be explained either by Yen1 deregulation having more severe consequences due to its specific activities or by yeast system being generally more sensitive to misregulation of any nuclease. Our efforts to try to distinguish between these two possibilities have not allowed us to reach conclusive results, if interpreted conservatively (Figure 8). The expression in yeast of a deregulated version of GEN1, GEN1 ${ }^{1-527 n u c}$, produces a milder phenotype than Yen $1^{\mathrm{ON}}$ both in the increase of sensitivity to MMS in wild-type cells and in increased resistance to MMS in mus $81 \Delta$ yen $1 \Delta$ double mutants. These results would suggest that GEN1 1-527nuc does not have a similar capacity to target branched DNA molecules to $Y e n 1^{\text {ON }}$ in yeast, regardless of their physiological or pathological nature for the cell. Notwithstanding, it has been shown that expression of GEN1 can process repair intermediates and restore sporulation in S.pombe mus81 $\Delta$ mutants (95), and the difference in the detrimental effect between Yen $1^{\mathrm{ON}}$ and GEN1 ${ }^{1-527 n u c}$ expression in wild-type cells seems overtly higher than in their protective effect in mus81 1 yen $1 \Delta$ strains (Figures $8 \mathrm{D}$ and $8 \mathrm{E}$ ). Therefore, we consider that, to some extent, Yen1 may present specific properties that lead to increased toxicity when prematurely activated compared to GEN1. However, whether this potential toxicity of Yen1 is due to the novel activities described in this work, or if they actually manifest in vivo, remains unclear. The nicked dsDNA-specific 5'-3'exonuclease activity described in this paper has been previously described for other members of the Rad2/XPG family, like class II human FEN1 $(96,97)$ and class III EXO1 (98), and even in the class IV Yen1/GEN1 ortholog DmGEN (43). Additionally, even if not specifically tested, the low ligation efficiency observed for the resolution products of OsGEN-L, AtGEN1 and AtSEND1 $(48,56)$, could arguably be due to the presence of a similar activity. With respect to Yen1 ability to excise one arm from a nicked HJ (Ref-I activity (48)) or an intact HJ (arm-chopping) (Supp. Fig. 3), at least one of these activities has also been described or can be observed in the experiments with the plant, fly and mammalian orthologs $(48,49,56)$ (Figure 2 and Supp. Fig.1), and hence seem rather widespread among the subclass IV of the Rad2/XPG family of nucleases. Despite this apparent conservation, it is not straightforward to envisage a possible biological role for an activity like the arm-chopping in the context of disengaging two DNA molecules connected by HJs, as it 
would inevitably lead to the generation of a DSB (Supp. Fig. 3). Alternatively, it has been proposed that replication fork reversal, which leads to the formation of a HJ-like structure, may help stabilize stalled replisomes, sometimes leading to situations of transient over-replication (99). Then, template unwinding followed by flap processing or end-resection of the regressed arm would be required for its removal and replication termination. In this context, if such intermediates persisted until late stages of mitosis, the endonucleolytic processing of the regressed arm by arm-chopping could hypothetically provide an alternative way for its elimination. In the future, it would be interesting to take advantage of structural data to explore possible separation-of-function mutants that lack some of these non-canonical activities. With such tools in hand, we could ask if they actually play any functional role in vivo, like the processing of particularly adamant recombination or replication intermediates, or simply represent collateral consequences of the evolutionary adaptation of a monomeric SSE to perform a reaction that requires its dimerization and coordinated cleavage on a Holliday junction.

\section{SUPPLEMENTARY DATA}

Supplementary data contains Supplementary Tables 1-4 and 5 Supplementary Figures.

\section{ACKNOWLEDGEMENTS}

The authors would like to thank Gary Chan and Stephen C. West for various yeast strains, plasmids and proteins; Daniela Kobbe for the pIR9 plasmid; Joao Matos and Tomás Lama Díaz for constructive discussions and for critical reading of the manuscript and Marta Picado for technical assistance with fluorescence microscopy.

\section{FUNDING}

The work in the Blanco lab was supported by Ministerio de Economía, Industria y Competitividad (MINECO), Agencia Estatal de Investigación (AEI) and the European Union (European Regional Development Fund - ERDF) [RYC-2012-10835, BFU2013-41554-P, BFU2016-78121-P] and by Xunta de Galicia (XdG) and ERDF [ED431F-2016/019, ED431B- 
2016/016 and ED431C 2019/013]. CIMUS receives financial support from the XdG and ERDF (Centro Singular de Investigación de Galicia accreditation 2019-2022) [ED431G 2019/02]. F.J.A. and R.C are recipients of pre-doctoral fellowships from XdG [ED481A-2015/011 and ED481A-2018/041] and V. H.-N. from MINECO and AEI [BES-2014-068734].

\section{CONFLICT OF INTEREST}

None declared.

\section{REFERENCES}

1. Wild,P. and Matos,J. (2016) Cell cycle control of DNA joint molecule resolution. Curr. Opin. Cell Biol., 40, 74-80.

2. Wu,L. and Hickson,I.D. (2003) The Bloom's syndrome helicase suppresses crossing over during homologous recombination. Nature, 426, 870-874.

3. Andersen,S.L., Bergstralh,D.T., Kohl,K.P., LaRocque,J.R., Moore,C.B. and Sekelsky,J. (2009) Drosophila MUS312 and the vertebrate ortholog BTBD12 interact with DNA structurespecific endonucleases in DNA repair and recombination. Mol Cell, 35, 128-135.

4. Boddy,M.N., Gaillard,P.H.L., McDonald,W.H., Shanahan,P., Yates,J.R. and Russell,P. (2001) Mus81-Eme1 are essential components of a Holliday junction resolvase. Cell, 107, 537-548.

5. Castor,D., Nair,N., Déclais,A.-C., Lachaud,C., Toth,R., Macartney,T.J., Lilley,D.M.J., Arthur,J.S.C. and Rouse,J. (2013) Cooperative Control of Holliday Junction Resolution and DNA Repair by the SLX1 and MUS81-EME1 Nucleases. Mol. Cell, 52, 221-233.

6. Fekairi,S., Scaglione,S., Chahwan,C., Taylor,E.R., Tissier,A., Coulon,S., Dong,M.Q., Ruse,C., Yates,J.R., Russell,P., et al. (2009) Human SLX4 is a Holliday junction resolvase subunit that binds multiple DNA repair/recombination endonucleases. Cell, 138, 78-89.

7. Fricke,W.M. and Brill,S.J. (2003) Slx1-Slx4 is a second structure-specific endonuclease functionally redundant with Sgs1-Top3. Genes Dev, 17, 1768-1778.

8. Garner,E., Kim,Y., Lach,F.P., Kottemann,M.C. and Smogorzewska,A. (2013) Human GEN1 and the SLX4-associated nucleases MUS81 and SLX1 are essential for the resolution of replication-induced Holliday junctions. Cell Rep., $\mathbf{5}$.

9. Interthal,H. and Heyer,W.D. (2000) MUS81 encodes a novel helix-hairpin-helix protein involved in the response to UV- and methylation-induced DNA damage in Saccharomyces cerevisiae. Mol Gen Genet, 263, 812-827.

10. Ip,S.C., Rass,U., Blanco,M.G., Flynn,H.R., Skehel,J.M. and West,S.C. (2008) Identification of Holliday junction resolvases from humans and yeast. Nature, 456, 357-61. 
11. Kaliraman,V., Mullen,J.R., Fricke,W.M., Bastin-Shanower,S.A. and Brill,S.J. (2001) Functional overlap between Sgs1-Top3 and the Mms4-Mus81 endonuclease. Genes Dev, 15, 2730-2740.

12. Munoz,I.M., Hain,K., Declais,A.C., Gardiner,M., Toh,G.W., Sanchez-Pulido,L., Heuckmann,J.M., Toth,R., Macartney,T., Eppink,B., et al. (2009) Coordination of structurespecific nucleases by human SLX4/BTBD12 is required for DNA repair. Mol Cell, 35, 116127.

13. Svendsen,J.M., Smogorzewska,A., Sowa,M.E., O’Connell,B.C., Gygi,S.P., Elledge,S.J. and Harper,J.W. (2009) Mammalian BTBD12/SLX4 assembles a Holliday junction resolvase and is required for DNA repair. Cell, 138, 63-77.

14. Wechsler,T., Newman,S. and West,S.C. (2011) Aberrant chromosome morphology in human cells defective for Holliday junction resolution. Nature, 471, 642-646.

15. Wyatt,H.D.M., Sarbajna,S., Matos,J. and West,S.C. (2013) Coordinated actions of SLX1-SLX4 and MUS81-EME1 for Holliday junction resolution in human cells. Mol. Cell, 52, 234-247.

16. Manhart,C.M., Ni,X., White,M.A., Ortega,J., Surtees,J.A. and Alani,E. (2017) The mismatch repair and meiotic recombination endonuclease Mlh1-Mlh3 is activated by polymer formation and can cleave DNA substrates in trans. PLoS Biol., 15.

17. Ranjha,L., Anand,R. and Cejka,P. (2014) The Saccharomyces cerevisiae Mlh1-Mlh3 Heterodimer Is an Endonuclease That Preferentially Binds to Holliday Junctions. J. Biol. Chem., 289, $5674-5686$.

18. Rogacheva,M.V., Manhart,C.M., Chen,C., Guarne,A., Surtees,J. and Alani,E. (2014) Mlh1-Mlh3, a Meiotic Crossover and DNA Mismatch Repair Factor, Is a Msh2-Msh3-stimulated Endonuclease. J. Biol. Chem., 289, 5664-5673.

19. Zakharyevich,K., Tang,S.M., Ma,Y.M. and Hunter,N. (2012) Delineation of joint molecule resolution pathways in meiosis identifies a crossover-specific resolvase. Cell, 149, 334-347.

20. Bennett,R.J. and West,S.C. (1996) Resolution of Holliday junctions in genetic recombination: RuvC protein nicks DNA at the point of strand exchange. Proc Natl Acad Sci USA, 93, $12217-12222$.

21. Bennett,R.J., Dunderdale,H.J. and West,S.C. (1993) Resolution of Holliday junctions by RuvC resolvase: Cleavage specificity and DNA distortion. Cell, 74, 1021-1031.

22. Connolly,B., Parsons,C.A., Benson,F.E., Dunderdale,H.J., Sharples,G.J., Lloyd,R.G. and West,S.C. (1991) Resolution of Holliday junctions in vitro requires the Escherichia coli ruvC gene product. Proc Natl Acad Sci USA, 88, 6063-6067.

23. Górecka,K.M., Komorowska,W. and Nowotny,M. (2013) Crystal structure of RuvC resolvase in complex with Holliday junction substrate. Nucleic Acids Res., 41, 9945-9955.

24. Iwasaki,H., Takahagi,M., Shiba,T., Nakata,A. and Shinagawa,H. (1991) Escherichia coli RuvC protein is an endonuclease that resolves the Holliday structure. EMBO J, 10, 4381-4389.

25. Shah,R., Cosstick,R. and West,S.C. (1997) The RuvC dimer resolves Holliday junctions by a dual incision mechanism that involves base-specific contacts. EMBO J, 16, 1464-1472.

26. Mizuuchi,K., Kemper,B., Hays,J. and Weisberg,R.A. (1982) T4 endonuclease VII cleaves Holliday structures. Cell, 29, 357-365. 
27. Lilley,D.M.J. and Kemper,B. (1984) Cruciform-resolvase interactions in supercoiled DNA. Cell, 36, 413-422.

28. Giraud-Panis,M.J.E. and Lilley,D.M.J. (1997) Near simultaneous DNA cleavage by the subunits of the junction-resolving enzyme T4 endonuclease VII. EMBO J, 16, 2528-2534.

29. Birkenbihl,R.P. and Kemper,B. (2002) High affinity of endonuclease VII for the Holliday structure containing one nick ensures productive resolution. J Mol Biol, 321, 21-28.

30. de Massy,B., Weisberg,R.A. and Studier,F.W. (1987) Gene 3 endonuclease of bacteriophage T7 resolves conformationally branched structures in double-stranded DNA. J Mol Biol, 193, $359-376$.

31. Duckett,D.R., Murchie,A.I.H., Diekmann,S., Von Kitzing,E., Kemper,B. and Lilley,D.M.J. (1988) The structure of the Holliday junction and its resolution. Cell, 55, 79-89.

32. Hadden,J.M., Declais,A.C., Carr,S.B., Lilley,D.M.J. and Phillips,S.E.V. (2007) The structural basis of Holliday junction resolution by T7 endonuclease. Nature, 449, 621-624.

33. Kleff,S. and Kemper,B. (1988) Initiation of heteroduplex loop repair by T4-encoded endonuclease VII in vitro. $E M B O J, 7,1527-1535$.

34. White,M.F. and Lilley,D.M.J. (1996) The structure-selectivity and sequence-preference of the junction-resolving enzyme Cce1 of Saccharomyces cerevisiae. J Mol Biol, 257, 330-341.

35. White,M.F. and Lilley,D.M.J. (1997) Characterization of a Holliday junction-resolving enzyme from Schizosaccharomyces pombe. Mol Cell Biol, 17, 6465-6471.

36. Whitby,M.C. and Dixon,J. (1997) A new Holliday junction resolving enzyme from Schizosaccharomyces pombe that is homologous to Cce1 from Saccharomyces cerevisiae. $J$ Mol Biol, 272, 509-522.

37. Oram,M., Keeley,A. and Tsaneva,I. (1998) Holliday junction resolvase in Schizosaccharomyces pombe has identical endonuclease activity to the Cce1 homolog Ydc2. Nucl Acids Res, 26, 594-601.

38. Chan,Y.W. and West,S. (2015) GEN1 promotes Holliday junction resolution by a coordinated nick and counter-nick mechanism. Nucleic Acids Res., 43, 10882-10892.

39. Fogg,J.M. and Lilley,D.M.J. (2000) Ensuring productive resolution by the junction-resolving enzyme RuvC: Large enhancement of the second-strand cleavage rate. Biochemistry, 39, $16125-16134$.

40. Fogg,J.M., Schofield,M.J., Declais,A.C. and Lilley,D.M.J. (2000) Yeast resolving enzyme CCE1 makes sequential cleavages in DNA junctions within the lifetime of the complex. Biochemistry, 39, 4082-4089.

41. Wyatt,H.D.M. and West,S.C. (2014) Holliday Junction Resolvases. Cold Spring Harb. Perspect. Biol., 6, a023192.

42. Furukawa,F., Kimura,M., ishibashi,T., Mori,Y., Hashimoto,J. and Sakaguchi,K. (2003) OsSEND1: a new RAD2 nuclease family member in higher plants. Plant Mol Biol, 51, 59-70. 
43. Ishikawa,G., Kanai,Y., Takata,K., Takeuchi,R., Shimanouchi,K., Ruike,T., Furukawa,T., Kimura,S. and Sakaguchi,K. (2004) DmGEN, a novel RAD2 family endo-exonuclease from Drosophila melanogaster. Nucl Acids Res, 32, 6251-6259.

44. Lee,S.-H., Princz,L.N., Klügel,M.F., Habermann,B., Pfander,B. and Biertümpfel,C. (2015) Human Holliday junction resolvase GEN1 uses a chromodomain for efficient DNA recognition and cleavage. eLife, 4, e12256.

45. Lieber,M.R. (1997) The Fen-1 family of structure-specific nucleases in eukaryotic DNA replication, recombination and repair. Bioessays, 19, 233-240.

46. Liu,Y., Freeman,A.D.J., Déclais,A.-C., Wilson,T.J., Gartner,A. and Lilley,D.M.J. (2015) Crystal Structure of a Eukaryotic GEN1 Resolving Enzyme Bound to DNA. Cell Rep., 13, 25652575 .

47. Bailly,A.P., Freeman,A., Hall,J., Declais,A.C., Alpi,A., Lilley,D.M.J., Ahmed,S. and Gartner,A. (2010) The Caenorhabditis elegans homolog of Gen1/Yen1 resolvases links DNA damage signaling to DNA double-strand break repair. PLoS Genet, 6, e1001025.

48. Bauknecht,M. and Kobbe,D. (2014) AtGEN1 and AtSEND1, two paralogs in Arabidopsis, possess holliday junction resolvase activity. Plant Physiol., 166, 202-216.

49. Bellendir,S.P., Rognstad,D.J., Morris,L.P., Zapotoczny,G., Walton,W.G., Redinbo,M.R., Ramsden,D.A., Sekelsky,J. and Erie,D.A. (2017) Substrate preference of Gen endonucleases highlights the importance of branched structures as DNA damage repair intermediates. Nucleic Acids Res., 45, 5333-5348.

50. Chan,Y.W. and West,S.C. (2014) Spatial control of the GEN1 Holliday junction resolvase ensures genome stability. Nat. Commun., 5, 4844.

51. Freeman,A.D.J., Liu,Y., Déclais,A.-C., Gartner,A. and Lilley,D.M.J. (2014) GEN1 from a Thermophilic Fungus Is Functionally Closely Similar to Non-Eukaryotic Junction-Resolving Enzymes. J. Mol. Biol., 426, 3946-3959.

52. Kanai,Y., Ishikawa,G., Takeuchi,R., Ruike,T., Nakamura,R., Ihara,A., Ohashi,T., Takata,K., Kimura,S. and Sakaguchi,K. (2007) DmGEN shows a flap endonuclease activity, cleaving the blocked-flap structure and model replication fork. FEBS J, 274, 3914-3927.

53. Moritoh,S., Miki,D., Akiyama,M., Kawahara,M., Izawa,T., maki,H. and Shimamoto,K. (2005) RNAi-mediated silencing of OsGEN-L (OsGEN-like), a new member of the Rad2/XPG nuclease family, causes male sterility by defect of microspore development in rice. Plant Cell Physiol, 46, 699-715.

54. Rass,U., Compton,S.A., Matos,J., Singleton,M.R., Ip,S.C., Blanco,M.G., Griffith,J.D. and West,S.C. (2010) Mechanism of Holliday junction resolution by the human GEN1 protein. Genes Dev, 24, 1559-69.

55. Shah Punatar,R., Martin,M.J., Wyatt,H.D.M., Chan,Y.W. and West,S.C. (2017) Resolution of single and double Holliday junction recombination intermediates by GEN1. Proc. Natl. Acad. Sci. U. S. A., 114, 443-450.

56. Yang,Y., Ishino,S., Yamagami,T., Kumamaru,T., Satoh,H. and Ishino,Y. (2012) The OsGEN-L protein from Oryza sativa possesses Holliday junction resolvase activity as well as 5'-flap endonuclease activity. $J$ Biochem, 151, 317-327. 
57. Agmon,N., Yovel,M., Harari,Y., Liefshitz,B. and Kupiec,M. (2011) The role of Holliday junction resolvases in the repair of spontaneous and induced DNA damage. Nucleic Acids Res, 39, 7009-19.

58. Blanco,M.G., Matos,J., Rass,U., Ip,S.C. and West,S.C. (2010) Functional overlap between the structure-specific nucleases Yen1 and Mus81-Mms4 for DNA-damage repair in S. cerevisiae. DNA Repair Amst, 9, 394-402.

59. Ho,C.K., Mazón,G., Lam,A.F. and Symington,L.S. (2010) Mus81 and Yen1 promote reciprocal exchange during mitotic recombination to maintain genome integrity in budding yeast. $\mathrm{Mol}$ Cell, 40, 988-1000.

60. Johnson,R.E., Kovvali,G.K., Prakash,L. and Prakash,S. (1998) Role of yeast Rth1 nuclease and its homologs in mutation avoidance, DNA repair, and DNA replication. Curr Genet, 34, 21-29.

61. Tay,Y.D. and Wu,L. (2010) Overlapping roles for Yen1 and Mus81 in cellular Holliday junction processing. J Biol Chem, 285, 11427-11432.

62. García-Luis,J. and Machín,F. (2014) Mus81-Mms4 and Yen1 resolve a novel anaphase bridge formed by noncanonical Holliday junctions. Nat. Commun., 5, 5652.

63. Matos,J., Blanco,M.G., Maslen,S., Skehel,J.M. and West,S.C. (2011) Regulatory control of the resolution of DNA recombination intermediates during meiosis and mitosis. Cell, 147, 15872.

64. de Muyt,A., Jessop,L., Kolar,E., Sourirajan,A., Chen,J., Dayani,Y. and Lichten,M. (2012) BLM helicase ortholog Sgs1 is a central regulator of meiotic recomination intermediate metabolism. Mol Cell, 46, 43-53.

65. Falquet,B., Ölmezer,G., Enkner,F., Klein,D., Challa,K., Appanah,R., Gasser,S.M. and Rass,U. (2020) Disease-associated DNA2 nuclease-helicase protects cells from lethal chromosome under-replication. Nucleic Acids Res., 48, 7265-7278.

66. Ölmezer,G., Levikova,M., Klein,D., Falquet,B., Fontana,G.A., Cejka,P. and Rass,U. (2016) Replication intermediates that escape Dna2 activity are processed by Holliday junction resolvase Yen1. Nat. Commun., 7, 13157.

67. Blanco,M.G., Matos,J. and West,S.C. (2014) Dual Control of Yen1 Nuclease Activity and Cellular Localization by Cdk and Cdc14 Prevents Genome Instability. Mol. Cell, 54, 94-106.

68. Eissler,C.L., Mazón,G., Powers,B.L., Savinov,S.N., Symington,L.S. and Hall,M.C. (2014) The $\mathrm{Cdk} / \mathrm{Cdc} 14$ Module Controls Activation of the Yen1 Holliday Junction Resolvase to Promote Genome Stability. Mol. Cell, 54, 80-93.

69. Kosugi,S., Hasebe,M., Tomita,M. and Yanagawa,H. (2009) Systematic identification of cell cycle-dependent yeast nucleocytoplasmic shuttling proteins by prediction of composite motifs. Proc Natl Acad Sci U A, 106, 10171-10176.

70. Talhaoui,I., Bernal,M., Mullen,J.R., Dorison,H., Palancade,B., Brill,S.J. and Mazón,G. (2018) Slx5-Slx8 ubiquitin ligase targets active pools of the Yen1 nuclease to limit crossover formation. Nat. Commun., 9, 5016.

71. Alonso-Ramos,P., Álvarez-Melo,D., Strouhalova,K., Pascual-Silva,C., Garside,G.B., Arter,M., Bermejo,T., Grigaitis,R., Wettstein,R., San-Segundo,P., et al. (2020) The conserved Cdc14 
phosphatase ensures effective resolution of meiotic recombination intermediates. bioRxiv, $10.1101 / 571083$.

72. Arter,M., Hurtado-Nieves,V., Oke,A., Zhuge,T., Wettstein,R., Fung,J.C., Blanco,M.G. and Matos,J. (2018) Regulated Crossing-Over Requires Inactivation of Yen1/GEN1 Resolvase during Meiotic Prophase I. Dev. Cell, 45, 785-800.e6.

73. Bittmann,J., Grigaitis,R., Galanti,L., Amarell,S., Wilfling,F., Matos,J. and Pfander,B. (2020) An advanced cell cycle tag toolbox reveals principles underlying temporal control of structureselective nucleases. eLife, 9.

74. Elango,R., Sheng,Z., Jackson,J., DeCata,J., Ibrahim,Y., Pham,N.T., Liang,D.H., Sakofsky,C.J., Vindigni,A., Lobachev,K.S., et al. (2017) Break-induced replication promotes formation of lethal joint molecules dissolved by Srs2. Nat. Commun., 8, 1790.

75. Grigaitis,R., Ranjha,L., Wild,P., Kasaciunaite,K., Ceppi,I., Kissling,V., Henggeler,A., Susperregui,A., Peter,M., Seidel,R., et al. (2020) Phosphorylation of the RecQ Helicase Sgs1/BLM Controls Its DNA Unwinding Activity during Meiosis and Mitosis. Dev. Cell, 53, 706-723.e5.

76. Matos,J., Blanco,M.G. and West,S.C. (2013) Cell-Cycle Kinases Coordinate the Resolution of Recombination Intermediates with Chromosome Segregation. Cell Rep., 4, 76-86.

77. Michel,A.H., Hatakeyama,R., Kimmig,P., Arter,M., Peter,M., Matos,J., De Virgilio,C. and Kornmann,B. (2017) Functional mapping of yeast genomes by saturated transposition. eLife, 6, e23570.

78. Wild,P., Susperregui,A., Piazza,I., Dörig,C., Oke,A., Arter,M., Yamaguchi,M., Hilditch,A.T., Vuina,K., Chan,K.C., et al. (2019) Network Rewiring of Homologous Recombination Enzymes during Mitotic Proliferation and Meiosis. Mol. Cell, 75, 859-874.e4.

79. Mumberg,D., Muller,R. and Funk,M. (1995) Yeast vectors for the controlled expression of heterologous proteins in different genetic backgrounds. Gene, 156, 119-122.

80. Rass,U. and West,S.C. (2006) Synthetic junctions as tools to identify and characterise Holliday junction resolvases. In Campbell,J.L., Modrich,P. (eds), Meth. Enzymol. Elsevier, San Diego, Vol. 408, pp. 485-501.

81. Osman,F., Dixon,J., Doe,C.L. and Whitby,M.C. (2003) Generating crossovers by resolution of nicked Holliday junctions: A role of Mus81-Eme1 in meiosis. Mol Cell, 12, 761-774.

82. Schwartz,E.K. and Heyer,W.D. (2011) Processing of joint molecule intermediates by structureselective endonucleases during homologous recombination in eukaryotes. Chromosoma, 120, 109-127.

83. Osman,F., Gaskell,L. and Whitby,M.C. (2009) Efficient second strand cleavage during Holliday junction resolution by RuvC requires both increased junction flexibility and an exposed 5'phosphate. PLoS One, 4, e5347.

84. West,S.C. (1997) Processing of recombination intermediates by the RuvABC proteins. Ann Rev Genet, 31, 213-244.

85. Lilley,D.M.J. (2000) Structures of helical junctions in nucleic acids. Quat Rev Biophys, 33, 109159. 
86. Bennett,R.J. and West,S.C. (1995) RuvC protein resolves Holliday junctions via cleavage of the continuous (non-crossover) strands. Proc Natl Acad Sci USA, 92, 5635-5639.

87. Bennett,R.J. and West,S.C. (1995) Structural analysis of the RuvC-Holliday junction complex reveals an unfolded junction. $J$ Mol Biol, 252, 213-226.

88. Komori,K., Sakae,S., Shinagawa,H., Morikawa,K. and Ishino,Y. (1999) A Holliday junction resolvase from Pyrococcus furiosus: Functional similarity to Escherichia coli RuvC provides evidence for conserved mechanism of homologous recombination in Bacteria, Eukarya, and Archaea. Proc Natl Acad Sci USA, 96, 8873-8878.

89. Komori,K., Sakae,S., Fujikane,R., Morikawa,K., Shinagawa,H. and Ishino,Y. (2000) Biochemical characterization of the Hjc Holliday junction resolvase of Pyrococcus furiosus. Nucl Acids Res, 28, 4544-4551.

90. Mueller,J.E., Kemper,B., Cunningham,R.P., Kallenbach,N.R. and Seeman,N.C. (1988) T4 endonuclease VII cleaves the crossover strands of Holliday junction analogs. Proc Natl Acad Sci USA, 85, 9441-9445.

91. Gough,G.W. and Lilley,D.M.J. (1985) DNA bending induced by cruciform formation. Nature, 313, 154-156.

92. Lilley,D.M.J. (2017) Holliday junction-resolving enzymes - structures and mechanisms. FEBS Lett., 591, 1073-1082.

93. Lanz,M.C., Yugandhar,K., Gupta,S., Sanford,E., Faça,V., Vega,S., Joiner,A., Fromme,C., Yu,H. and Smolka,M.B. (2019) In-depth and 3-Dimensional Exploration of the Budding Yeast Phosphoproteome. bioRxiv, 10.1101/700070.

94. Sobhy,M.A., Bralić,A., Raducanu,V.-S., Takahashi,M., Tehseen,M., Rashid,F., Zaher,M.S. and Hamdan,S.M. (2019) Resolution of the Holliday junction recombination intermediate by human GEN1 at the single-molecule level. Nucleic Acids Res., 47, 1935-1949.

95. Lorenz,A., West,S.C. and Whitby,M.C. (2010) The human Holliday junction resolvase GEN1 rescues the meiotic phenotype of a Schizosaccharomyces pombe mus 81 mutant. Nucl Acids Res, 38, 1866-1873.

96. Harrington,J.J. and Lieber,M.R. (1994) The characterization of a mammalian DNA structure specific endonuclease. EMBO J, 13, 1235-1246.

97. Murante,R.S., Huang,L., Turchi,J.J. and Bambara,R.A. (1994) The calf 5'- to 3'-exonuclease is also an endonuclease with both activities dependent on primers annealed upstream of the point of cleavage. J. Biol. Chem., 269, 1191-1196.

98. Lee,B.I. and Wilson,D.M. (1999) The RAD2 domain of human exonuclease 1 exhibits 5' to 3' exonuclease and flap structure-specific endonuclease activities. J Biol Chem, 274, 3776337769.

99. Neelsen,K.J. and Lopes,M. (2015) Replication fork reversal in eukaryotes: from dead end to dynamic response. Nat. Rev. Mol. Cell Biol., 16, 207-220. 


\section{FIGURE LEGENDS}

Figure 1. Mapping of Yen1 incisions on branched DNA substrates. (A) Graphical representation of Yen1 and GEN1 domains. Serines in consensus CDK phosphorylation sites are indicated in Yen1. (B) FTH-tagged Yen $1^{\mathrm{ND}}$, Yen1 ${ }^{\mathrm{P}}$, Yen $1^{\lambda}$, Yen $1^{\mathrm{ON}-\mathrm{P}}$ and Yen $1^{\mathrm{ON}-\lambda}$ were purified and analysed by SDS-PAGE and stained with Coomassie. Molecular weight markers are indicated in $\mathrm{kDa}$. (C) Holliday junction X0 (20 nM) was 5'-end labelled with ${ }^{32} \mathrm{P}$ (asterisk) on each strand (red) and incubated with $5 \mathrm{nM}$ Yen1 $1^{\mathrm{ND}}(\mathrm{ND})$, Yen1 $1^{\mathrm{P}}(\mathrm{P})$, Yen $1^{\lambda}(\lambda)$ or GEN1 $1^{1-527}$ (G) for $10 \mathrm{~min}$ at $30^{\circ} \mathrm{C}$ or $37^{\circ} \mathrm{C}$, respectively. (-) indicates no enzyme. Products were analysed by $10 \%$ denaturing PAGE and phosphorimaging. A mixture of $5^{\prime}-{ }^{32} \mathrm{P}-$-end-labeled oligos of defined length (25, 30 and $35 \mathrm{nt}$ ) were used as markers (M). (D-F) As in (C), employing a (D) replication fork, (E) 3-way junction or (F) 5'-flap as a substrate. (G) Schematic representation of incision sites identified for the HJ, 3WJ, RF and 5'-flap substrates. Only the nucleotide sequence near the branch point is shown. Arrow size indicates preferential cleavage sites for Yen1 (black) and GEN1 (white).

Figure 2. Mapping of Yen1 incisions on nicked HJs. Reactions with different nicked X0 HJs and Yen $1^{\lambda}$ or GEN $1^{1-527}$ were carried out and labelled as in Figure 1. (A) Reactions using nicked X0 substrates labelled on the strand opposite the nicked were analyed by $10 \%$ denaturing PAGE or (B) 10\% native PAGE (cleavage products depicted on the right). (C-D) same as (AB), but employing nicked X0 substrates labelled on the 5'strand with respect to the nick. (E-F) same as (A-B), but employing nicked X0 substrates labelled on the 3'strand with respect to the nick. Dotted lines in some gels indicate splicing of superfluous lanes. (G) Schematic representation of incision sites identified for the different nicked X0 substrates. Please note the discontinuity of one strand in each of them. Only the nucleotide sequence near the branch point is shown. Arrow size indicates preferential cleavage sites for Yen1 (black) and GEN1 (white).

Figure 3. Yen1 can resolve HJs symmetrically. (A) Scheme of the SP-containing XO HJ employed in the assay (X0-2SP), which contains 3 hydrolysis-resistant phosphorothioate linkages in positions 30,31,32 and 33 of oligos 2 and 4 (indicated by a blue box). (B) Reactions were carried out and labelled essentially as in Figure 1, using $5 \mathrm{nM} \mathrm{X0-2SP,} \mathrm{5'-32} \mathrm{P}$-labelled (asterisk) and $5 \mathrm{nM} \mathrm{Yen} 1^{\lambda}\left(10 \mathrm{~min}, 30^{\circ} \mathrm{C}\right)$ or $\mathrm{GEN} 1^{1-527}\left(5 \mathrm{~min}, 37^{\circ} \mathrm{C}\right)$. Reaction products were analysed by $10 \%$ denaturing-PAGE followed by phosphorimaging and quantified using ImageQuant. (C) Reactions with X0 or X0-2SP (5 nM) 5'-32 P -labelled in oligo 1 were 
incubated with Yen $1^{\lambda}$ or GEN1 in the same conditions as in (B) and analysed by $10 \%$ denaturing PAGE. (D) The same reactions as in (C) were analysed by $10 \%$ native PAGE (left panel). The formation of nicked dsDNA products and the total amount of all cleavage products were quantified (right panel). Data represented as mean values $\pm \operatorname{SD}(n=3)$.

Figure 4. Yen 1 shows a bias for the cleavage of the crossing strands of a HJ. (A) Representation of the stacking conformers of the J3 HJ substrate. In its predominant state, oligos $\mathrm{x}$ and $\mathrm{h}$ (grey) behave as continuous strands while $\mathrm{b}$ and $\mathrm{r}$ (black) are crossing strands. (B) $5 \mathrm{nM} \mathrm{J3-HJ} 5^{\prime}{ }^{3}{ }^{32} \mathrm{P}$-labelled on the indicated strands was incubated with $5 \mathrm{nM}$ Yen $1^{\lambda}\left(30^{\circ} \mathrm{C}\right.$, $10 \mathrm{~min}$ ) or $\mathrm{GEN} 1^{1-527}\left(37^{\circ} \mathrm{C}, 5 \mathrm{~min}\right)$. (-) control reaction without enzyme. Reaction products were analysed by $12 \%$ denaturing PAGE and phosphorimaging. A mixture of 5 '-32 P-endlabelled oligos of defined length $(15,16$ and $17 \mathrm{nt})$ were used as markers (M). (C) Schematic representation of the main cleavage sites on the J3 HJ by Yen1 (black arrows) and GEN1 (white arrows). (D) Quantification of the proportion of the cleavage of crossing vs continuous strands from $(B)$. Data represented as mean values $\pm \operatorname{SD}(n=3)$.

Figure 5. A 5'-3' nick-specific exonuclease activity prevents the religation of the resolution products by Yen1. (A) Scheme of the religation experiment employing the asymmetrical X1T HJ substrate. Symmetric cleavage of this substrate, which contains a $53 \mathrm{nt}, 5$ '-labelled oligo (red), and its subsequent ligation generates a new 60-nt labelled strand. (B) $1 \mathrm{nM} \mathrm{X1-T}$ was incubated with $10 \mathrm{nM}$ Yen 1 or GEN1 for $30 \mathrm{~min}$ at $30^{\circ} \mathrm{C}$ or $37^{\circ} \mathrm{C}$, respectively. Reactions were then supplemented with ligation buffer and T4 DNA ligase (5 U) and incubated for $1 \mathrm{~h}$ at RT. Products were analysed by $10 \%$ denaturing PAGE followed by phosphorimaging and quantified using ImageQuant. A mixture of 5' -32 P-end-labeled oligos of defined length $(53,34$, 32, 30, 28, 26 and $24 \mathrm{nt}$ ) were used as markers (M). (C) $0.5 \mathrm{nM}$ nicked dsDNA, either 5'-32 Pend (left panels) or 3'-32P-end (right panels) labelled were incubated with increasing concentrations of $\operatorname{Yen}^{\lambda}(0,0.25,0.5,1,2,4,8 \mathrm{nM})$ for $10 \mathrm{~min}$ at $30^{\circ} \mathrm{C}$. Products were then analysed by $10 \%$ native (top panels) or denaturing (bottom panels) PAGE and phosphorimaging. (D) $0.5 \mathrm{nM}$ of $3{ }^{3}{ }^{32} \mathrm{P}$-labelled dsDNA substrates with gaps of increasing length were incubated with increasing concentrations of Yen1 $(0,0.5,2,8 \mathrm{nM})$ for $10 \mathrm{~min}$ at $30^{\circ} \mathrm{C}$. Products were analysed as in (C). (E) $50 \mathrm{nM}$ nicked dsDNA or exonuclease-resistant (SP-linkage in the 5' nucleotide, in blue) nicked dsDNA, 3'-6FAM-end labelled on the indicated strand (red) were incubated with Yen1 ${ }^{\mathrm{ND}}$, Yen1 ${ }^{\lambda}$ and GEN1 $(10 \mathrm{nM})$ for $10 \mathrm{~min}$ at $30^{\circ} \mathrm{C}$ or $37^{\circ} \mathrm{C}$, respectively. (-) indicates no enzyme. Fluorescent products were analysed by 
13\% denaturing-PAGE and scanned at $488 \mathrm{~nm}$ in a Typhoon FLA 9500. (F) As in (B), but employing both the unmodified X1-T HJ substrate and a SP-containing variant in position 31 of its oligo 3 .

Figure 6. Yen1 processes plasmid-borne cruciform structures by coordinated incisions. (A) Schematic representation of the cruciform cleavage assay used to determine whether incisions are coordinated or not. A third possibility incorporating arm-chopping (central pathway) is added to the two classical outcomes of the assay. (B) $4.5 \mathrm{nM}$ pIR9 plasmid was incubated with $90 \mathrm{nM} \mathrm{Yen} 1^{\mathrm{P}}$ or $\mathrm{Yen} 1^{\lambda}$ at $30^{\circ} \mathrm{C}$ for the indicated times. Products were analysed in $0.8 \%$ agarose gels and visualised by EtBr staining in a Gel Doc $\mathrm{Xr}+$ (Bio-Rad). Quantification was performed by using the Image Lab software (Bio-Rad). OC: open circle; L: linear; SC: supercoiled. (C) Ligation experiment with pIR9. $4.5 \mathrm{nM}$ pIR9 was incubated with $90 \mathrm{nM}$ of Yen1 ${ }^{\mathrm{P}}$ or $10 \mathrm{U}$ $\mathrm{Nt} . \mathrm{BspQI}$ for $1 \mathrm{~h}$ at $30^{\circ} \mathrm{C}$ and $50^{\circ} \mathrm{C}$, respectively. Products were then purified, treated with $\mathrm{T} 4$ ligase for $1 \mathrm{~h}$ at $37^{\circ} \mathrm{C}$, and then analysed and quantified as in (B). EcoRI was used as a control of the extrusion level of the plasmid. (D) Scheme of the experimental set-up to detect the hairpins released by arm-chopping on pIR9. (E) $4.5 \mathrm{nM}$ pIR9 was incubated with $90 \mathrm{nM}$ of different versions of Yen1 (Yen $1^{\lambda}$, Yen1 ${ }^{\mathrm{ON}-\lambda}$ and Yen1 ${ }^{\mathrm{ND}}$ ), $50 \mathrm{nM}$ of GEN1, $10 \mathrm{U}$ of Nt.BspQI or EcoRI for $90 \mathrm{~min}$. Half of the reaction was loaded on a $0.8 \%$ agarose gel (upper panel) and visualised with EtBr post-staining in a Gel Doc (Bio-Rad). The other half was denatured and labelled with T4 PNK and ${ }^{32} \mathrm{P}-\gamma$-ATP, analysed by $15 \%$ denaturing PAGE and visualised by phosphorimaging in a Typhoon FLA 9500. (-) indicates no enzyme. The arrow indicates products of expected sizes.

Figure 7. Yen1 dimerization on the substrate favours its first incision. (A) Schematic representation of a modified X0 with a phoshorothioate linkage (in blue) between 31-32 nt of oligo 3 (X0-SP). (B) $5 \mathrm{nM}$ unmodified X0 5'-32P-end labelled in oligo 1 (X01) and X0-SP 5'${ }^{32} \mathrm{P}$-end labelled in oligonucleotide 1 (SP1) or 3 (SP3) were incubated with $5 \mathrm{nM}$ Yen1 ${ }^{\lambda}$ for 5 $\min$ at $30^{\circ} \mathrm{C}$ or $5 \mathrm{nM} \mathrm{GEN1} 1^{1-527}$ for $2.5 \mathrm{~min}$ at $37^{\circ} \mathrm{C}$. (-) indicates control reaction with no enzyme. Products were analysed by $10 \%$ native PAGE. Possible reaction products are indicated on the right. Cleavage was quantified as shown. (C) Same reactions as in (B) were analysed by $10 \%$ denaturing PAGE. DNA was labelled in the indicated strands (red). 5'-32 P-end-labeled oligos of defined length $(25,30$ and $35 \mathrm{nt})$ were used as markers (M). (D) X0-SP (5 nM) 5'${ }^{32} \mathrm{P}$-end labelled in oligo 1 was incubated with $5 \mathrm{nM} \mathrm{Yen} 1^{\lambda}$ and the indicated concentrations of 
Yen $1^{\mathrm{ND}}$ for $5 \mathrm{~min}$ at $30^{\circ} \mathrm{C}$. Products were analysed by $10 \%$ denaturing PAGE. (E) Quantification of the reaction shown in (D). Data represented as mean values $\pm \operatorname{SD}(n=3)$.

Figure 8. Expression of deregulated Yen1 and GEN1 mutants in S. cerevisiae. (A) Westernblot analysis of protein expression levels in soluble extracts from WT or mus81 $1 \Delta$ yen $1 \Delta$ strains

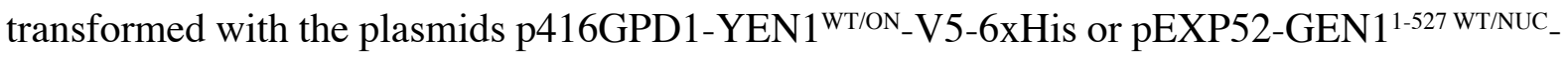
V5-6xHis growing in SC-URA containing 1\% raffinose and 2\% galactose. Proteins were detected with an $\alpha-\mathrm{V} 5$ antibody and Ponceau staining was employed as a loading control. (B) Resolution assay employing soluble extracts from (A). $2 \mu \mathrm{g}$ total protein was incubated with $50 \mathrm{nM}$ of IRDye-700 fluorescent $\mathrm{X} 0-1 *$ for $1 \mathrm{~h}$ at $30^{\circ} \mathrm{C}$. Products were analysed in $10 \%$ native PAGE and visualised in an Odyssey (LI-COR) infrared scanner. (C) Analysis of the subcellular localization of Yen1 and GEN1 variants by immunofluorescence employing $\alpha$-V5 (1:200) as primary antibody and $\alpha$-mouse Alexa 488 (1:200) as secondary antibody. DNA was stained with DAPI. (D) Wild-type strains carrying the indicated constructs were plated on media with increasing amounts of MMS, grown at $30^{\circ} \mathrm{C}$ for $72 \mathrm{~h}$ and photographed. (E) As in (D), but employing mus81 $\Delta$ yenl $\Delta$ strains. 
bioRxiv preprint doi: https://doi.org/10.1101/2020.12.08.413625; this version posted December 8, 2020. The copyright holder for this

A preprint (which was not certified by peer review) is the author/funder. All rights reserved. No reuse allowed without permission.

C
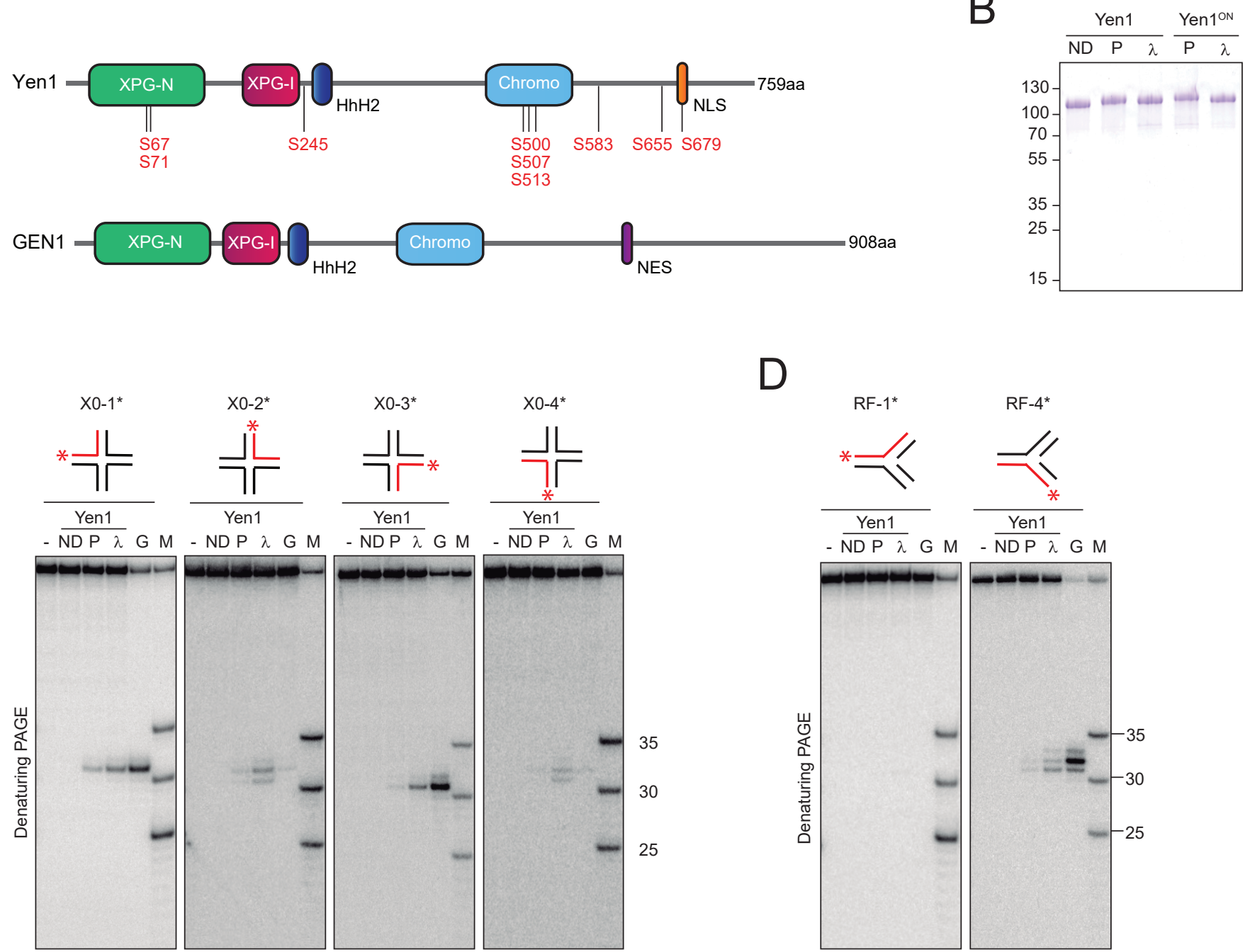

D

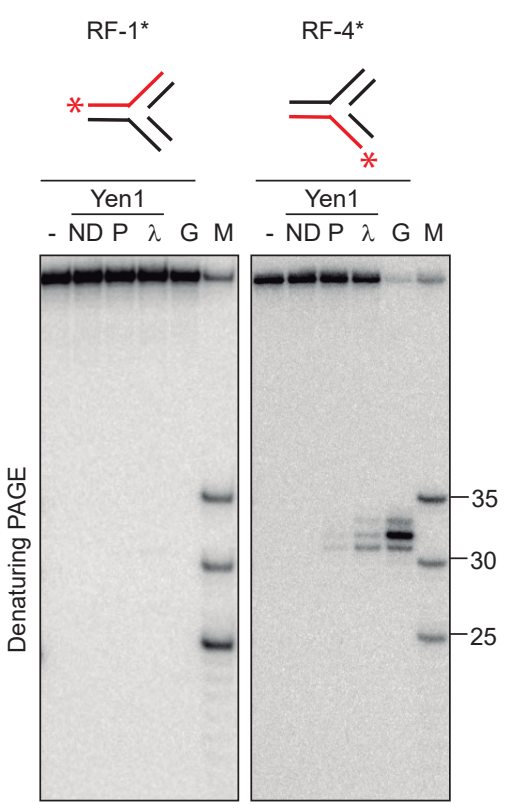

E

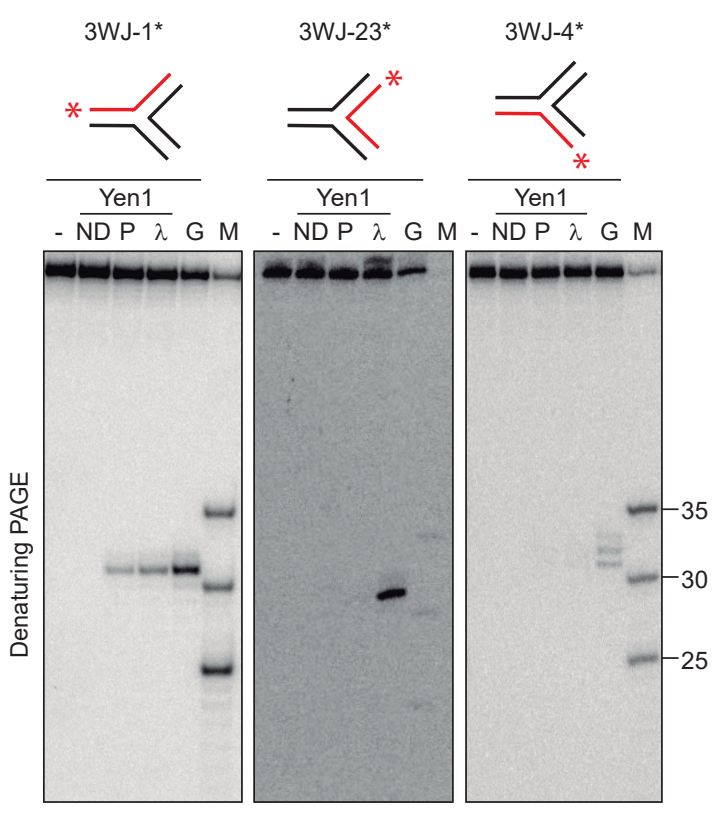

$F$

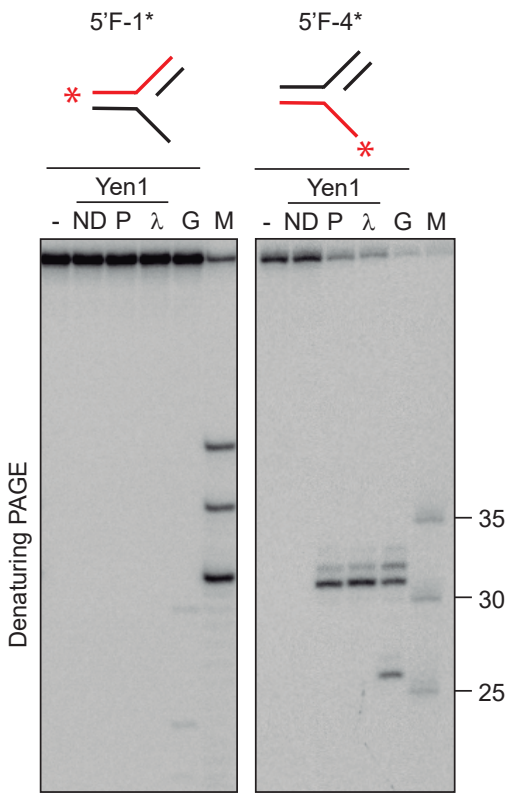

$G$
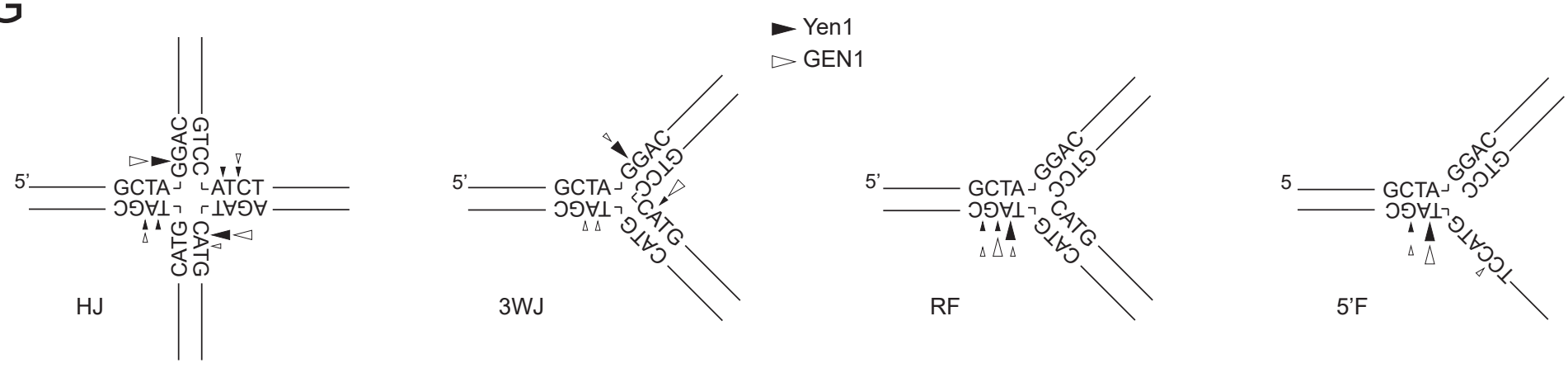
bioRxiv preprint doi: https://doi.org/10.1101/2020.12.08.413625; this version pgsfed December 8, 2020. The copyright holder for this

A preprint (which was not certified by peer review) is the author/funder. All rightsreserved. No reuse allowed without permission.
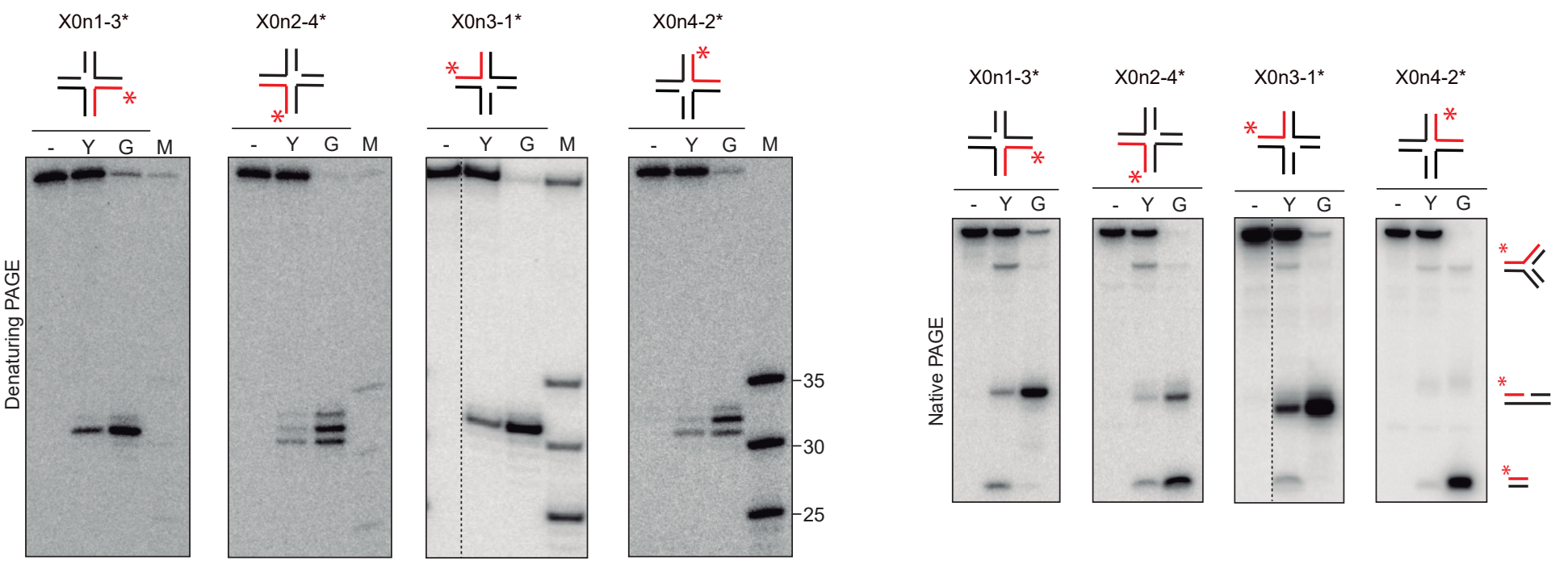

C
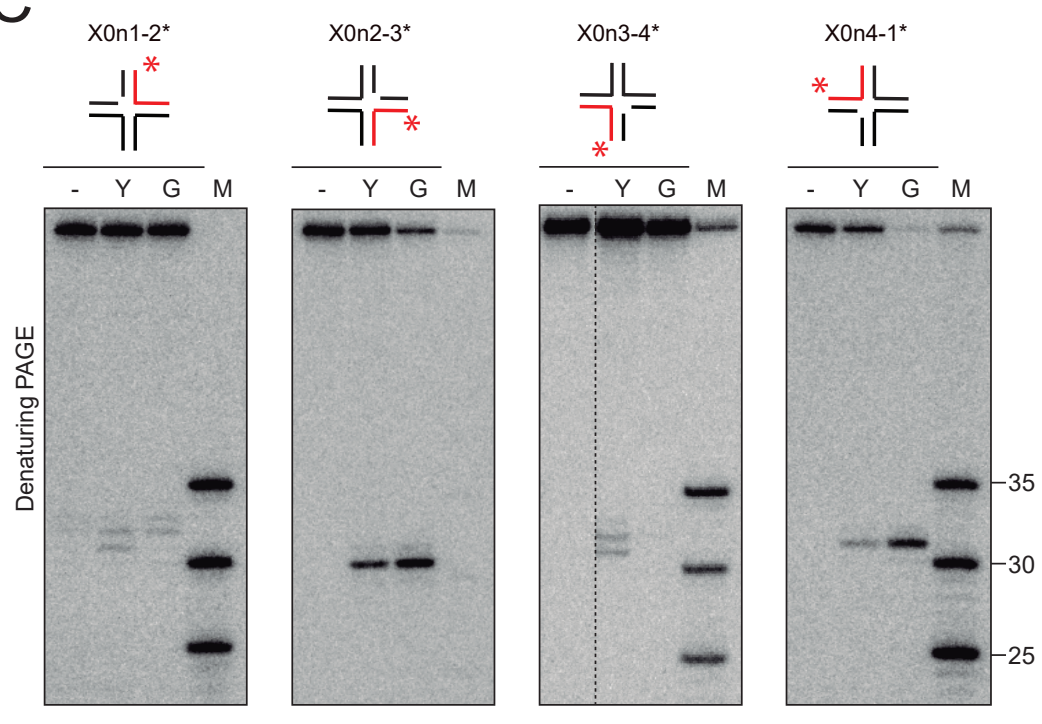

D

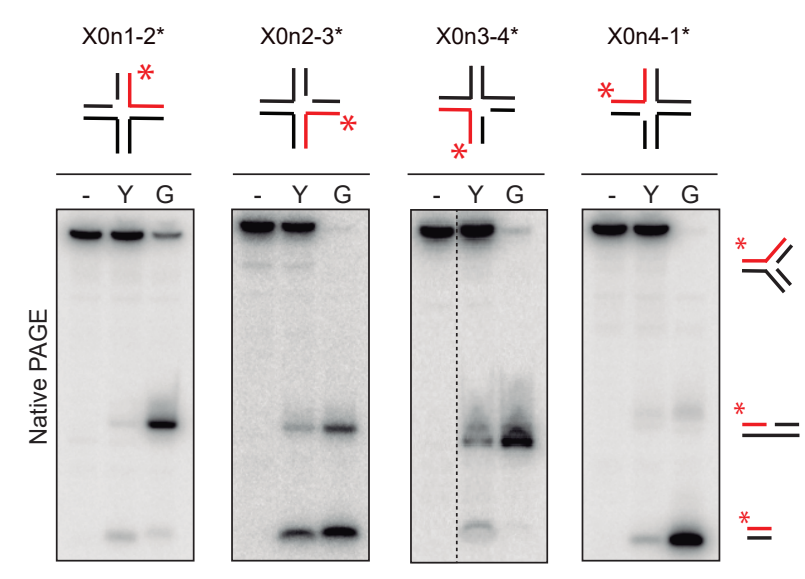

$\mathrm{E}$

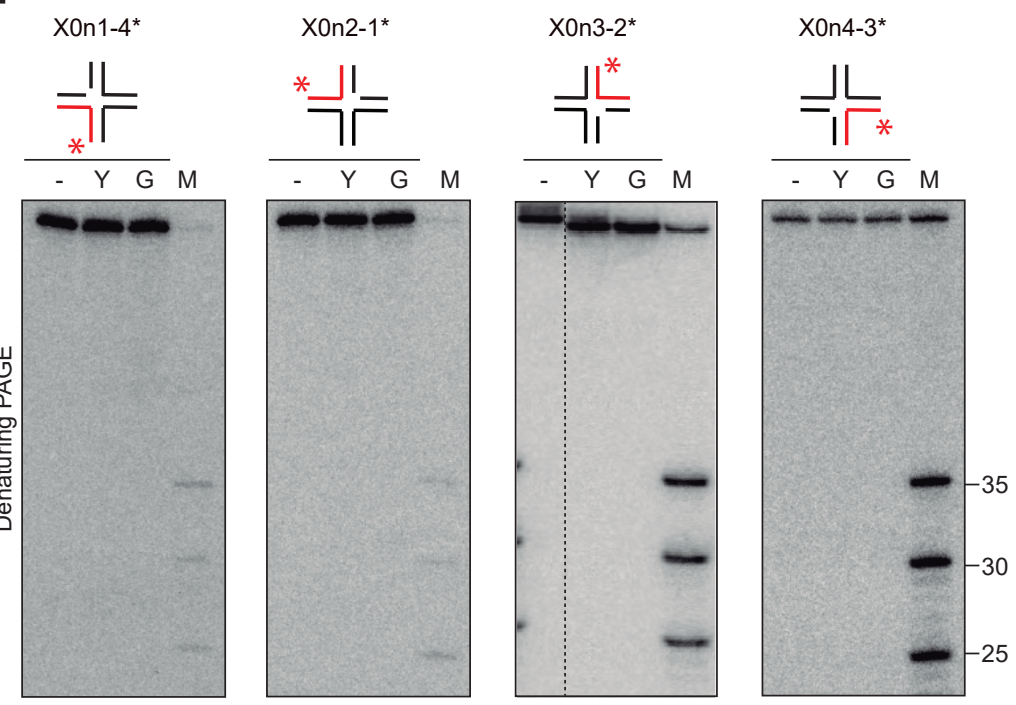

$\mathrm{F}$

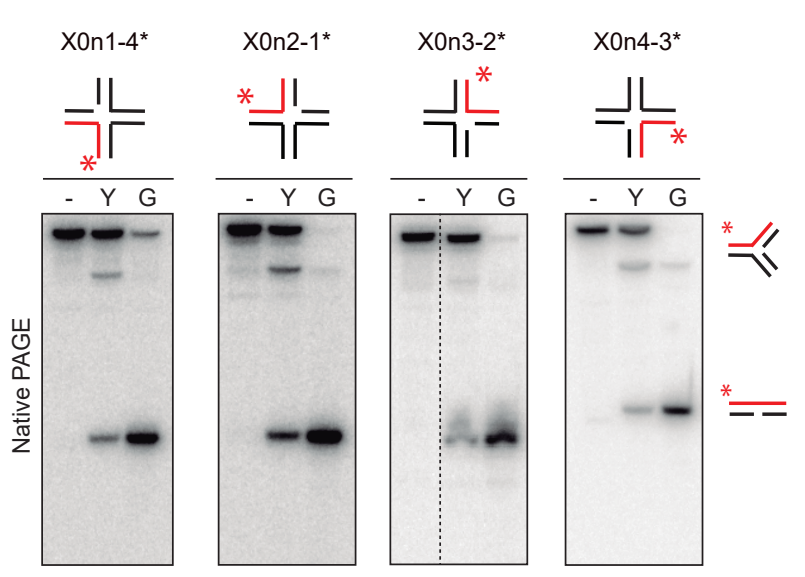

G
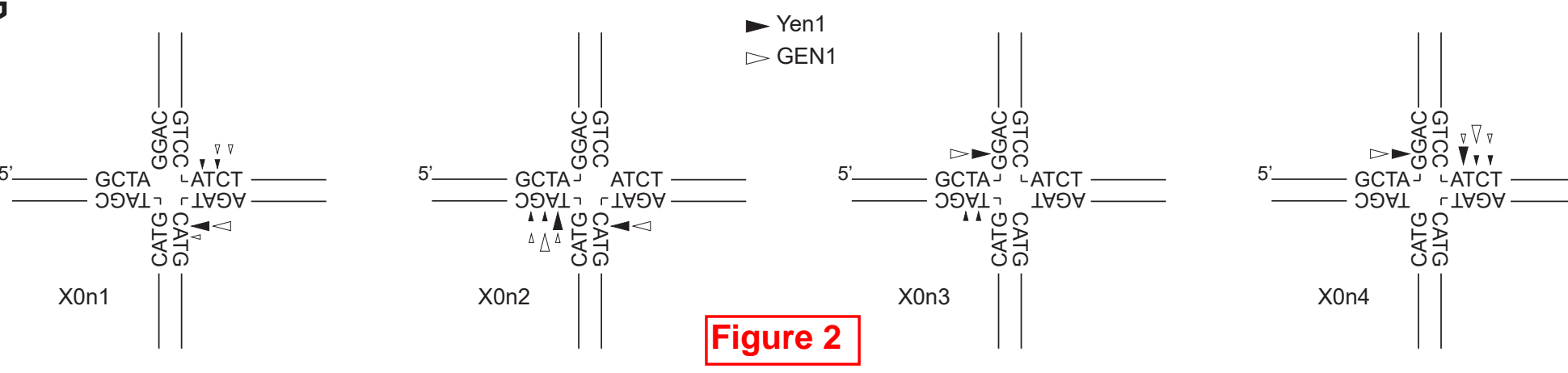
A

bioRxiv preprint doi: https://doi.org/10.1101/2020.12.08.413625; this versionposted December \&, 2020. The cepyright holder for this preprint (which was not certified by peer review) is the authopinder. Aff ights reserved. No reuse allowed wilthout permission.

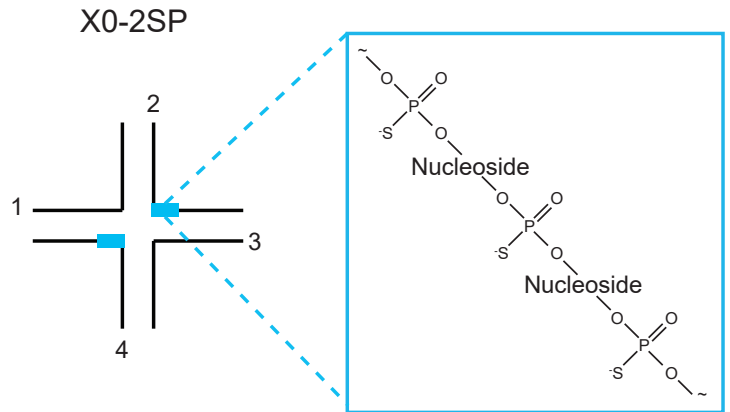

C

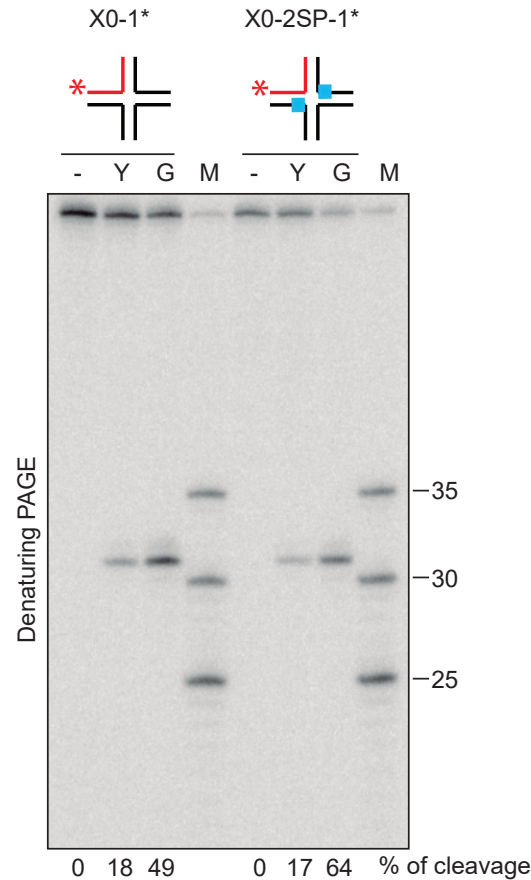

D

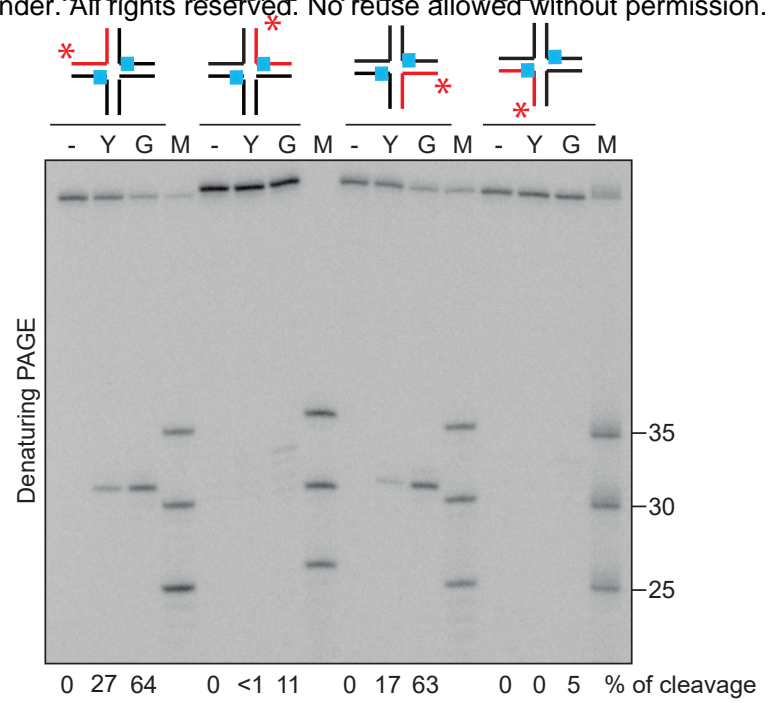

- $\%$ of total cleavage

- $\%$ of nicked duplex

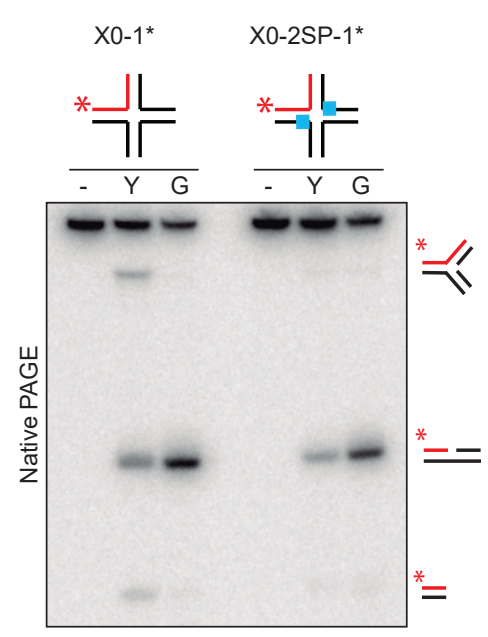

GEN1

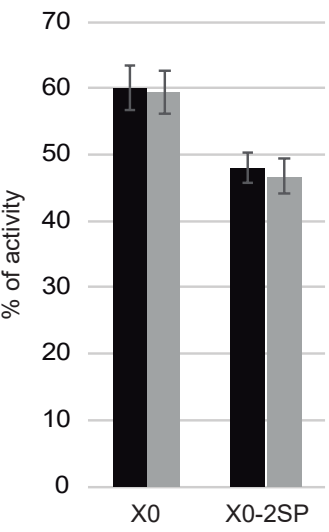


bioRxiv preprint doi: https://doi.org/10.1101/2020.12.08.413625; this version posted December 8, 2020. The copyright holder for this

preprint (which was not certified by peer review) is the author/funder. All rights reserved. No reuse allowed without permission.

A
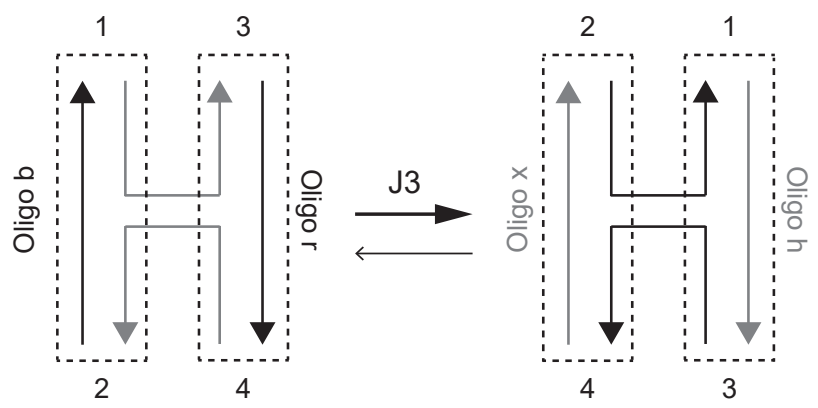

- Yen1
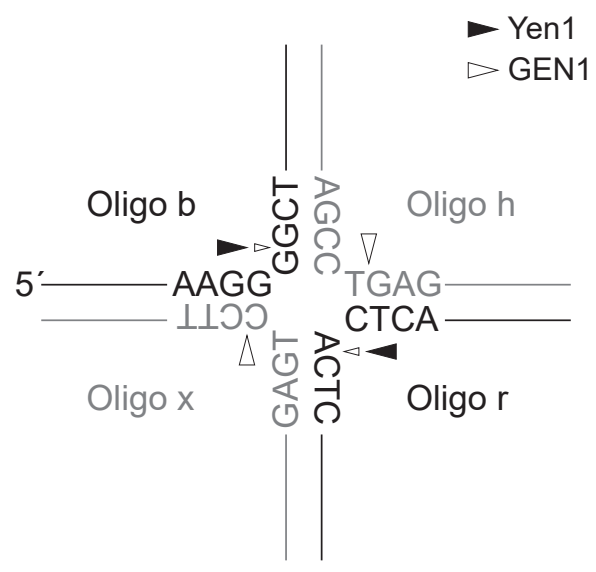

B

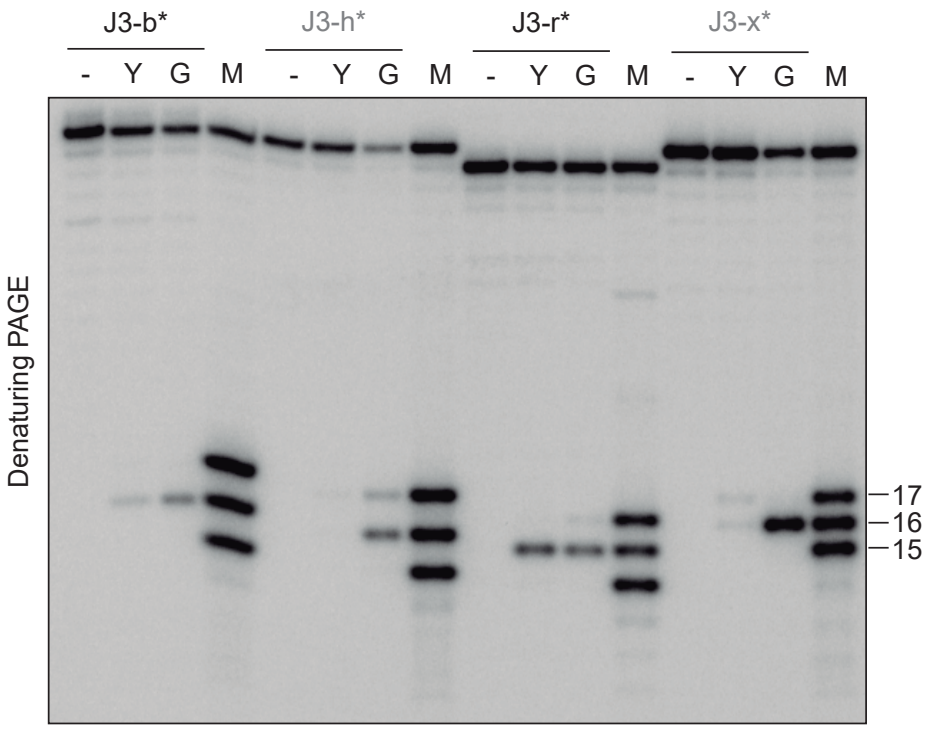

D

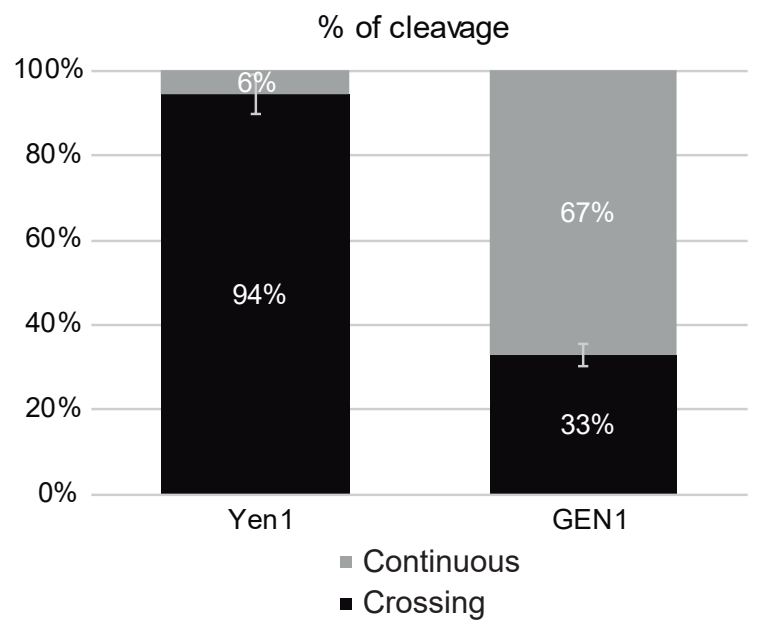


bioRxiv preprint doi: https://doi.org/10.1101/2020.12.08.413625; this version posted December 8, 2020. The copyright holder for this

preprint (which was not certified by peer review) is the author/funder. All rights reserved. No reuse allowed without permission.

A

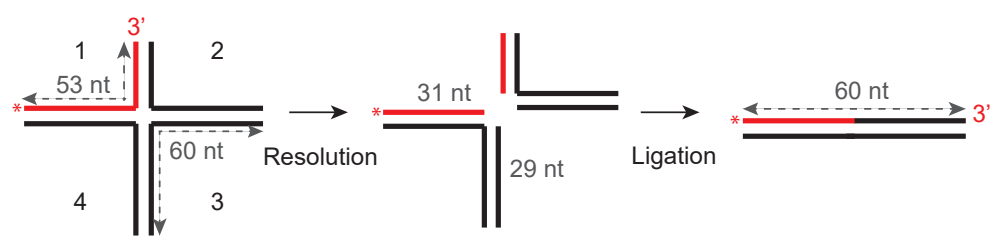

C

B
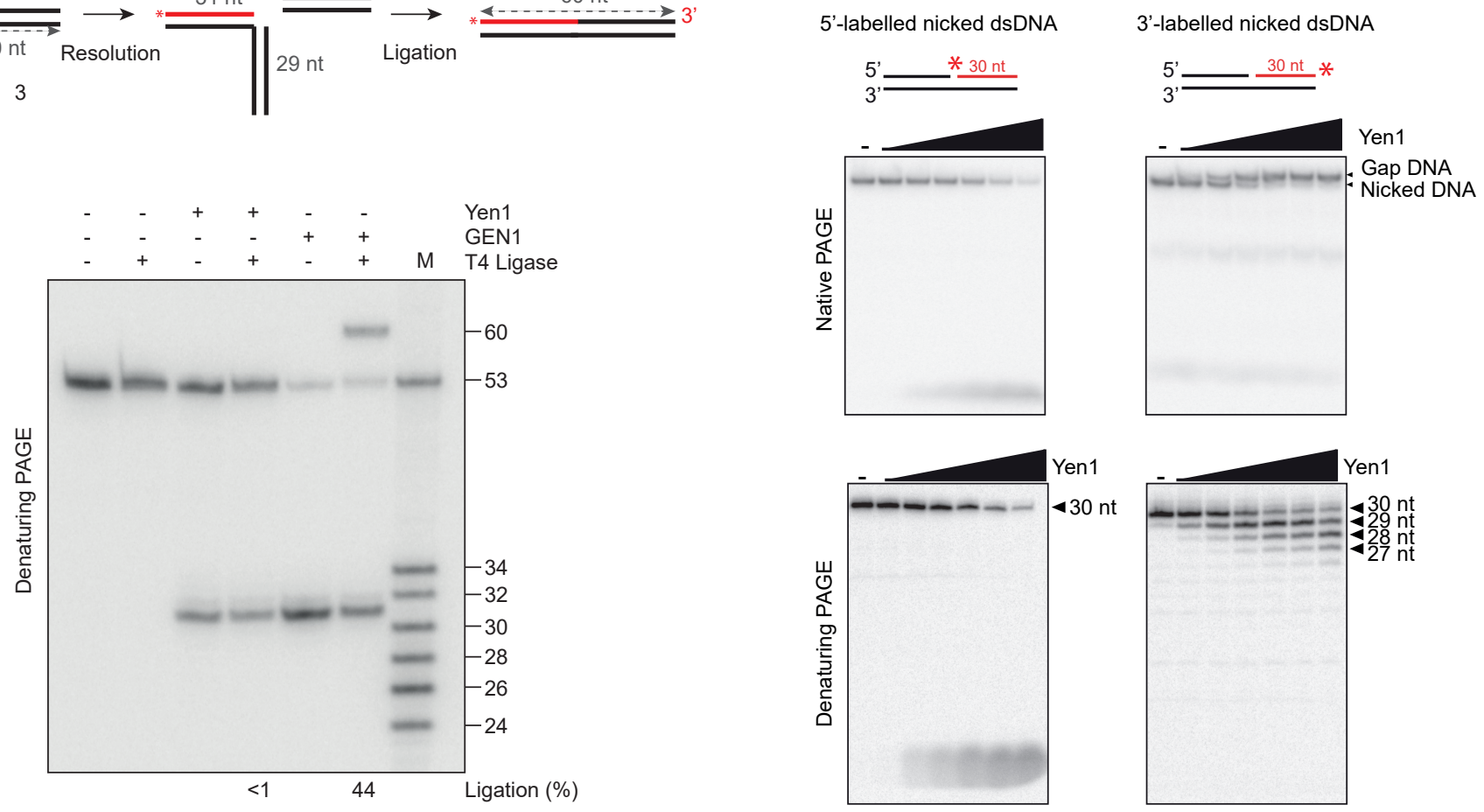

$\mathrm{D}$

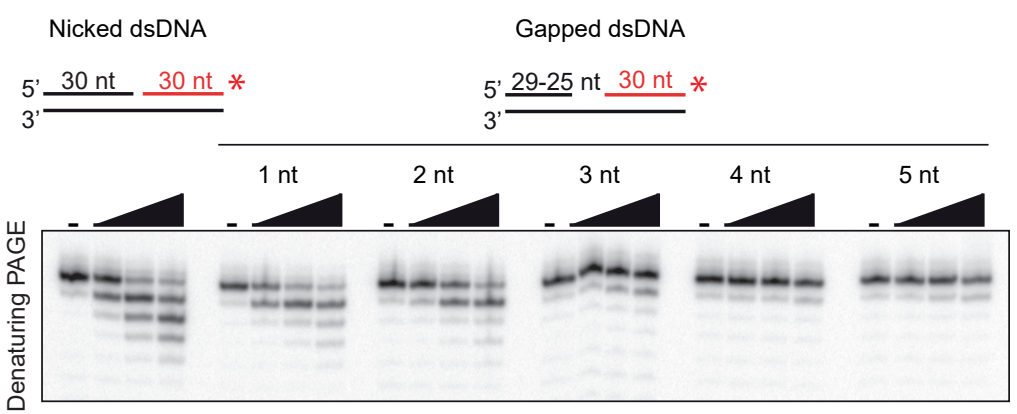

$\mathrm{F}$

$E$
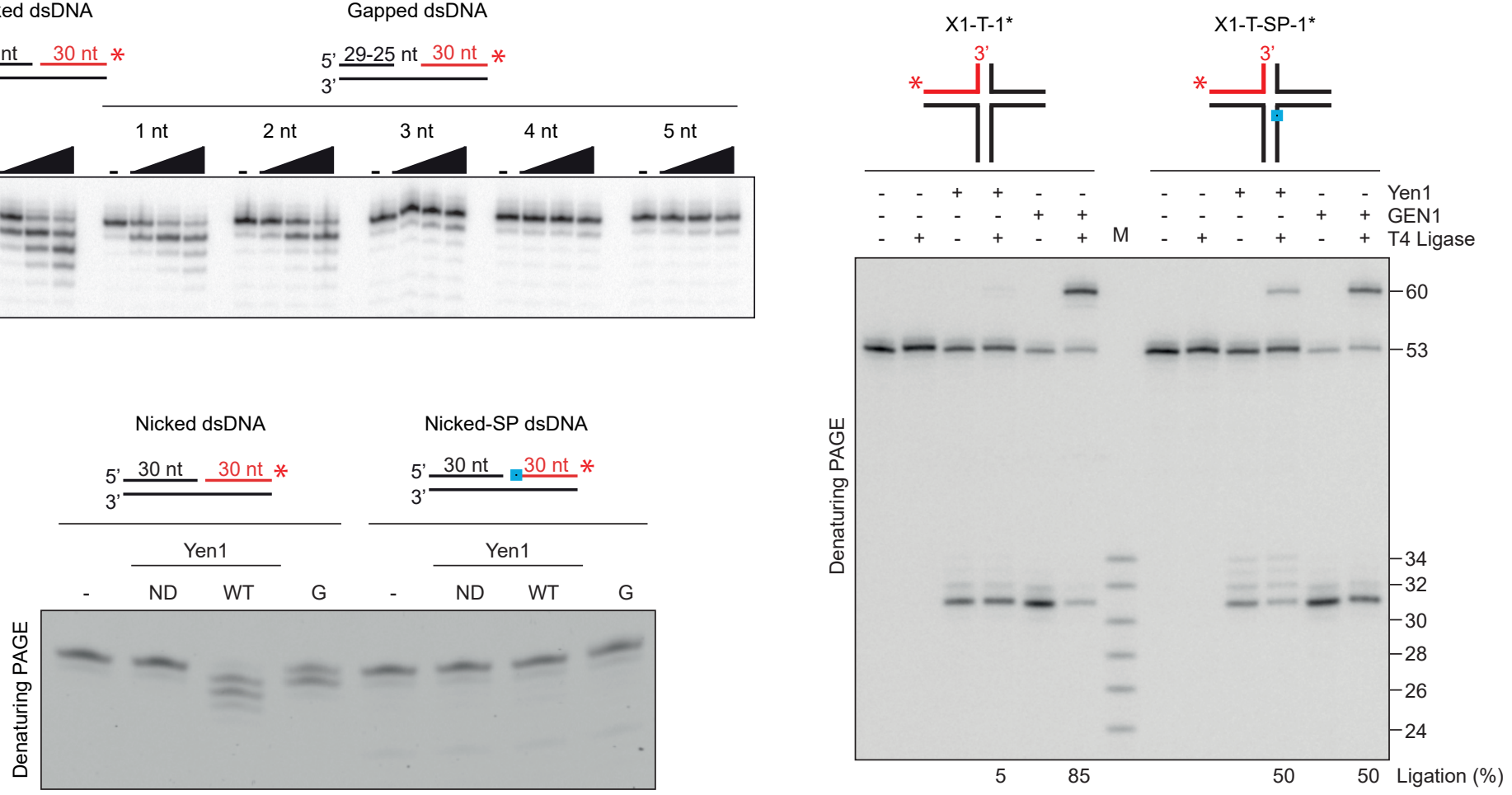
A

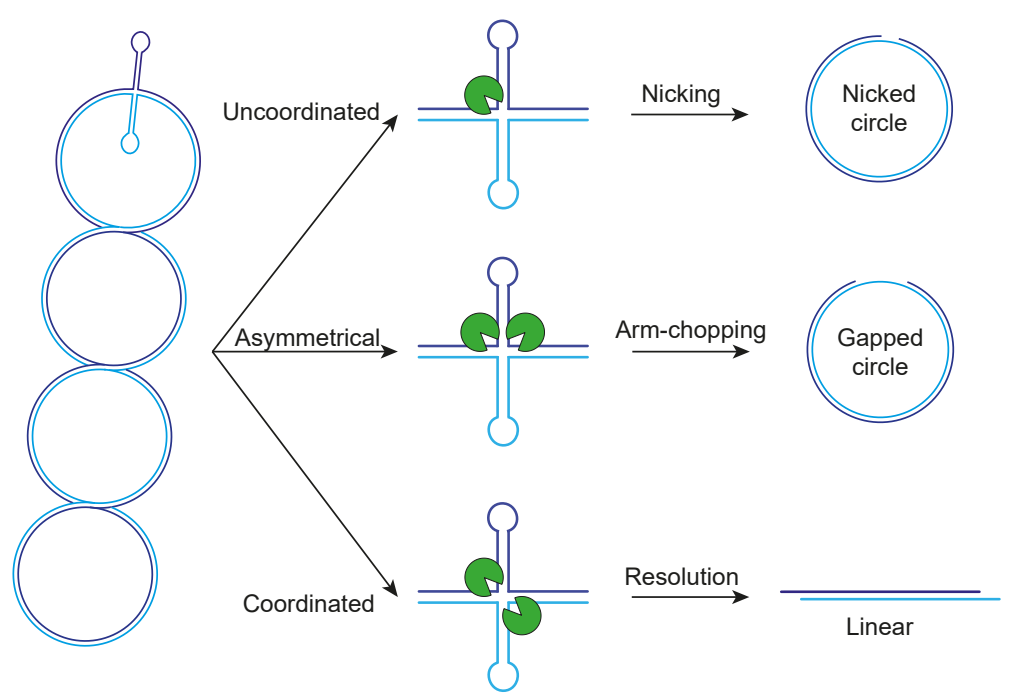

B
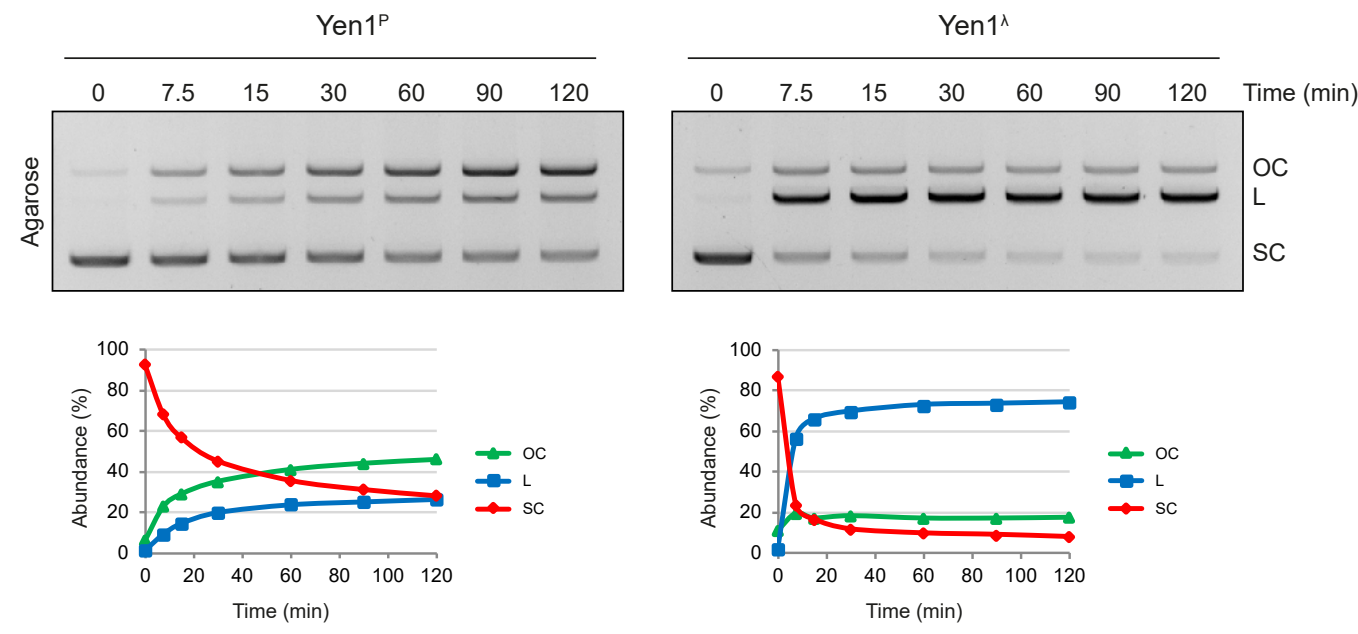

C
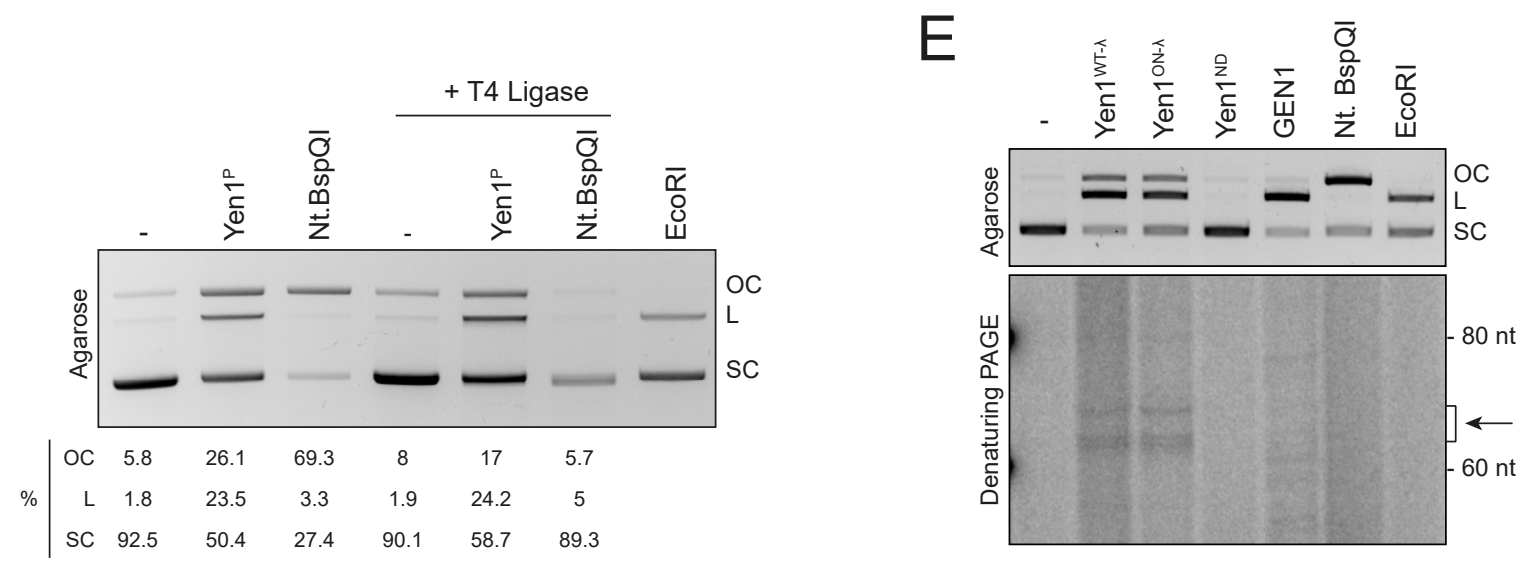

$\mathrm{D}$

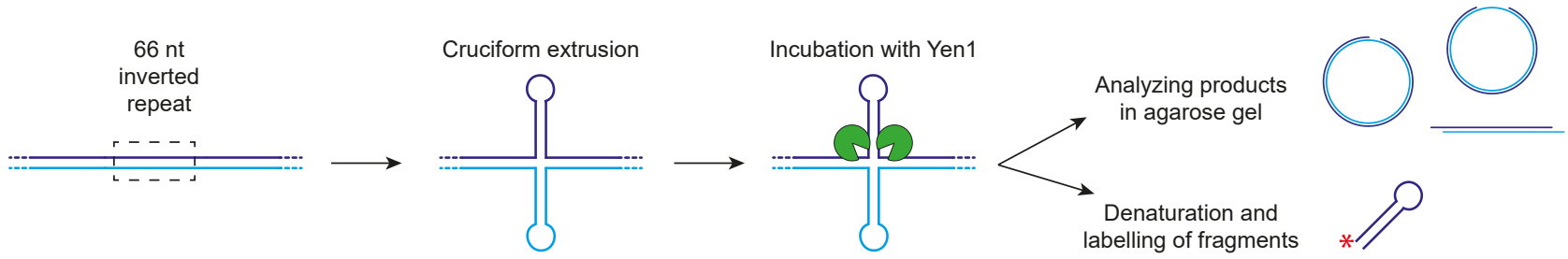


bioRxiv preprint doi: https://doi.org/10.1101/2020.12.08.413625; this version posted December 8, 2020. The copyright holder for this

A preprint (which was not certified by peer review) is the author/funder. All rights reserved. No reuse allowed without permission.

B
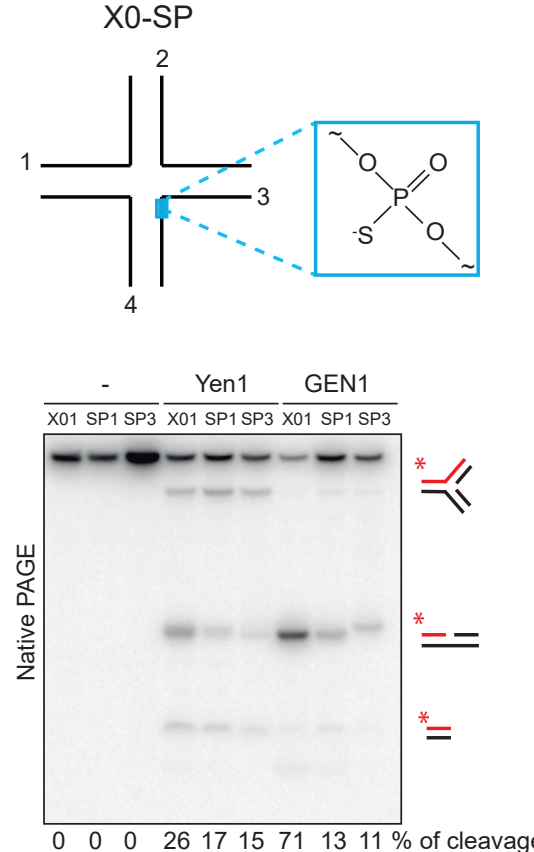

$\mathrm{XO}^{*}$ 1 $^{*} \mathrm{XO}-\mathrm{SP}-1^{*} \mathrm{XO}-\mathrm{SP}-3^{*}$

$\mathrm{D}$

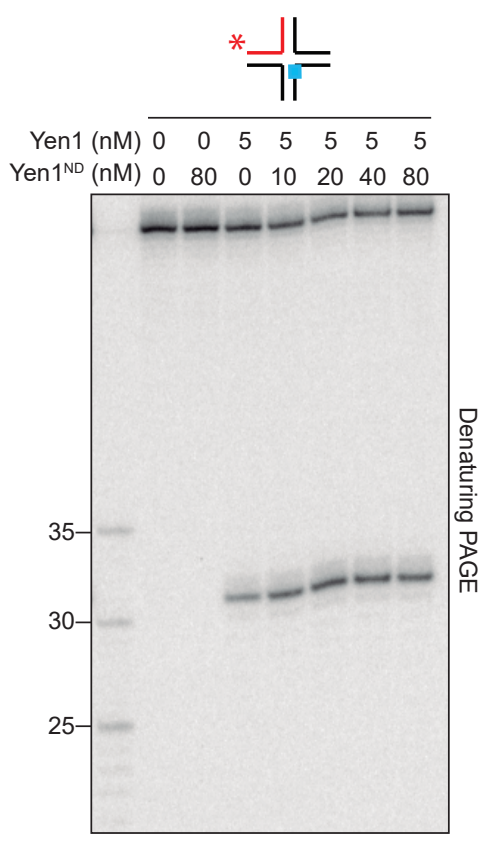

$E$

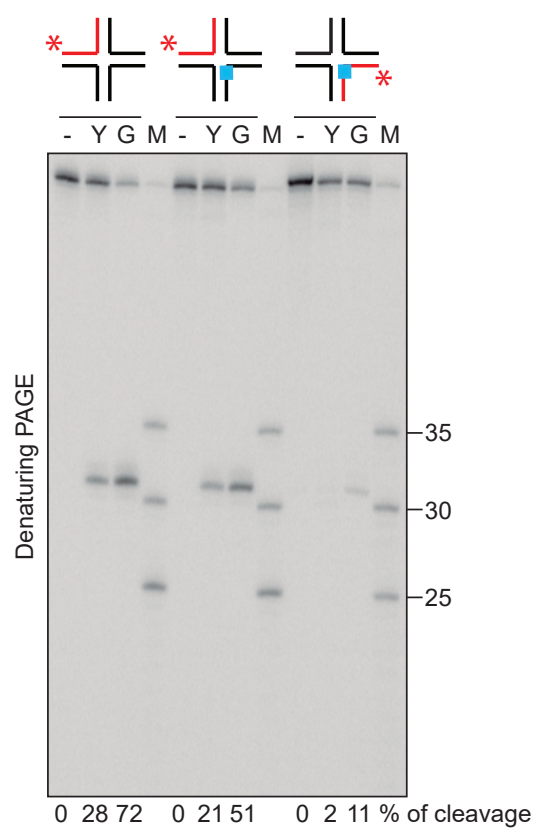

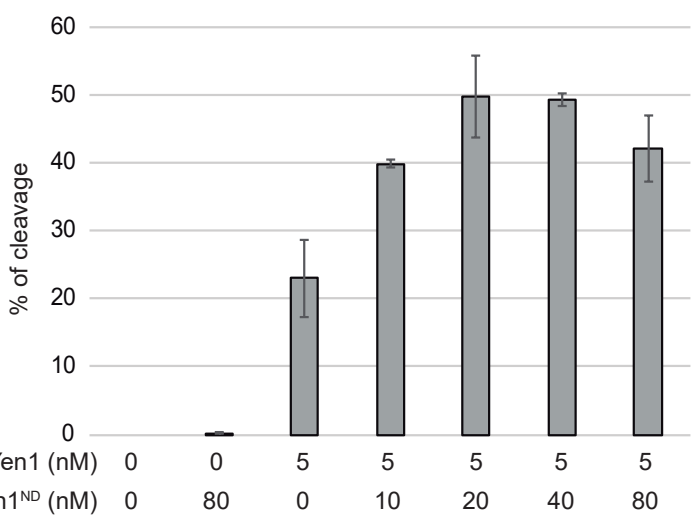


A

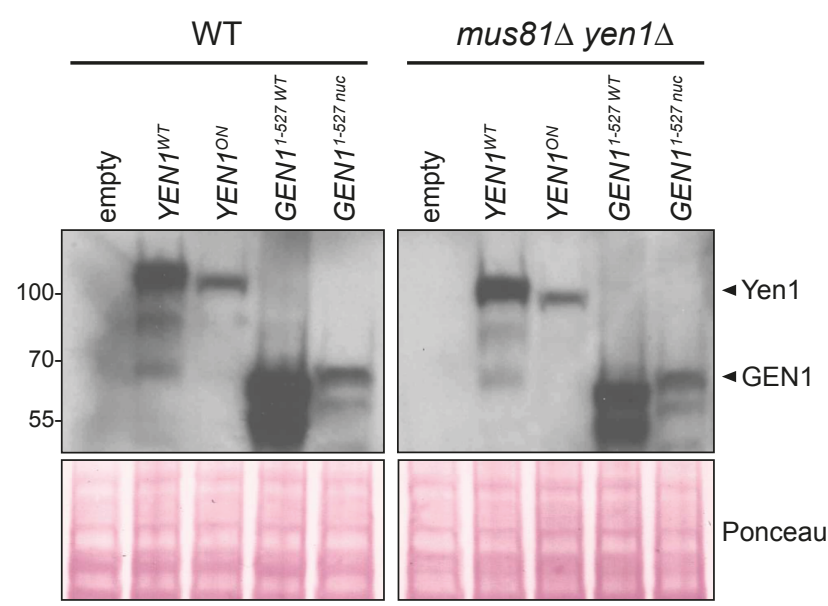

C

\section{DAPI}
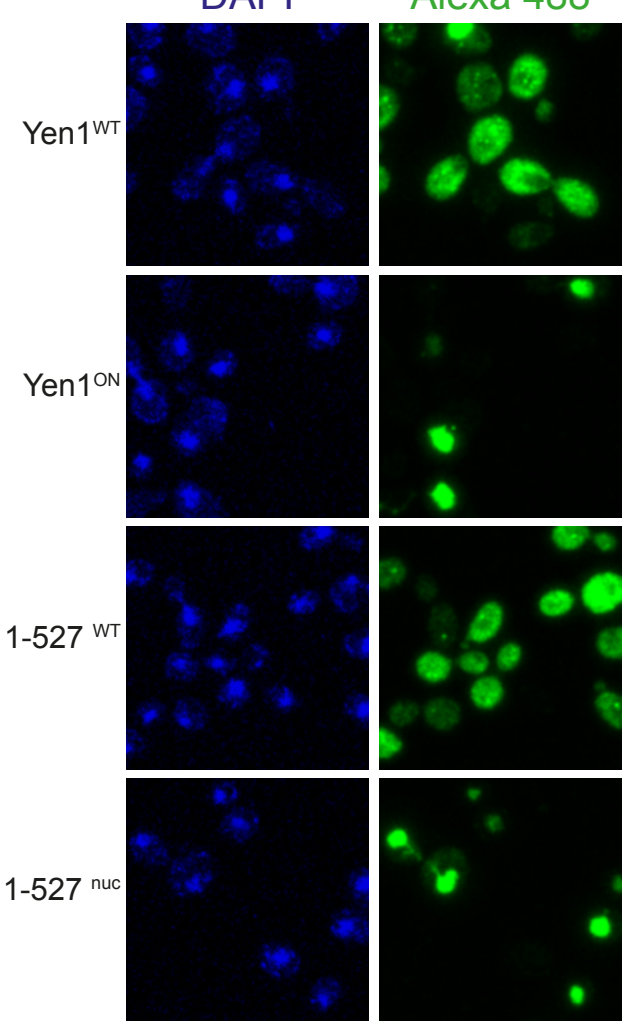

B

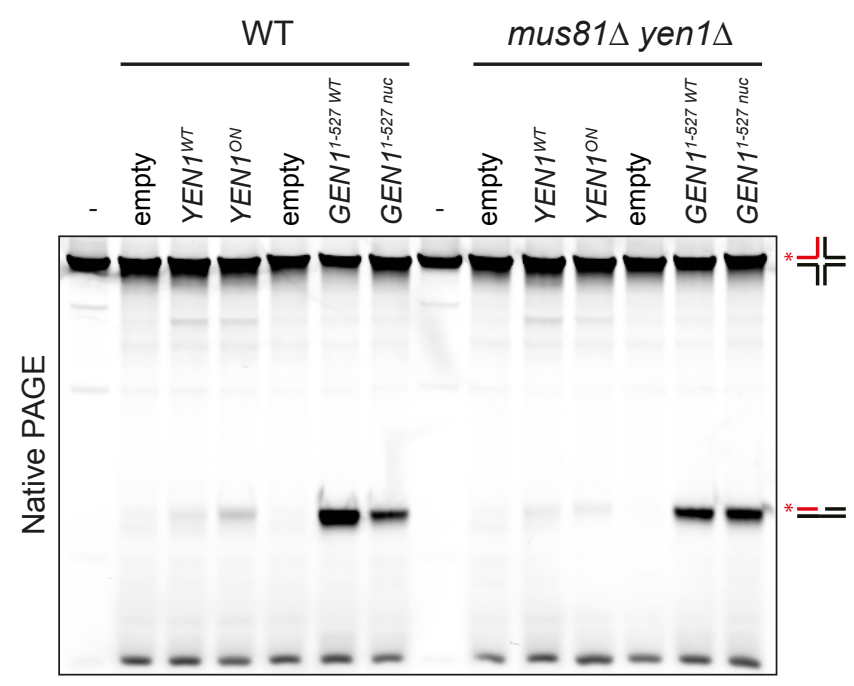

$\mathrm{D}$

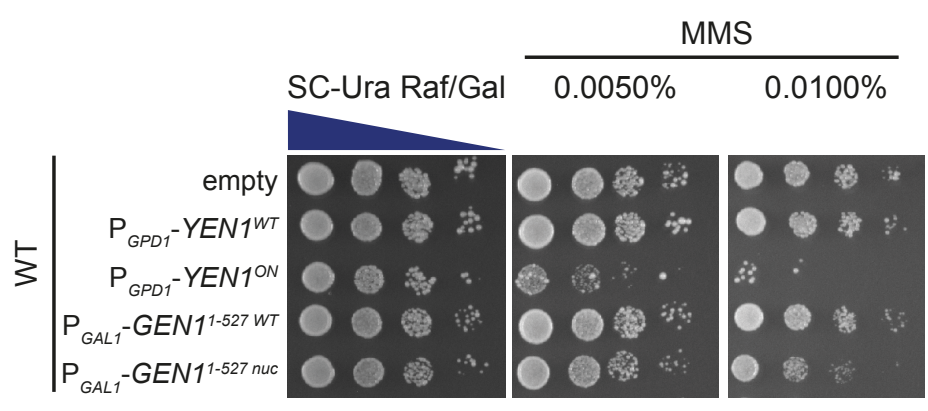

$E$
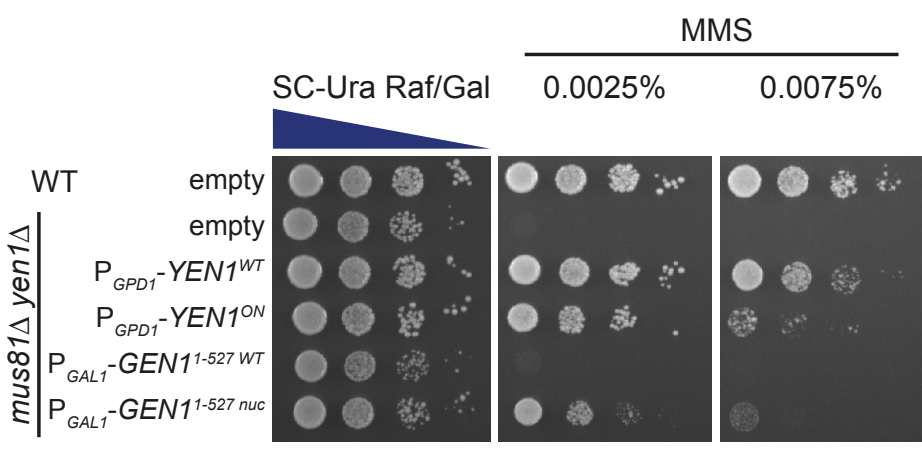


\section{SUPPLEMENTARY DATA}

Supplementary data contains Supplementary Figures 1-5 and Supplementary Tables 1-4

\section{Supplementary Figure legends}

Supplementary Figure 1. Range of substrates cleaved by Yen1. The same reactions shown in Figure $1 \mathrm{C}-\mathrm{F}$ were analysed in $10 \%$ native PAGE and phosphorimaging. Reaction products are depicted on the right. All labels as in Figure 1.

Supplementary Figure 2. Substrates not processed by Yen1. Reactions as those described for Figure 1C-F and Supp. Fig.1 were carried out employing the following substrates: $3^{\prime}$-flap (3'F), splayed arm (SA), dsDNA, ssDNA and poly-dT. All substrates were 5'-32P-end labelled at the indicated strand (red) and incubated with Yen1 ${ }^{\mathrm{ND}}$, Yen1 ${ }^{\mathrm{P}}$, Yen1 ${ }^{\lambda}$ and GEN1 $1^{1-527}(5 \mathrm{nM})$ as described. Reaction products were analysed by $10 \%$ denaturing or native PAGE and phosphorimaging. All labels as in Figure 1 and Supp. Fig. 1.

Supplementary Figure 3. Graphic representation of the different modes for the processing of nicked and fully ligated HJs. (A) Nicked HJs can be counter-nicked, presumably by a Yen1 monomer, in the strand opposite the nicked strand, releasing two nicked dsDNA molecules (top row). Alternatively, the incision may occur on a strand that anneals with the nicked strand (Ref$I$ activity), releasing a short dsDNA duplex and a replication fork-like (RF-like) structure, which can be further cleaved into a nicked dsDNA molecule and a second short dsDNA duplex (bottom row). (B) Intact HJs may be canonically resolved through coordinated incisions on opposite strands by a Yen1 dimer to release two nicked dsDNA molecules (top row). If coordinated cleavage occurs by coordinated incisions on annealing strands (arm-chopping), a short dsDNA duplex and a replication fork-like (RF-like) structure are released similarly to Ref-I activity. Further processing of the RF-like would also generate a nicked dsDNA molecule and a second short dsDNA duplex (bottom row).

Supplementary Figure 4. Yen1 is a monomer in solution. (A) Determination of Yen1 Stokes radius. Fractions from size exclusion chromatography of $20 \mu \mathrm{g}$ Yen $1^{\lambda}$ were analysed by SDSPAGE and Coomassie staining. The peak fraction number where filtration standards (thyroglobulin, $\gamma$-globulin, ovalbumin and myoglobin; BioRad) eluted is indicated by arrows. The observed $\mathrm{K}_{\mathrm{av}}$ values and known Stokes radii of the standards were employed to calculate the Stokes radius for Yen1. (B) Determination of Yen1 sedimentation coefficient. Fractions 
collected after ultracentrifugation of $25 \mu \mathrm{g}$ Yen $1^{\lambda}$ through glycerol gradients were analysed as in (A) and the peak fraction for each MW standard plotted to estimate Yen1 S-value. (C). Estimation of the apparent MW for Yen1 from the observed hydrodynamic values employing the Siegel and Monty equation (1). The calculated MW for FTH-tagged Yen1 is 93 Kda.

Supplementary Figure 5. Comparison of the activity of Yen1 and Yen1 ${ }^{\mathrm{ON}}$. (A) Reactions as described in Figure 1C-F and Supp. Fig 1 were carried out with $20 \mathrm{nM}$ substrate and $5 \mathrm{nM}$ Yen $1^{\lambda}(\mathrm{WT})$ or $\mathrm{Yen}^{\mathrm{ON}}(\mathrm{ON})$ for $10 \mathrm{~min}$ at $30^{\circ} \mathrm{C}$. Reaction products were analysed by $10 \%$ denaturing (top) or native (bottom) PAGE and phosphorimaging. All labels as in Figure 1 and Supp. Fig. 1. (B-C) Time-course analysis of Yen $1^{\mathrm{P}}$, Yen $1^{\lambda}$ and Yen $1^{\mathrm{ON}-\mathrm{P}}$ activity on HJ and 5'flap substrates. $50 \mathrm{nM}$ of an IRDye-800 fluorescent X0 HJ or $10 \mathrm{nM} 5^{\prime}$-flap were incubated

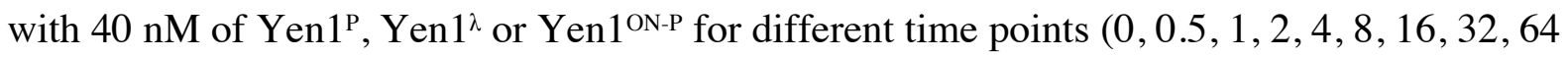
min). Products were analysed in $10 \%$ native-PAGE and visualised by phosphorimaging as stated above. Figure only shows a representative image of the experiments. (C) Quantification of the gels described in (B). Data represents mean \pm SD from two independent experiments. (D) Same as in (B), but the image representing the assay with Yen $1^{\mathrm{ON}-\mathrm{P}}$ and Yen $1^{\mathrm{ON}-\lambda}$. (E) Quantification of gels in (D). Data represents mean \pm SD from two independent experiments. (F) Comparison of the phosphorylation status of different Yen1 versions. $1 \mu \mathrm{g}$ of FTH-tagged Yen $1^{\mathrm{P}}$, Yen $1^{\lambda}$, Yen $1^{\mathrm{ON}-\mathrm{P}}$ or Yen $1^{\mathrm{ON}-\lambda}$ was loaded in two independent SDS-PAGE gels, one of them containing Phos-Tag to specifically reduce the mobility of phosphorylated proteins. Proteins were detected using $\alpha$-FLAG-HRP antibody. 


\section{Supplementary Tables}

Supplementary Table 1. S. cerevisiae strains used in this study.

\begin{tabular}{|c|c|c|}
\hline Strain & Relevant genotype & Source \\
\hline YWL165 a & BY4741 MATa & Open Biosystems \\
\hline YWL170 a & mus $81 \Delta:: H I S 3 M X$ yen $1 \Delta::$ KanMX & (2) - \\
\hline FJA42 a & $U R A 3:: p 416 G P D$ & This study \\
\hline FJA43 ${ }^{\text {a }}$ & $P_{G P D 1}-Y E N 1-V 5-6 x H I S:: U R A 3:: p 416 G P D$ & This study \\
\hline FJA44 ${ }^{\text {a }}$ & $P_{G P D I}-Y E N 1^{O N_{-}}$V5-6xHIS::URA3::p416GPD & This study \\
\hline FJA45 ${ }^{\text {a }}$ & $P_{G A L 1-G E N 1^{1-527}-V 5-6 x H I S:: U R A 3:: p Y E S-D E S T 52}$ & This study \\
\hline FJA46 ${ }^{\mathrm{a}}$ & $P_{\text {GALI-GEN1 }} 1^{1-527 n u c}-V 5-6 x H I S: \because U R A 3: \because p Y E S-D E S T 52$ & This study \\
\hline FJA47 ${ }^{\text {a }}$ & 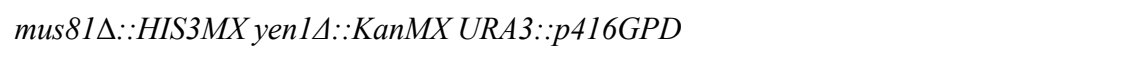 & This study \\
\hline FJA48 ${ }^{\text {a }}$ & 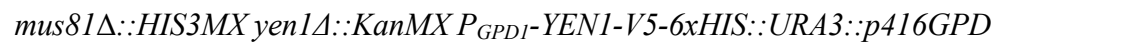 & This study \\
\hline FJA49 a & mus $81 \Delta:: H I S 3 M X$ yen $1 \Delta:: K_{\text {KanMX }} P_{G P D I^{-}}$YEN1 $^{O N_{-} V 5-6 x H I S:: U R A 3:: p 416 G P D}$ & This study \\
\hline FJA50 a & mus $81 \Delta: \because H I S 3 M X$ yen $1 \Delta:: K a n M X P_{G A L 1}-G E N 1^{1-527}-V 5-6 x H I S: \because U R A 3: \because p Y E S-D E S T 52$ & This study \\
\hline FJA51a & 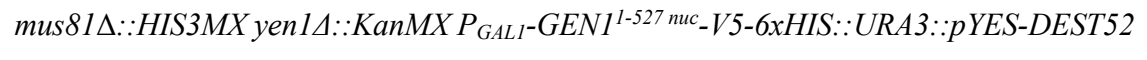 & This study \\
\hline YWL2017 b & $\begin{array}{l}\text { yen } 1 \Delta:: H I S 3 M X \text { pep } 4 \Delta:: K a n M X \text { bar } 1 \Delta:: H p h N T 1 \\
\text { ura3-52::URA3- } P_{G A L 1}-Y E N 1^{N D}-3 x F L A G-2 x T E V-10 x H I S\end{array}$ & (3) \\
\hline YWL2309 & $\begin{array}{l}\text { yen } 1 \Delta:: H I S 3 M X \text { pep } 4 \Delta:: K a n M X \text { bar } 1 \Delta:: H p h N T 1 \\
\text { ura3-52::URA3- } P_{G A L 1-c o Y E N 1}{ }^{O N}-3 x F L A G-2 x T E V-10 x H I S\end{array}$ & (3) \\
\hline YWL2507 b & 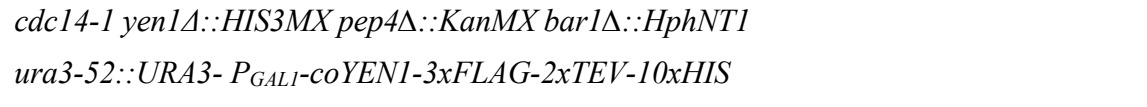 & (3) \\
\hline MGBY3185 & $\begin{array}{l}\text { yen } 1 \Delta:: H I S 3 M X \text { pep } 4 \Delta:: K a n M X \text { bar } 1 \Delta:: H p h N T 1 \\
\text { ura3-52::URA3-PGAL1-coGEN1-3xFLAG-2xTEV-10xHIS }\end{array}$ & This study \\
\hline
\end{tabular}

a. BY4741 derivative (MATa his3 1 leu2 $\triangle 0$ met15 150 ura3 $\triangle 0$ )

b. W303 derivative (MATa ura3-52; trp142; leu2-3,112; his3-11; ade2-1; can1-100) 
Supplementary Table 2. Plasmids used in this study.

\begin{tabular}{|c|c|}
\hline Plasmid & Source \\
\hline pIR9 & (4) \\
\hline p416GPD1 & $(5)$ \\
\hline p416ADH1-YEN1 ${ }^{\text {WT }}$-V5-6xHis & (2) \\
\hline p416ADH1-YEN1 ${ }^{\mathrm{ON}}-\mathrm{V} 5-6 \mathrm{xHis}$ & This work \\
\hline p416GPD1-YEN1 ${ }^{\text {WT }-V 5-6 x H i s ~}$ & This work \\
\hline p416GPD1-YEN1 ${ }^{\mathrm{ON}}-\mathrm{V} 5-6 \times \mathrm{His}$ & This work \\
\hline pYES-DEST52 & Invitrogen \\
\hline pAG306GAL-ccdB & (6) \\
\hline pENTR221-GEN1 ${ }^{\text {WT }}$-FTH-STOP & (7) \\
\hline pENTR221-GEN1nuc-FTH-STOP & This work \\
\hline pENTR221-GEN1 ${ }^{\mathrm{WT}}$-GO & This work \\
\hline pENTR221-GEN1 $1{ }^{\text {nuc }}-G O$ & This work \\
\hline pYES-EXP52-GEN1 $1{ }^{\text {WT}}-\mathrm{V} 5-6 \times \mathrm{His}$ & This work \\
\hline pYES-EXP52-GEN1 ${ }^{\text {nuc-V5-6xHis }}$ & This work \\
\hline pYES-EXP52-GEN1 1-527 WT-V5-6xHis & This work \\
\hline pYES-EXP52-GEN11-527 nuc-V5-6xHis & This work \\
\hline pAG306GAL-GEN1 ${ }^{\text {WT }}$-FTH & This work \\
\hline
\end{tabular}


Supplementary Table 3. Sequence of the oligonucleotides used for synthetic DNA substrates.

\begin{tabular}{|c|c|c|}
\hline Oligonucleotide & Size & Sequence 5'-3' \\
\hline $\mathrm{X} 0-1$ & 60 & ACGCTGCCGAATTCTACCAGTGCCTTGCTAGGACATCTTTGCCCACCTGCAGGTTCACCC \\
\hline X0-1 IRDye 800 & 60 & 5IRD800-ACGCTGCCGAATTCTACCAGTGCCTTGCTAGGACATCTTTGCCCACCTGCAGGTTCACCC \\
\hline X0-1 comp & 60 & GGGTGAACCTGCAGGTGGGCAAAGATGTCCTAGCAAGGCACTGGTAGAATTCGGCAGCGT \\
\hline $\mathrm{X} 0-2$ & 60 & GGGTGAACCTGCAGGTGGGCAAAGATGTCCATCTGTTGTAATCGTCAAGCTTTATGCCGT \\
\hline $\mathrm{X} 0-4$ & 60 & CGATAGTCGGATCCTCTAGACAGCTCCATGTAGCAAGGCACTGGTAGAATTCGGCAGCGT \\
\hline X0-4 AA & 60 & CGATAGTCGGATCCTCTAGACAGCTCCATGTAGCAAGGCACTGGTAGAATATAATAATAA \\
\hline $\mathrm{X} 0-23$ & 60 & GGGTGAACCTGCAGGTGGGCAAAGATGTCCCATGGAGCTGTCTAGAGGATCCGACTATCG \\
\hline $\mathrm{X} 0-1(1 / 2)$ & 30 & ACGCTGCCGAATTCTACCAGTGCCTTGCTA \\
\hline $\mathrm{X} 0-2(1 / 2)$ & 30 & GGGTGAACCTGCAGGTGGGCAAAGATGTCC \\
\hline $\mathrm{X} 0-2(2 / 2)-\mathrm{P}$ & 30 & [Phos]ATCTGTTGTAATCGTCAAGCTTTATGCCGT \\
\hline $\mathrm{X} 0-3(2 / 2)$ & 30 & CATGGAGCTGTCTAGAGGATCCGACTATCG \\
\hline $\mathrm{X} 0-3(2 / 2)-\mathrm{P}$ & 30 & [Phos]CATGGAGCTGTCTAGAGGATCCGACTATCG \\
\hline $\mathrm{X} 0-4(2 / 2)-\mathrm{P}$ & 30 & [Phos]TAGCAAGGCACTGGTAGAATTCGGCAGCGT \\
\hline Oligo b & 30 & TCCGTCCTAGCAAGGGGCTGCTACCGGAAG \\
\hline Oligo h & 30 & CTTCCGGTAGCAGCCTGAGCGGTGGTTGAA \\
\hline Oligo $\mathrm{r}$ & 30 & TTCAACCACCGCTCAACTCAACTGCAGTCT \\
\hline Oligo $\mathrm{x}$ & 30 & AGACTGCAGTTGAGTCCTTGCTAGGACGGA \\
\hline 5'T X1-4 & 61 & TCGATAGTCGGATCCTCTAGACAGCTCCATCTAGCAAGGCACTGGTAGAATTCGGCAGCGT \\
\hline $\mathrm{X} 0-2(3 \mathrm{SP})$ & 60 & GGGTGAACCTGCAGGTGGGCAAAGATGTCC*A*T*CTGTTGTAATCGTCAAGCTTTATGCCGT \\
\hline $\mathrm{X} 0-3(\mathrm{SP})$ & 60 & ACGGCATAAAGCTTGACGATTACAACAGATC*ATGGAGCTGTCTAGAGGATCCGACTATCG \\
\hline X0-4 (3SP) & 60 & CGATAGTCGGATCCTCTAGACAGCTCCATG*T*A*GCAAGGCACTGGTAGAATTCGGCAGCGT \\
\hline $\mathrm{X} 0-3(2 / 2)-\mathrm{P}-6 \mathrm{FAM}$ & 30 & [Phos]CATGGAGCTGTCTAGAGGATCCGACTATCG-6FAM \\
\hline $\mathrm{X} 0-3(2 / 2)-\mathrm{P}(\mathrm{SP})-6 \mathrm{FAM}$ & 30 & [Phos]C*ATGGAGCTGTCTAGAGGATCCGACTATCG-6FAM \\
\hline $\mathrm{X} 0-3(2 / 2)-\mathrm{P}(29)$ & 29 & [Phos]CATGGAGCTGTCTAGAGGATCCGACTATC \\
\hline $\mathrm{X} 0-1(1 / 2) 29$ & 29 & ACGCTGCCGAATTCTACCAGTGCCTTGCT \\
\hline $\mathrm{X} 0-1(1 / 2) 28$ & 28 & ACGCTGCCGAATTCTACCAGTGCCTTGC \\
\hline $\mathrm{X} 0-1(1 / 2) 27$ & 27 & ACGCTGCCGAATTCTACCAGTGCCTTG \\
\hline $\mathrm{X} 0-1(1 / 2) 26$ & 26 & ACGCTGCCGAATTCTACCAGTGCCTT \\
\hline $\mathrm{X} 0-1(1 / 2) 25$ & 25 & ACGCTGCCGAATTCTACCAGTGCCT \\
\hline
\end{tabular}


Supplementary Table 4. Oligonucleotide combination to generate the different DNA substrates.

\section{DNA synthetic substrate}

Holliday junction (HJ) X0: $\mathrm{X} 0-1+\mathrm{X} 0-2+\mathrm{X} 0-3+\mathrm{X} 0-4$

HJ X0-800: X0-1 IRDye $800+\mathrm{X} 0-2+\mathrm{X} 0-3+\mathrm{X} 0-4$

HJ X0-700: X0-1 IRDye $700+\mathrm{X} 0-2+\mathrm{X} 0-3+\mathrm{X} 0-4 \mathrm{AA}$

HJ J3: Oligo-b + Oligo-h + Oligo-r + Oligo-x

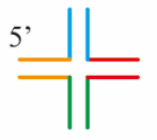

HJ X0-SP: $\mathrm{X} 0-1+\mathrm{X} 0-2+\mathrm{X} 0-3(\mathrm{SP})+\mathrm{X} 0-4$

HJ X0-2SP: X0-1 + X0-2 (3SP) + X0-3 + X0-4 (3 SP)

\begin{tabular}{l} 
3-way junction (3WJ): $\mathrm{X} 0-1+\mathrm{X} 0-4+\mathrm{X} 0-23$ \\
\hline '’-flap (5'F): $\mathrm{X} 0-1+\mathrm{X} 0-4+\mathrm{X} 0-2(1 / 2)$ \\
5'F-800: $\mathrm{X} 0-1$ IRDye $800+\mathrm{X} 0-4+\mathrm{X} 0-2(1 / 2)$ \\
Splayed arm (SA): X0-1+X0-4 \\
Single stranded DNA (ssDNA): X0-1 \\
Control ssDNA : poly-dT
\end{tabular}

X0 nicked 1 (X0n1): X01 (1/2) + X0-1 (2/2)-P + X0-2 + X0-3 + X0-4

$\mathrm{X} 0 \mathrm{n} 2: \mathrm{X} 0-1+\mathrm{X} 0-2(1 / 2)+\mathrm{X} 0-2(2 / 2)-\mathrm{P}+\mathrm{X} 0-3+\mathrm{X} 0-4$

$\mathrm{X} 0 \mathrm{n} 3: \mathrm{X} 0-1+\mathrm{X} 0-2+\mathrm{X} 0-3(1 / 2)+\mathrm{X} 0-3(2 / 2)-\mathrm{P}+\mathrm{X} 0-4$

$\mathrm{X} 0$ n4: X0-1 + X0-2 + X0-3 + X0-4 (1/2) + X0-4 (2/2)-P

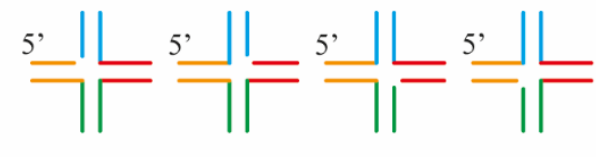

Replication fork (RF): X0-1 + X0-4 + X0-2 (1/2) + X0-3 (2/2)-P

RF-800: IRDye 800 X0-1 + X0-4 + X0-2 (1/2) + X0-3 (2/2)-P

5

1

3'-flap (3'F): X0-1 + X0-4 + X0-3 (2/2)-P

5

5

Double stranded DNA (dsDNA): X0-1 + X0-1 comp

$\underline{\underline{2}}$

Nicked dsDNA: X0-1 (1/2) + X0-3 (2/2)P + X0-4

Nicked dsDNA-3'-6FAM: X0-1 (1/2) + X0-3 (2/2)-P-6FAM + X0-4

5 ,

Nicked-SP dsDNA-3'-6FAM: X0-1 (1/2) + X0-3 (2/2)-P-(SP)-6FAM + X0-4

Nicked dsDNA for 3'labeling: X0-1 (1/2) + X0-3 (2/2) (29)-P + 5'T X0-4

Gapped DNA (1nt): X0-1 (1/2) $29+$ X0-3 (2/2)-P + X0-4

Gapped DNA (2nt): X0-1 (1/2) $28+\mathrm{X} 0-3(2 / 2)-\mathrm{P}+\mathrm{X} 0-4$

Gapped DNA (3nt): X0-1 (1/2) $27+\mathrm{X} 0-3$ (2/2)-P + X0-4

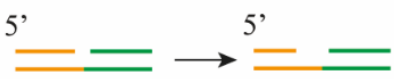

Gapped DNA (4nt): X0-1 (1/2) 26 + X0-3 (2/2) -P+ X0-4

Gapped DNA (5nt): X0-1 (1/2) 25 + X0-3 (2/2)-P + X0-4

Asymmetric HJ (X1-T): X1-1T + X1-2T + X1-3 + X1-4

$\mathrm{X} 1-\mathrm{T}-\mathrm{SP}: \mathrm{X} 1-1 \mathrm{~T}+\mathrm{X} 1-2 \mathrm{~T}+\mathrm{X} 1-3(\mathrm{SP})+\mathrm{X} 1-4$

X1-T for 3'-labelling: X1-1T + X1-2T + X1-3 + 5' T X1-4

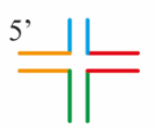




\section{SUPPLEMENTARY REFERENCES}

1. Siegel,L.M. and Monty,K.J. (1966) Determination of molecular weights and frictional ratios of proteins in impure systems by use of gel filtration and density gradient centrifugation. Application to crude preparations of sulfite and hydroxylamine reductases. Biochim. Biophys. Acta, 112, 346-362.

2. Blanco,M.G., Matos,J., Rass,U., Ip,S.C.Y. and West,S.C. (2010) Functional overlap between the structure-specific nucleases Yen1 and Mus81-Mms4 for DNA-damage repair in S. cerevisiae. DNA Repair, 9, 394-402.

3. Blanco,M.G., Matos,J. and West,S.C. (2014) Dual control of Yen1 nuclease activity and cellular localization by Cdk and Cdc14 prevents genome instability. Mol. Cell, 54, 94-106.

4. Bauknecht,M. and Kobbe,D. (2014) AtGEN1 and AtSEND1, two paralogs in Arabidopsis, possess holliday junction resolvase activity. Plant Physiol., 166, 202-216.

5. Mumberg,D., Muller,R. and Funk,M. (1995) Yeast vectors for the controlled expression of heterologous proteins in different genetic backgrounds. Gene, 156, 119-22.

6. Alberti,S., Gitler,A.D. and Lindquist,S. (2007) A suite of Gateway cloning vectors for high-throughput genetic analysis in Saccharomyces cerevisiae. Yeast, 24, 913-9.

7. Chan,Y.W. and West,S. (2015) GEN1 promotes Holliday junction resolution by a coordinated nick and counter-nick mechanism. Nucleic Acids Res., 43, 10882-10892. 
bioRxiv preprint doi: https://doi.org/10.1101/2020.12.08.413625; this version posted December 8, 2020. The copyright holder for this preprint (which was not certified by peer review) is the author/funder. All rights reserved. No reuse allowed without permission.
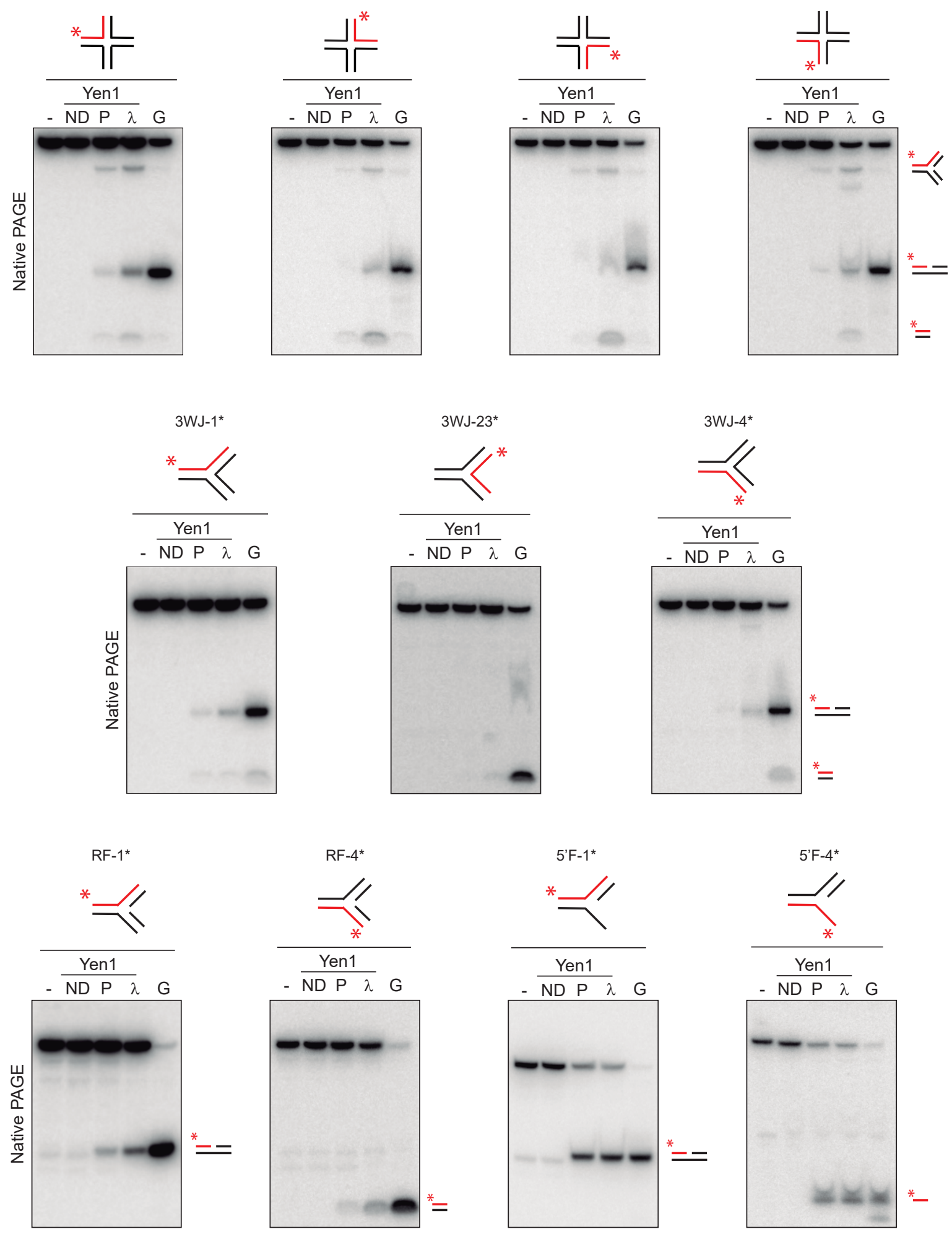
bioRxiv preprint doi: https://doi.org/10.1101/2020.12.08.413625; this version posted December 8, 2020. The copyright holder for this

preprint (which was not certified by peer, review) is the author/funder. All rights reserved. No reuse allowed, without permission.
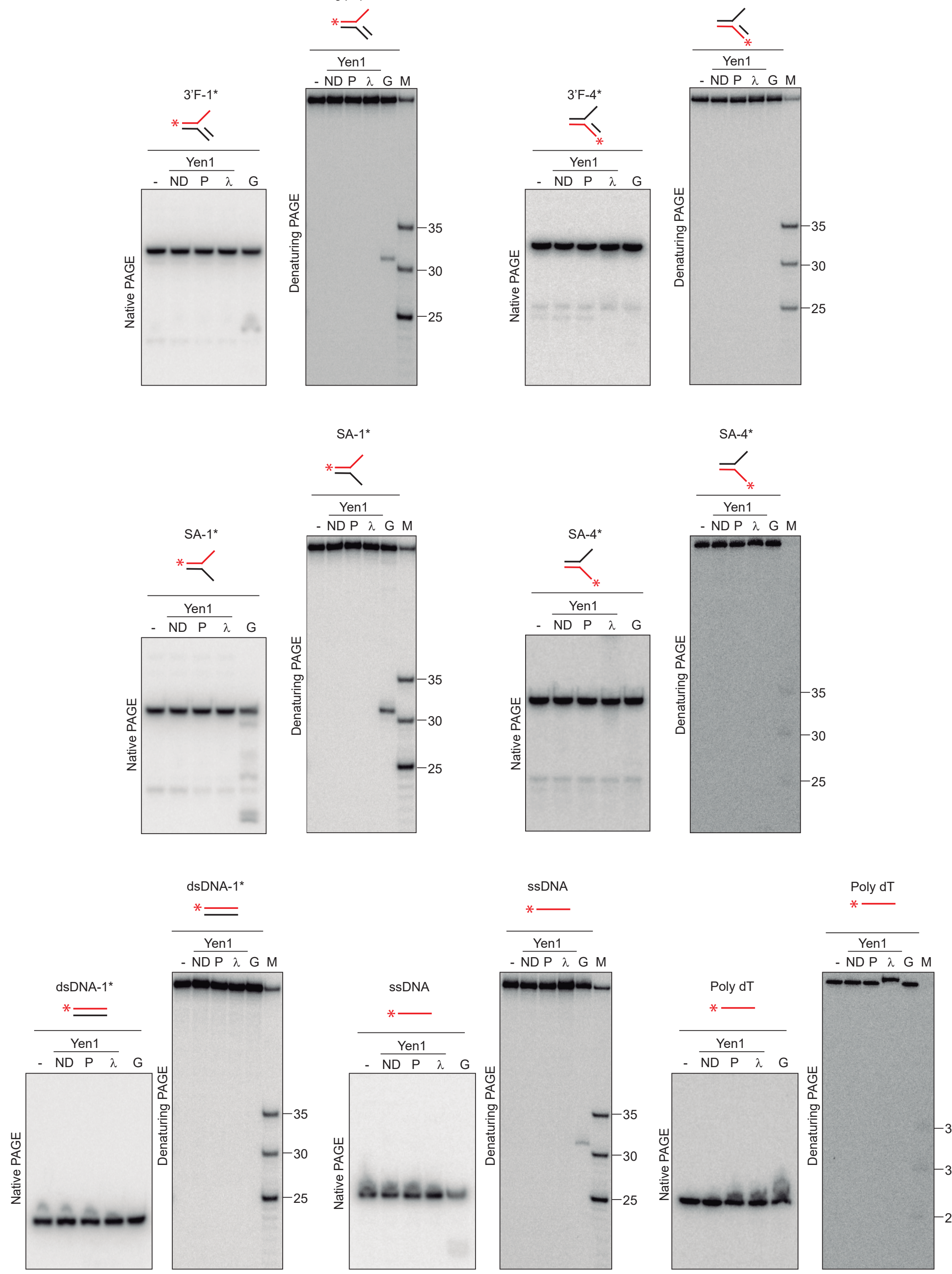
A
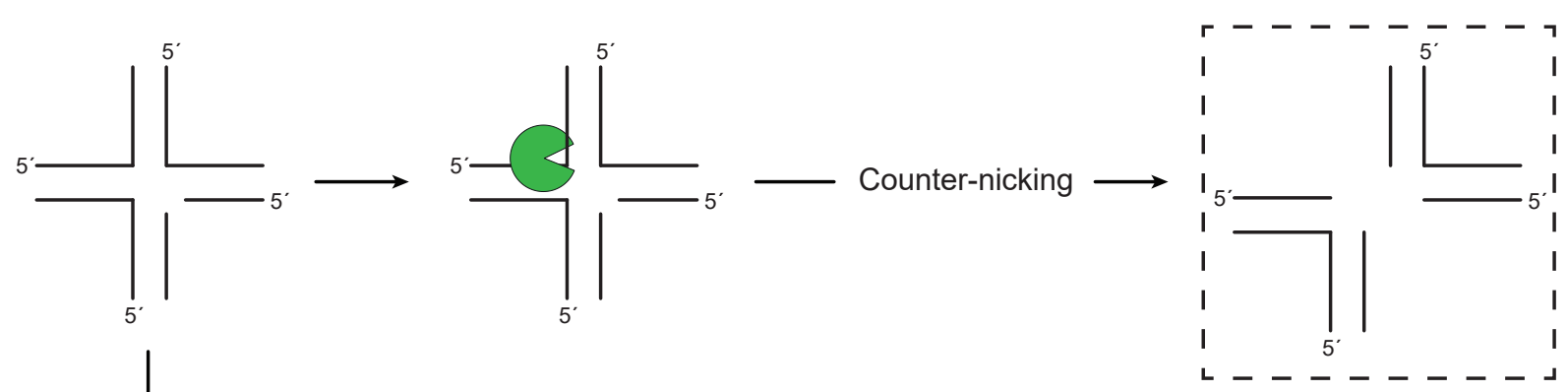<smiles>[3H]C</smiles>
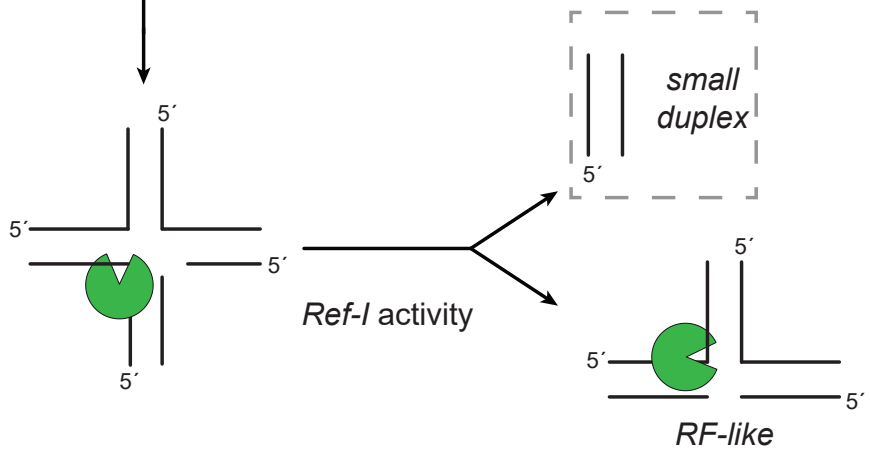

nicked duplex cleavage

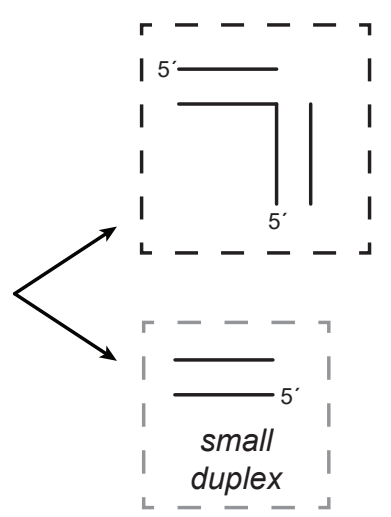

B
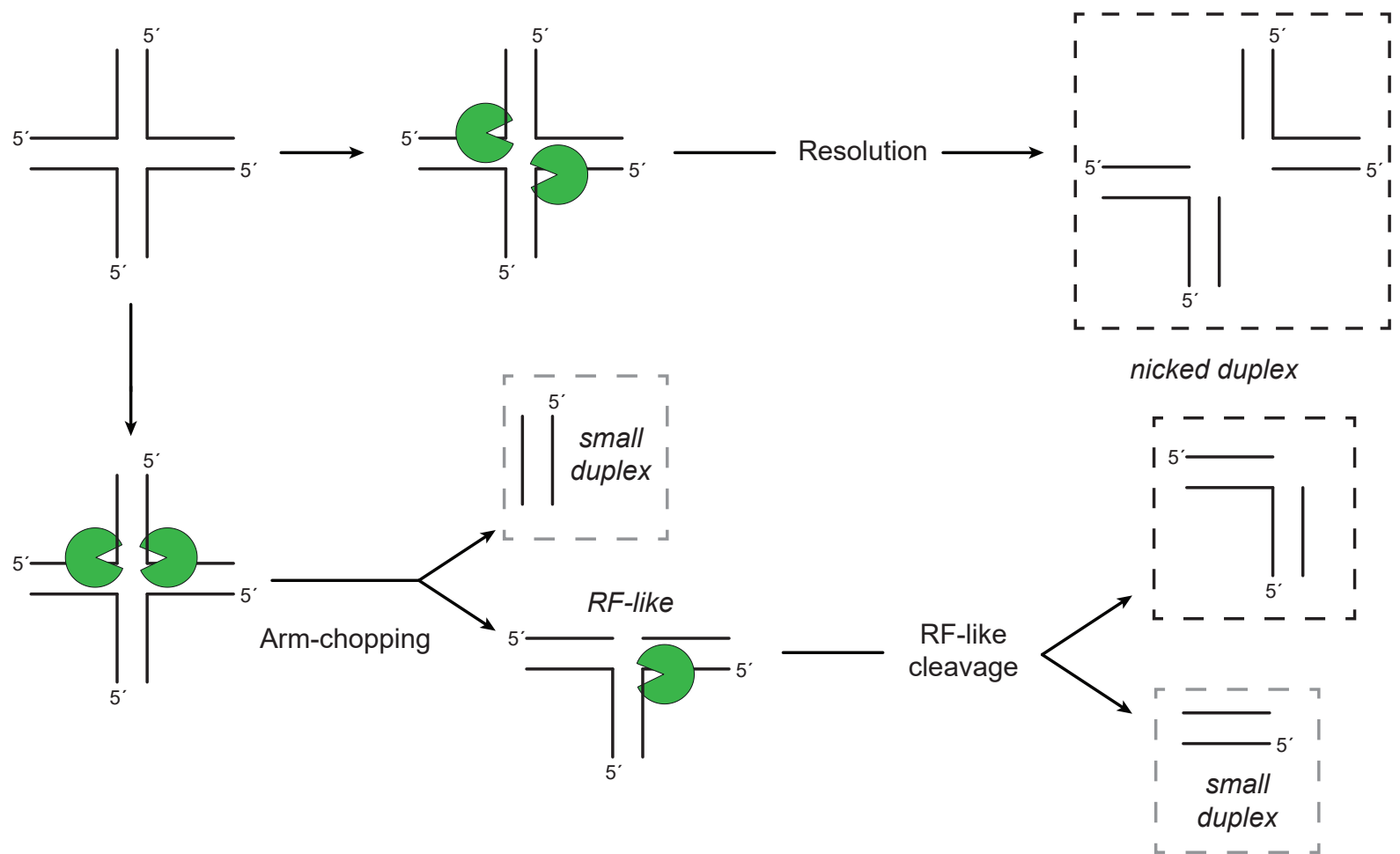
bioRxiv preprint doi: https://doi.org/10.1101/2020.12.08.413625; this version posted December 8,2020 . The copyright holder for this

preprint (which was not certified by peer review) is the author/funder. All rights reserved. No reuse allowed without permission.

A
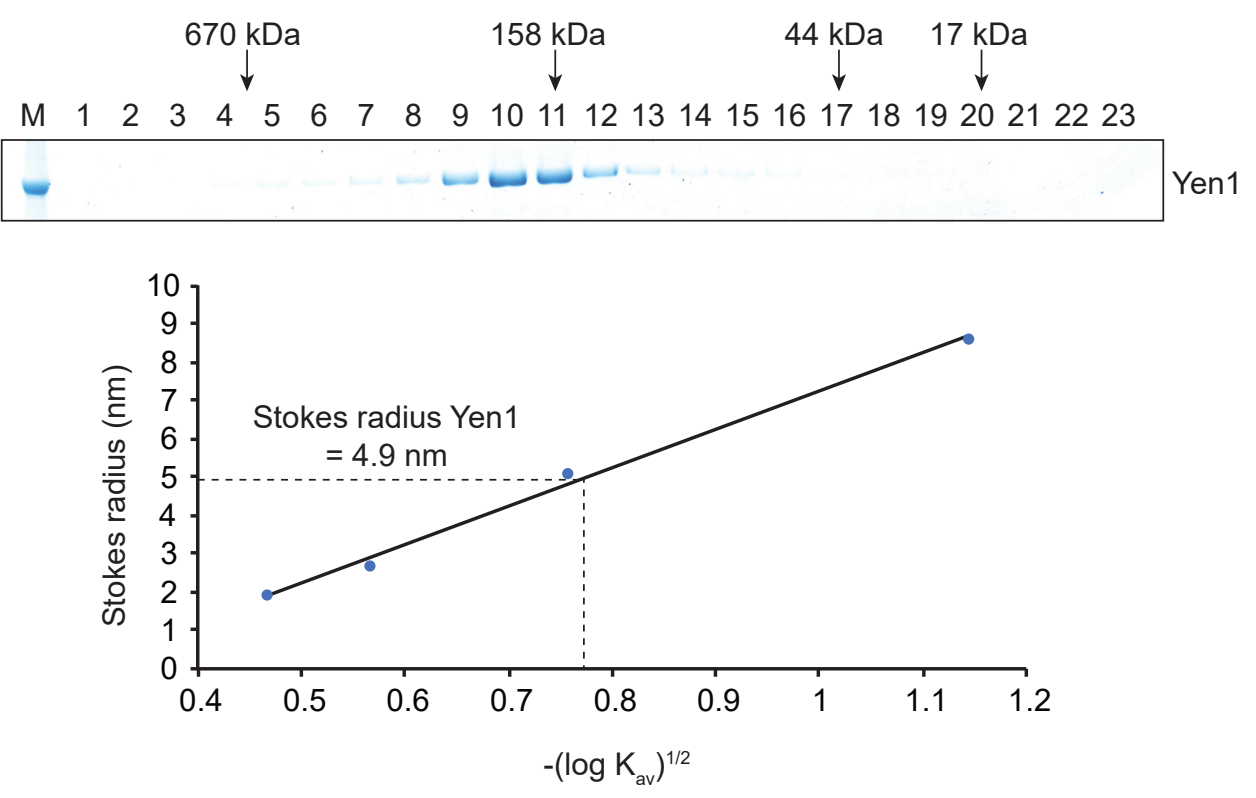

B

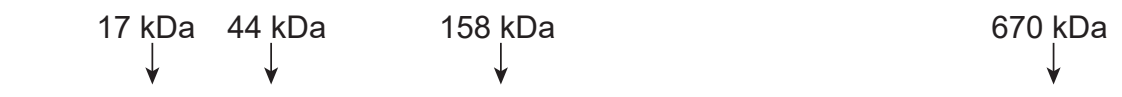

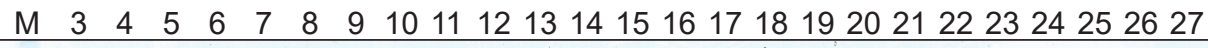

$100 \mathrm{kDa}$
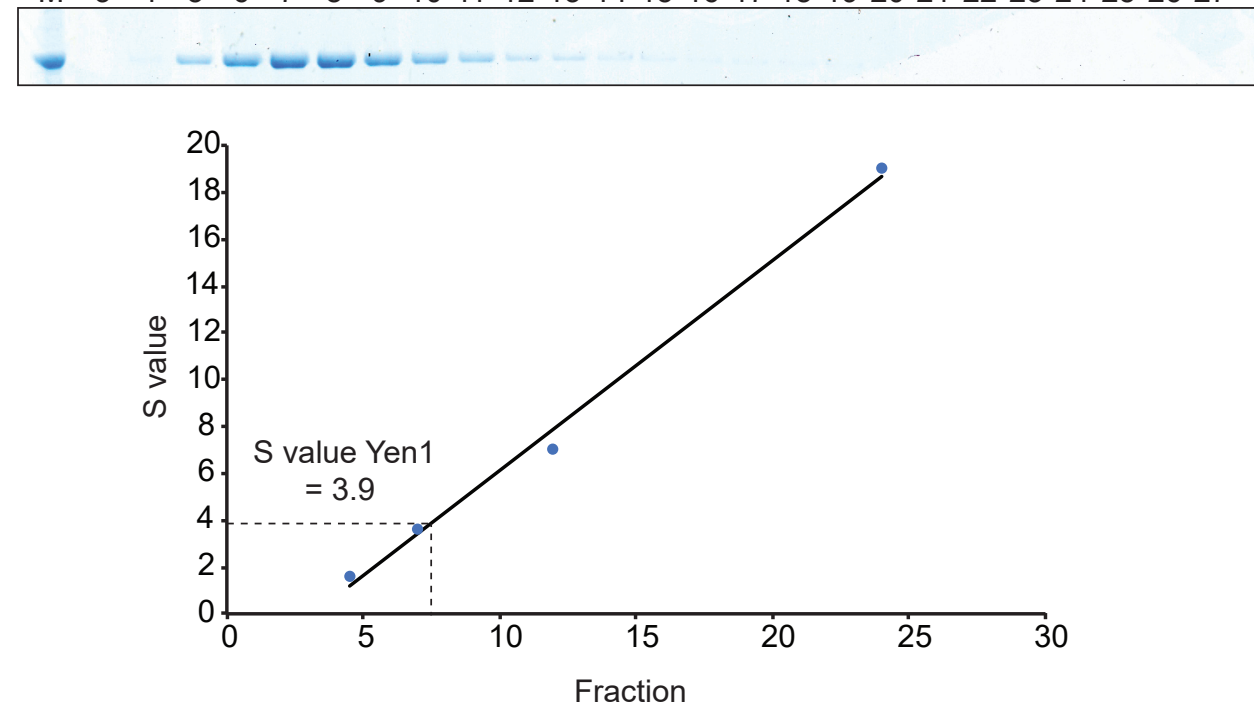

\begin{tabular}{|ll|}
\hline Predicted MW & $93 \mathrm{kDa}$ \\
Stokes radius & $4.9 \mathrm{~nm}$ \\
S value & 3.9 \\
Apparent MW & $\mathbf{8 0 ~} \mathbf{~ D a}$ \\
\hline
\end{tabular}


bioRxiv preprint doi: https://doi.org/10.1101/2020.12.08.413625; this version posted December 8, 2020. The copyright holder for this

A

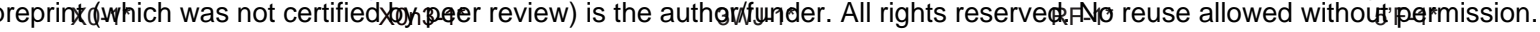
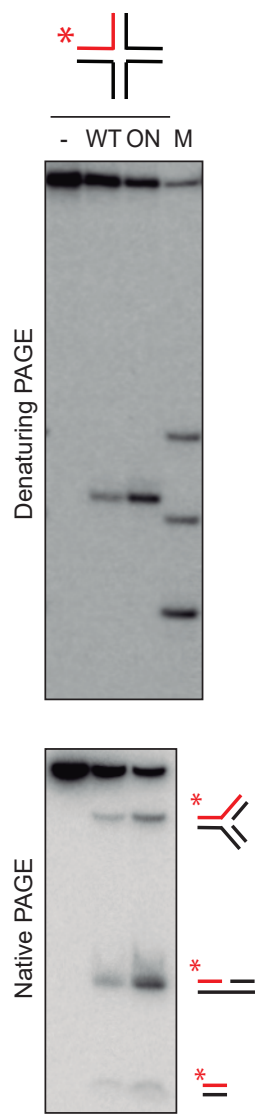
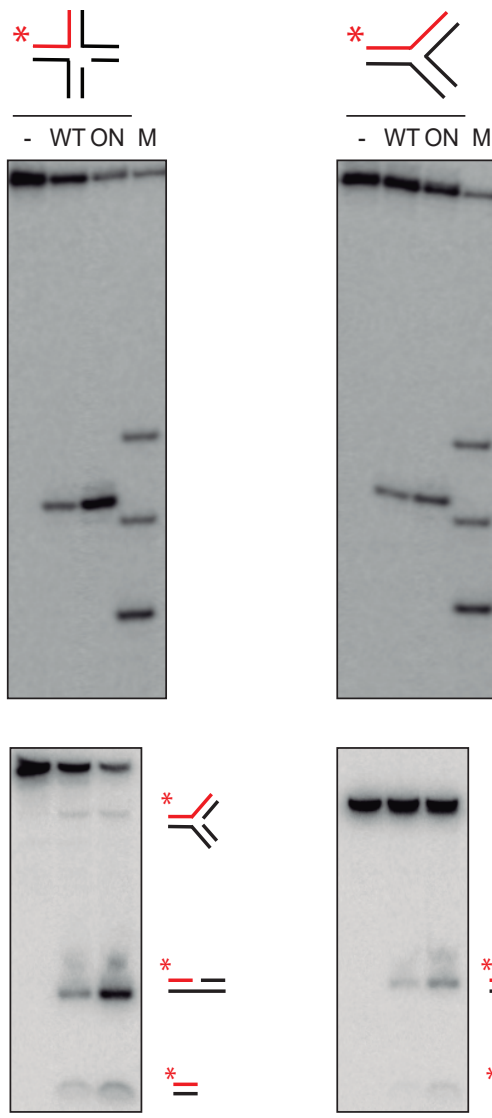
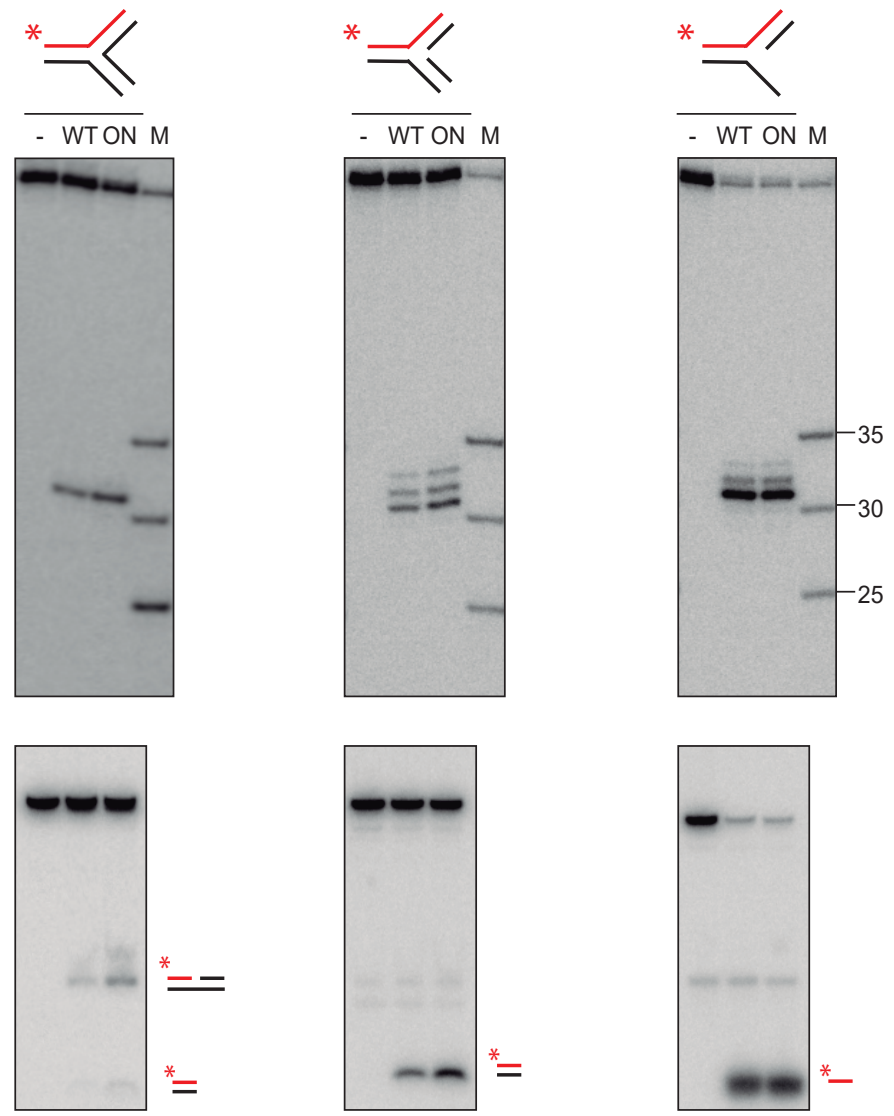

B

C
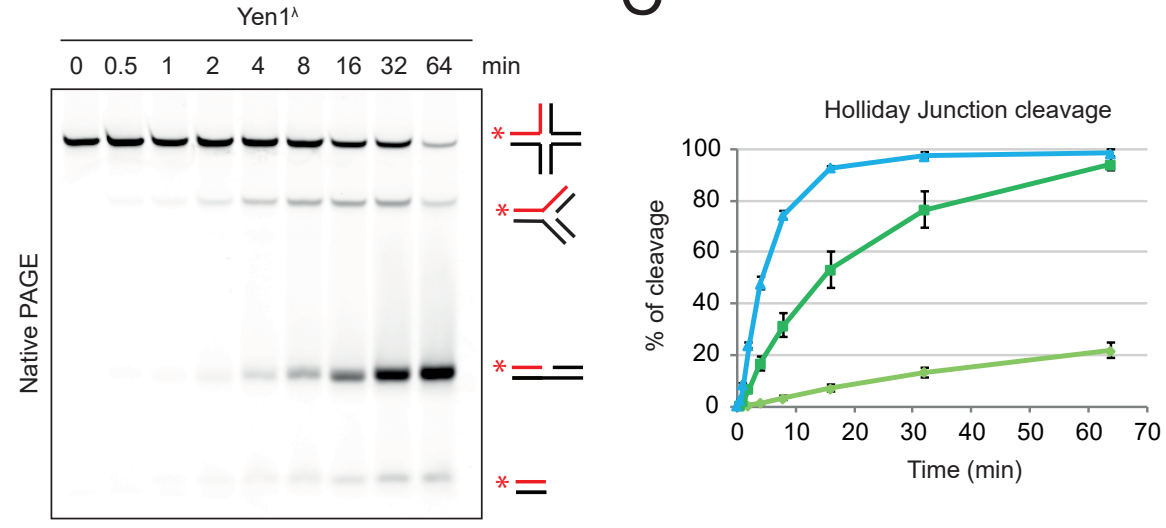

$\mathrm{D}$
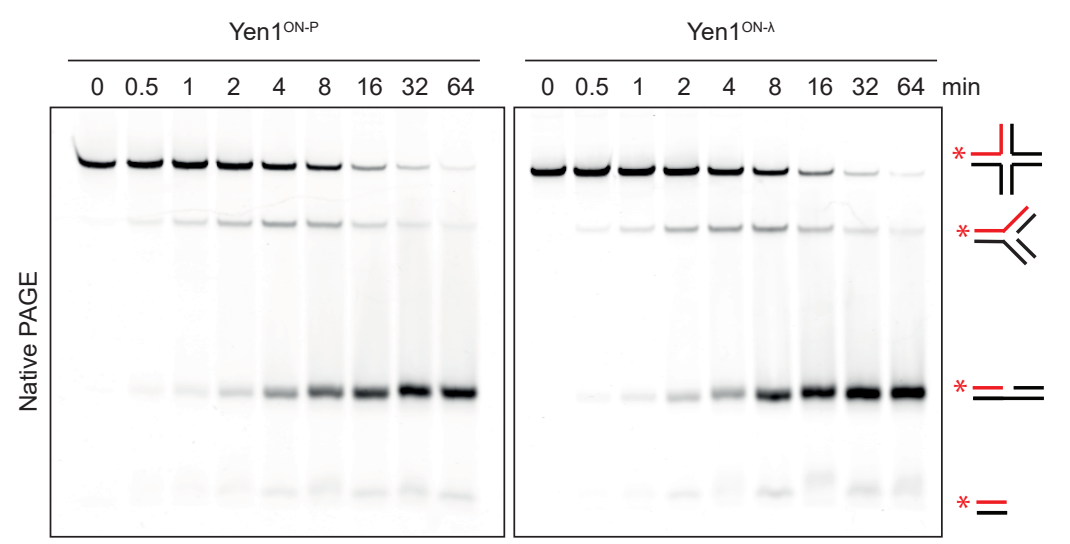

E

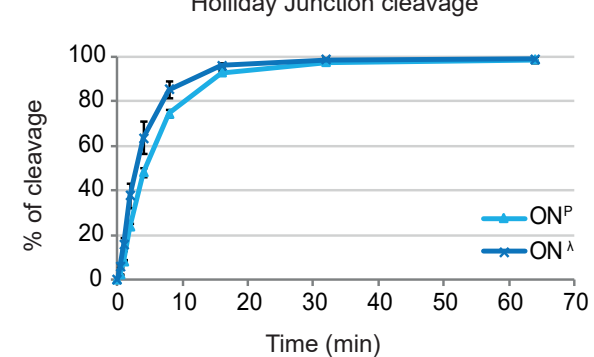

5'-Flap cleavage

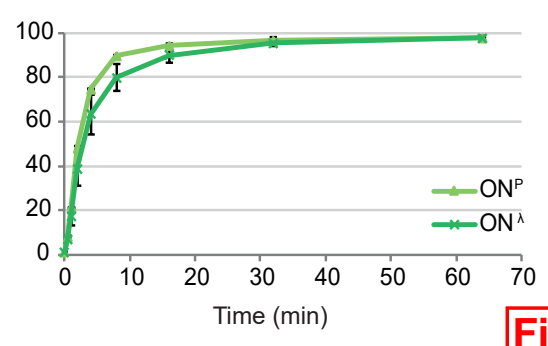

Replication fork cleavage

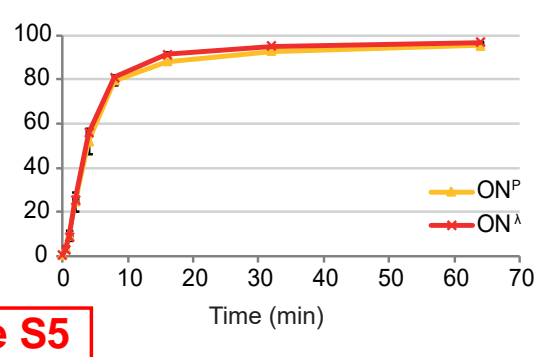

